\title{
OPTIMIZATION OF AIR SPARGING AND IN-LINE COAGULATION FOR ULTRAFILTRATION FOULING CONTROL
}

by

Appana Zhaoheng Lok

A thesis submitted in conformity with the requirements

for the degree of Master of Applied Science

Civil Engineering

University of Toronto

C Copyright by Appana Zhaoheng Lok 2017 


\title{
OPTIMIZATION OF AIR SPARGING AND IN-LINE COAGULATION FOR ULTRAFILTRATION FOULING CONTROL
}

\author{
Appana Zhaoheng Lok \\ Master of Applied Science, 2017 \\ Graduate Department of Civil Engineering \\ University of Toronto
}

\begin{abstract}
This research examined various strategies for ultrafiltration (UF) membranes fouling control. Continuous sparging (sparging during permeation and backwash) increased fouling rates when compared to sparging only during backwash. This was attributed to the removal of a the protective layer on the membrane when sparging continuously. Coagulating for only the first half of the permeation cycle (phased coagulation), which would lead to reduced coagulant and sludge disposal costs, did not negatively impact membrane performance in terms of fouling and organics removal when compared to continuous coagulation.

The difference in concentration factor (CF) between bench and full-scale UF systems may limit the applicability of bench-scale trials. Membrane resistance and permeate quality were compared between bench-scale trials conducted with $\mathrm{CF}=1$ water and elevated $\mathrm{CFs}$. The results indicate that the use of the same feed water as used at full-scale $(\mathrm{CF}=1)$ is appropriate to evaluate bench-scale fouling in UF systems operated in deposition mode.
\end{abstract}




\section{ACKNOWLEDGEMENTS}

This work was funded by the Natural Sciences and Engineering Research Council of Canada (NSERC) Chair in Drinking Water Research at the University of Toronto, and the Ontario Research Fund (ORF).

I would like to first thank my supervisors Dr. Robert C. Andrews and Dr. Pierre Bérubé for their support, guidance, and encouragement throughout the project. I would also like to thank Dr. Ron Hofmann and Dr. Susan Andrews for their support during my degree.

I would like to thank Liz Taylor-Edmonds for her assistance throughout my degree and Jim Wang for the help and guidance in the lab. Thank you to Michael McKie for his advice on pilot maintenance and help with troubleshooting the bench-scale UF setup. Thanks to Nicolas Peleato for his patience with my experiments and assistance with troubleshooting. Thanks to Chris Jiang and Tyler Yang for their assistance in the lab.

A special thank you to Kari-Anne Last at the Barrie Surface WTP for operating and sampling from the UF pilot as well as accommodating me on several sampling trips. Thank you to Frank Feng and Sara Battaglia at the Lakeview WTP for their help with biofilter pilot sampling and maintenance.

To my good friends, Dikshant Sharma, Divyam Beniwal, Karlye Wong, and Angela Fang, thank you for your help with classwork and labwork, and most importantly for sharing many jokes, laughs as well as frustrations over the past two years. I cannot express how important of our friendship has been to me during my Master's degree and I sincerely hope we stay close in the years to come. I wish you all the very best.

Lastly, I would like to thank my family for the constant support and encouragement all the way from Tokyo and Hong Kong. And as always, a special thank you to Joseph Blommesteyn for the continued love and support. 


\section{TABLE OF CONTENTS}

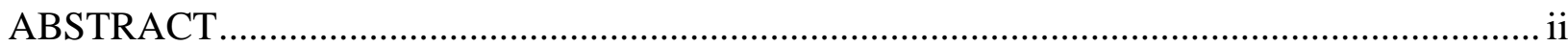

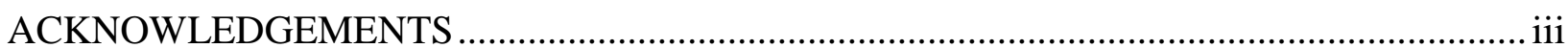

TABLE OF CONTENTS ................................................................................................ iv

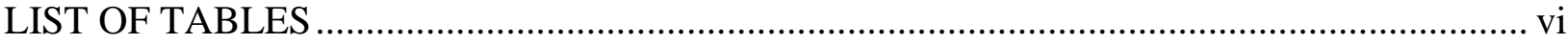

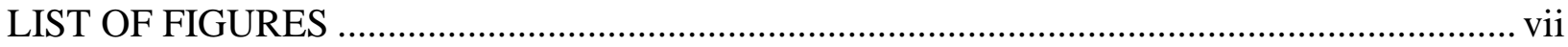

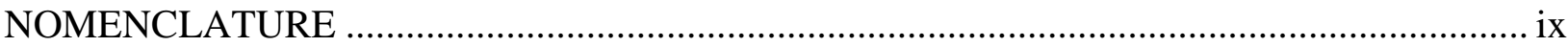

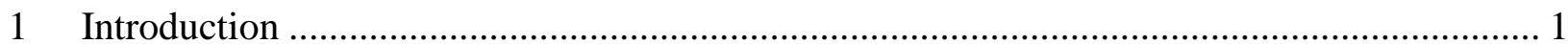

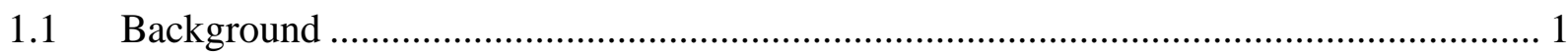

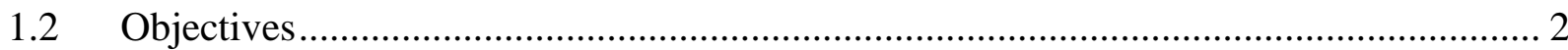

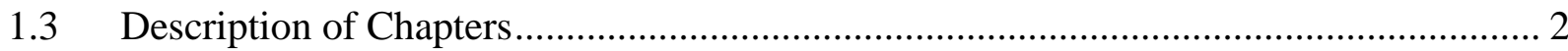

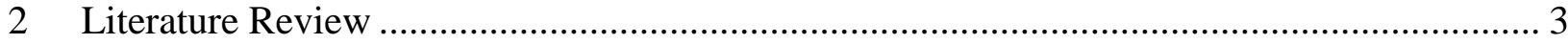

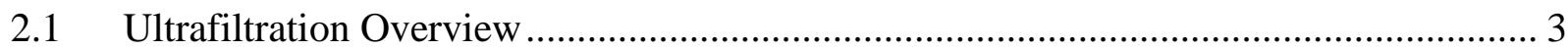

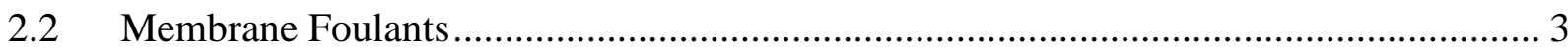

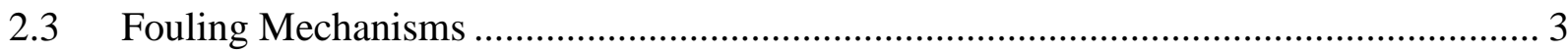

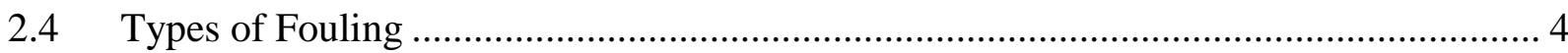

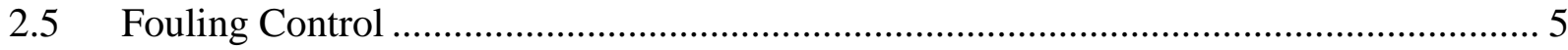

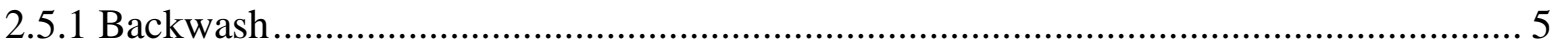

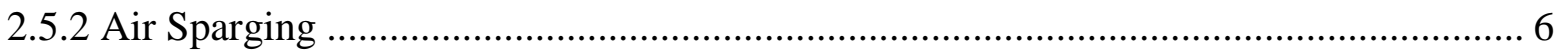

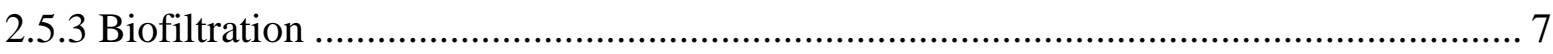

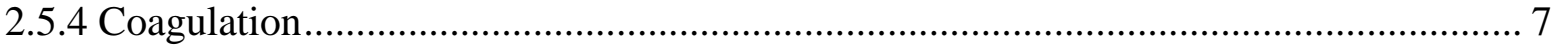

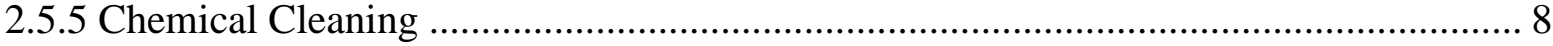

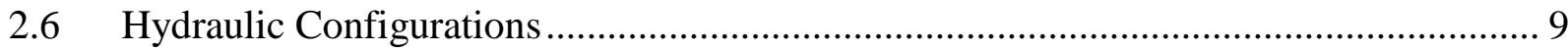

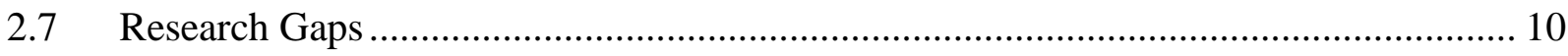

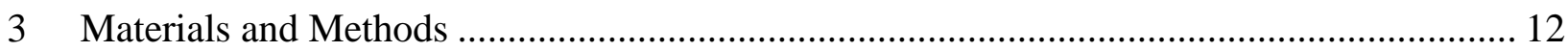

3.1 Water Matrices and Water Treatment Plants ...................................................... 12

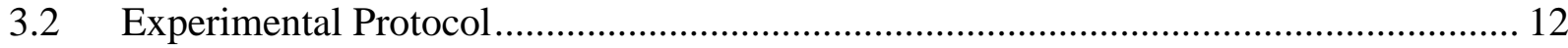

3.2.1 Air Sparging and In-line Coagulation Study ............................................... 12

3.2.2 Concentration Factor Study ........................................................................ 12

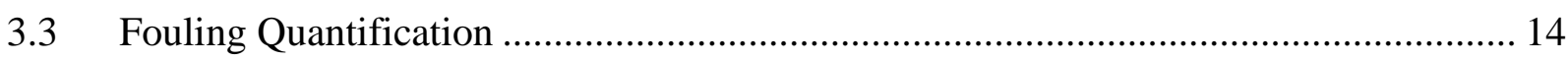

3.4 Membrane Filtration Apparatus ....................................................................... 14 


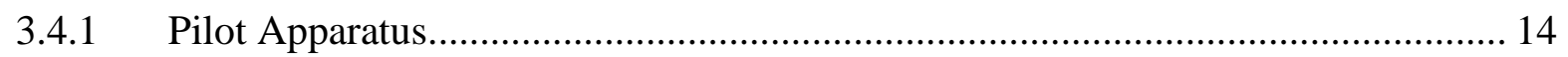

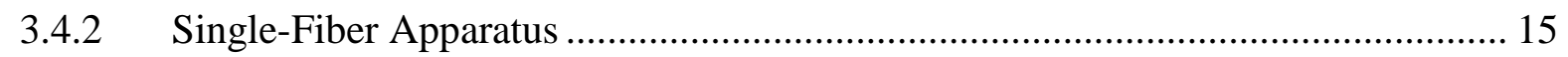

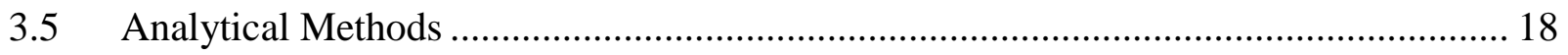

3.5.1 Dissolved Organic Carbon ................................................................................. 18

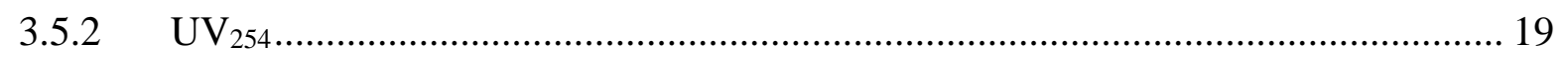

4 Optimization of Air Sparging and In-line Coagulation for Ultrafiltration Fouling Control . 20

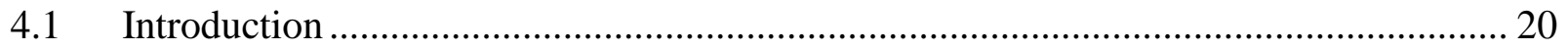

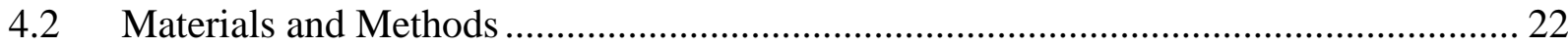

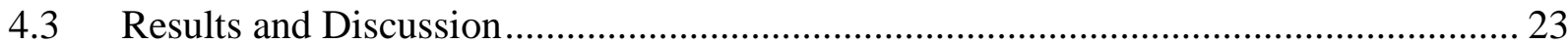

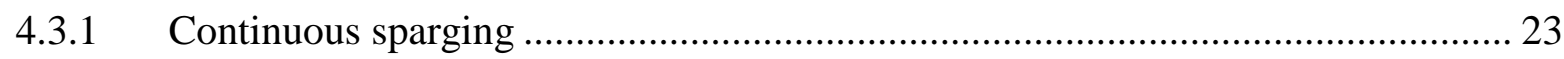

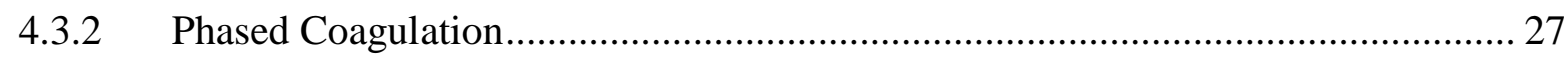

4.3.3 Removal of Particulate and Dissolved Organics ................................................ 28

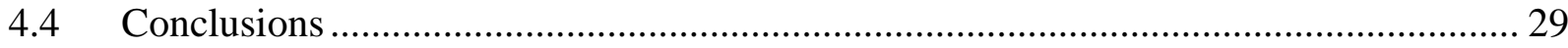

5 The Effect of Concentration Factor on Membrane Fouling ………………………............ 30

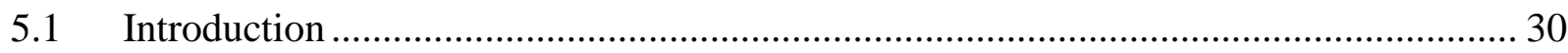

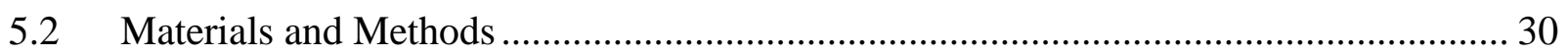

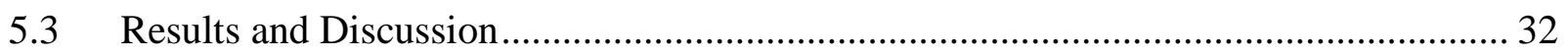

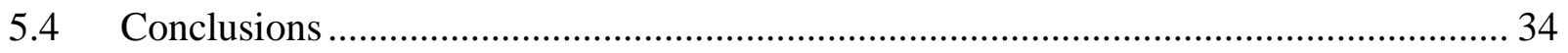

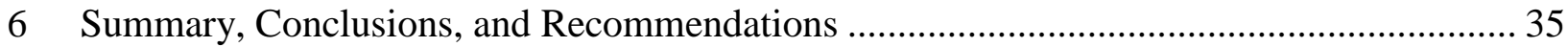

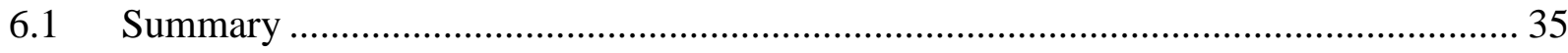

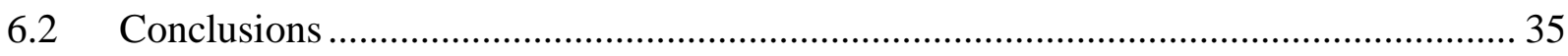

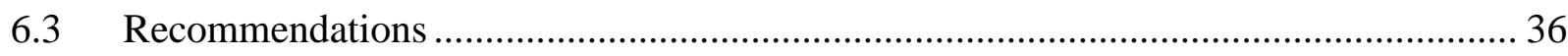

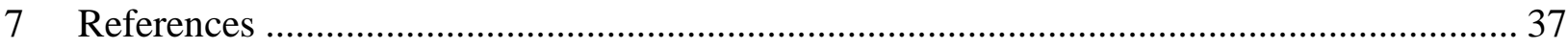

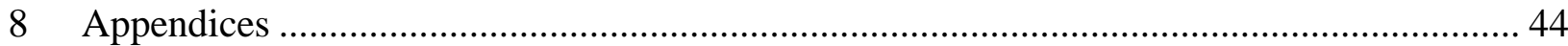

8.1 Raw Experimental Data for Air sparging and In-line coagulation Study ....................... 44

8.2 Bench-scale Membrane Surface Area and Flow Rate Calculations................................ 49

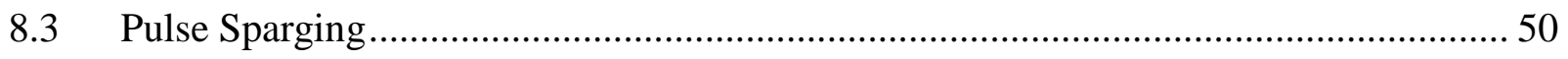

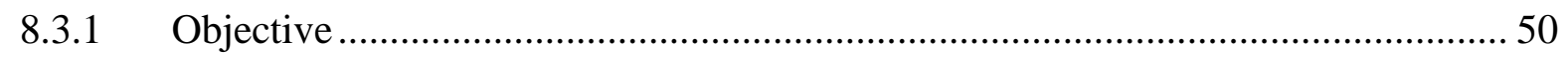

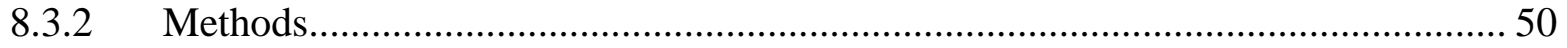

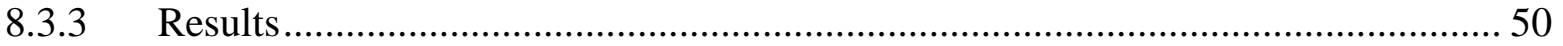

8.4 Effect of EBCT on Biofiltration Performance and Membrane Fouling ......................... 51

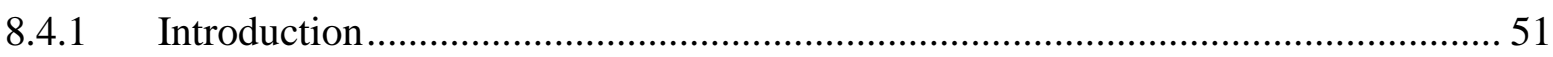

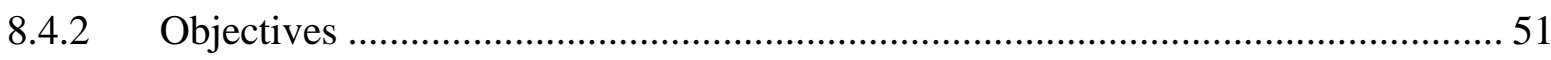




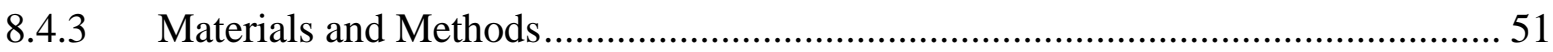

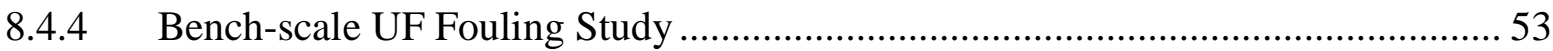

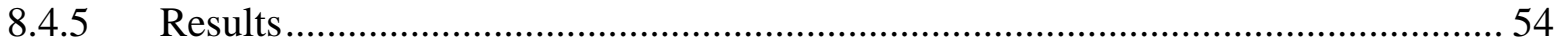

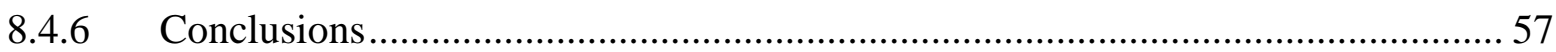

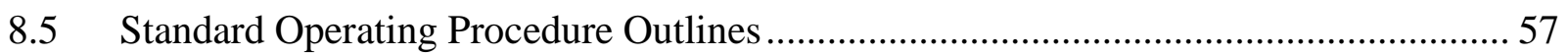

\section{LIST OF TABLES}

Table 2-1: Typical range of $\mathrm{CF}$ values for various hydraulic configurations............................... 10

Table 3-1: Description of the conditions for all pilot filtration tests .............................................. 13

Table 3-2: Properties of the single-fiber bench scale membrane.................................................. 17

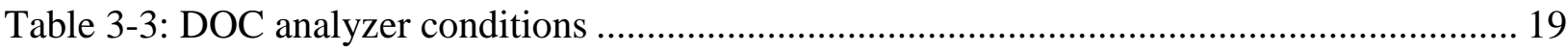

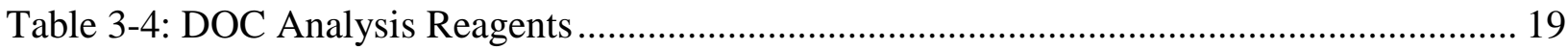

Table 4-1: Statistical comparison of irreversible resistance between the base condition $(4 \mathrm{mg} / \mathrm{L}$ continuous coagulation and sparging only during backwash) and various operating conditions. 24 Table 5-1: DOC and POC concentration in feed and reject water collected from Barrie and

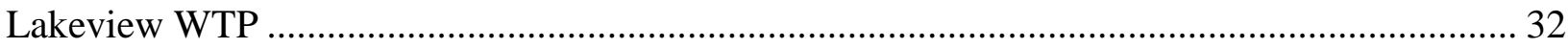

Table 5-2: Permeate DOC and POC concentrations at full and bench-scale................................. 34

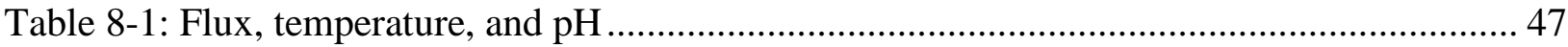

Table 8-2: Feed and permeate DOC, UV254, and SUVA ......................................................... 47

Table 8-3: Feed and permeate turbidity, particle counts, and POC ………………………........... 48

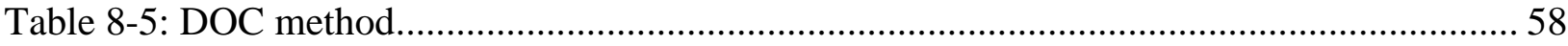

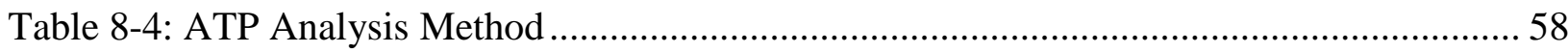




\section{LIST OF FIGURES}

Figure 2-1: Schematic of the membrane fouling mechanisms............................................. 4

Figure 2-2: Representation of contributions of intrinsic membrane resistance $\left(R_{m}\right)$, reversible resistance $\left(R_{\text {rev }}\right)$, and irreversible resistance $\left(R_{\text {irr }}\right)$ with continuous permeation and backwash

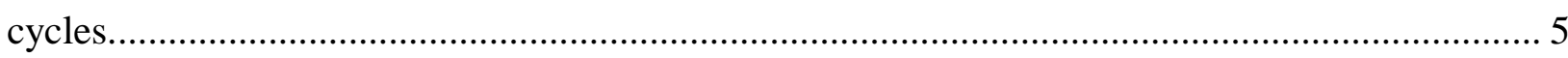

Figure 3-1: Schematic of the experiments for the concentration factor study ......................... 14

Figure 3-2: ZW pilot unit at the Barrie Surface WTP. (a) membrane module and chemical cleaning dosing, (b) particle counters and turbidity analyzers for raw and permeate water, (c) coagulant

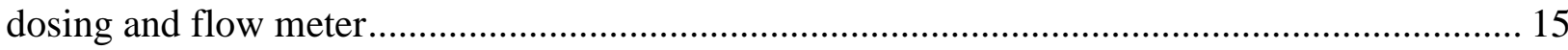

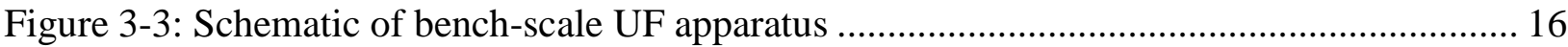

Figure 3-4: Sample Calibration Curve .................................................................................... 18

Figure 4-1: Typical resistance increase as a function of permeation time............................... 23

Figure 4-2: (i) Irreversible resistance vs. time and, (ii) irreversible resistance rates for (a) varying sparging duration, (b) reduced sparging intensity (c) varying sparging duration and coagulant dose 25

Figure 4-3: Proposed schematic of the fouling layer for various conditions during permeation . 26 Figure 4-4: Irreversible resistance for the base condition and phased coagulation................... 28

Figure 5-1: Results from filtration tests (a) Barrie Surface WTP, and (b) Lakeview WTP ......... 33 Figure 5-2: Resistance (averaged over the entire last permeation cycle) for each of the bench-scale filtration tests vs. organic carbon concentration (POC, DOC) in the solution filtered................ 33

Figure 8-1: Resistance vs. time for the base condition .................................................. 44

Figure 8-2: Resistance vs. time for phased 60 min. sparging ............................................ 44

Figure 8-3: Resistance vs. time for phased 110 min. sparging ........................................... 44

Figure 8-4: Resistance vs. time for no sparging ............................................................ 45

Figure 8-5: Resistance vs. time for no coag., continuous sparging ....................................... 45

Figure 8-6: Resistance vs. time for continuous sparging $5 \mathrm{~L} / \mathrm{min}$....................................... 45

Figure 8-7: Resistance vs. time for continuous sparging $20 \mathrm{~L} / \mathrm{min}$...................................... 45

Figure 8-8: Resistance vs. time for intermittent sparging $5 \mathrm{~L} / \mathrm{min}$.................................... 46

Figure 8-9: Resistance vs. time for intermittent sparging $20 \mathrm{~L} / \mathrm{min}$.................................... 46

Figure 8-10: Resistance vs. time for phased $60 \mathrm{~min}$. coagulation ........................................... 46 
Figure 8-11: Resistance vs. time for phased 10 min. coagulation ......................................... 46

Figure 8-12: Sample Milli-Q water permeation test for mounted membranes .......................... 49 Figure 8-13: (a) Irreversible resistance over time and (b) irreversible resistance rates for continuous coarse, intermittent coarse, and continuous pulse bubble sparging at 5 and $20 \mathrm{~L} / \mathrm{min}$............... 50 Figure 8-14: Schematic of Lakeview WTP pilot. indicates sampling location. ....................... 52 Figure 8-15: Daily average EBCT for Lakeview WTP's full-scale BACCs ............................ 54

Figure 8-16: Standard deviation of the daily EBCT averages shown in Figure 8-15 ................. 54 Figure 8-17: Relationship between EBCT and Lakeview WTP full-scale BACCs' \% DOC removal 55

Figure 8-18: Monthly average DOC for full-scale raw water, ozonated water, BACC effluent and

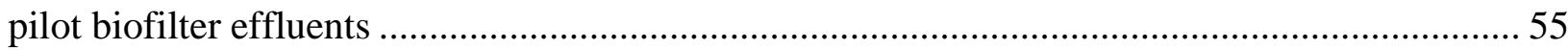

Figure 8-19: Monthly average $\mathrm{UV}_{254}$ values for full-scale raw water, ozonated water, BACC

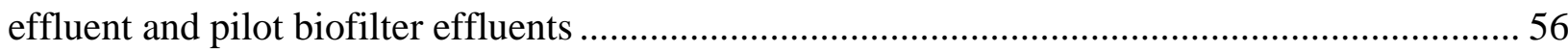
Figure 8-20: Biopolymers and humics for full-scale raw water, ozonated water, BACC effluent

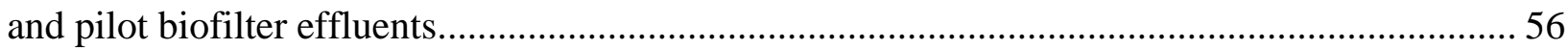

Figure 8-21: Typical resistance vs. time graph for 4 minute EBCT pilot effluent .................... 57 


\section{NOMENCLATURE}

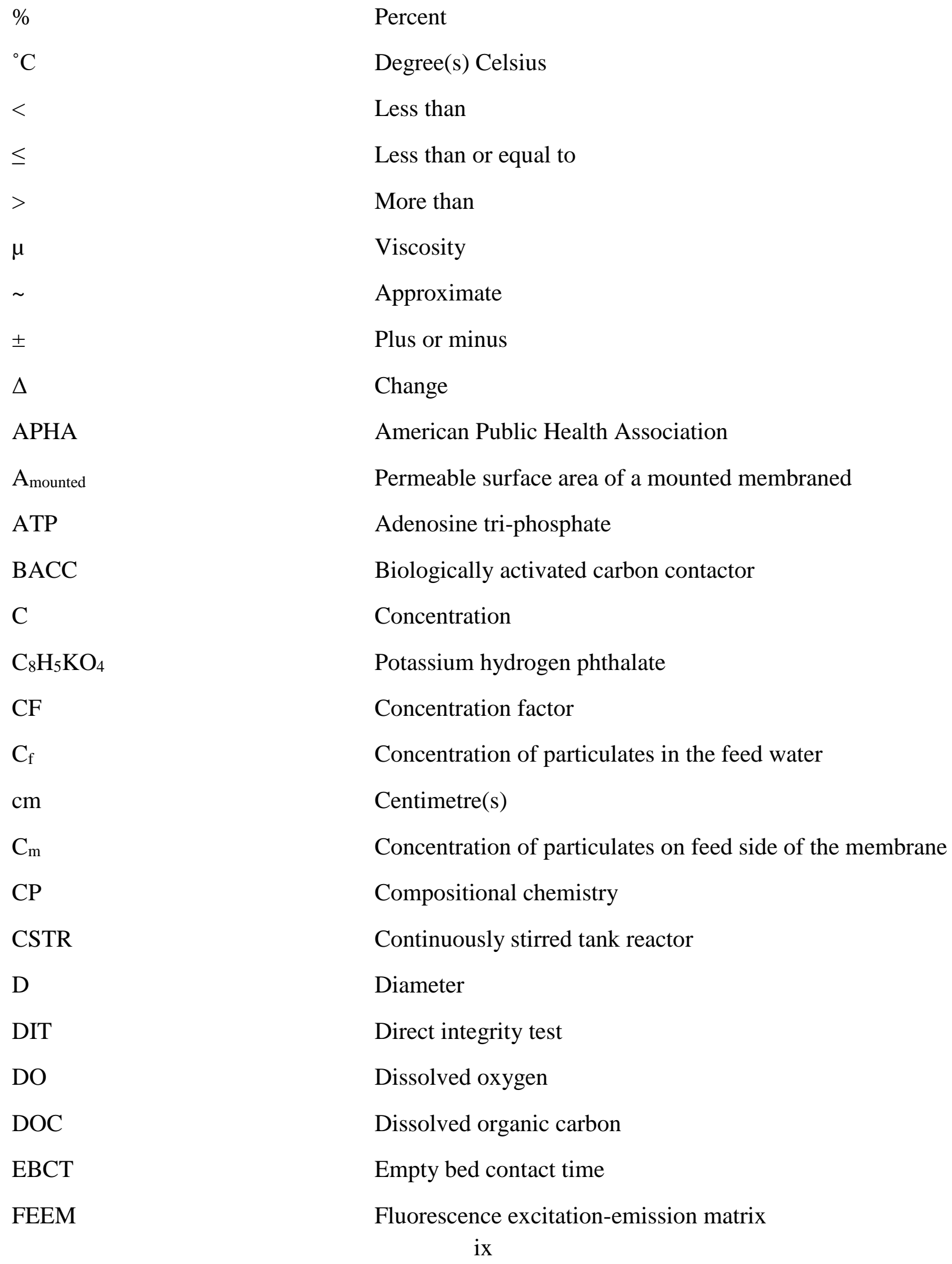




\section{FESEM}

g

GAC

GE

h

$\mathrm{h}^{-1}$

$\mathrm{H}_{2} \mathrm{SO}_{4}$

$\mathrm{H}_{3} \mathrm{PO}_{4}$

$\mathrm{Hz}$

in

J

KHP

$\mathrm{kg} / \mathrm{m} / \mathrm{s}$

$\mathrm{kPa}$

$\mathrm{kPa}^{-1}$

L

LC-OCD

$\mathrm{L} / \mathrm{h}$

$\mathrm{LMH}$

L/min

$\mathrm{L} / \mathrm{mg} / \mathrm{m}$

LRV $_{\text {DIT }}$

m

$\mathrm{m}^{-1}$

$\mathrm{m}^{2}$

$\mathrm{m}^{-2}$

$\mathrm{mg} / \mathrm{L}$

$\mathrm{mg} \mathrm{C} / \mathrm{L}$
Field Emission Scanning Electron Microscopy

$\operatorname{Gram}(\mathrm{s})$

Granular activated carbon

General Electric

$\operatorname{Hour}(\mathrm{s})$

1/hour(s)

Sulfuric acid

Phosphoric acid

Hertz

Inches

Flux

Potassium hydrogen phthalate

Kilogram(s) per meter per second

Kilopascal(s)

1/kilopascal(s)

Liter(s)

Liquid chromatography-organic carbon detection

Liter(s) per hour

Liter(s) per square metre per hour

Liter(s) per minute

Liter(s) per milligram per meter

Maximum log removal value that can be verified by direct integrity test

Metre(s)

$1 /$ meter(s)

Squared meter(s)

$1 /$ squared meter(s)

Milligram(s) per liter

Milligram(s) of carbon per liter 


\begin{tabular}{|c|c|}
\hline MI & Michigan \\
\hline $\min$ & Minute(s) \\
\hline $\mathrm{mL} / \mathrm{min}$ & Milliliter(s) per minute \\
\hline MLD & Megalitres per day \\
\hline $\mathrm{mm}$ & Millimeter(s) \\
\hline $\mathrm{mm}^{2}$ & Millimeter(s) squared \\
\hline $\mathrm{m} / \mathrm{s}$ & Meter(s) per second \\
\hline $\mathrm{N}_{2}$ & Nitrogen gas \\
\hline $\mathrm{NaOCl}$ & Sodium hypochlorite \\
\hline $\mathrm{NaOH}$ & Sodium hydroxide \\
\hline $\mathrm{Na}_{2} \mathrm{SO}_{4}$ & Sodium sulphate \\
\hline $\mathrm{nm}$ & Nanometer \\
\hline NOM & Natural organic matter \\
\hline NTU & Nephelometric Turbidity Unit \\
\hline OCD & Organic carbon detection \\
\hline $\mathrm{ON}$ & Ontario \\
\hline OND & Organic nitrogen detection \\
\hline $\mathrm{P}$ & Pressure \\
\hline $\mathrm{PACl}$ & Polyaluminum chloride \\
\hline PFR & Plug flow reactor \\
\hline $\mathrm{pH}$ & Negative $\log$ of the hydrogen ion concentration; $-\log \left\{\mathrm{H}_{+}\right\}$ \\
\hline POC & Particulate organic carbon \\
\hline psi & Pounds per square inch \\
\hline PVDF & Polyvinylidene difluoride \\
\hline Qbreach & Critical breach flow \\
\hline QC & Quebec \\
\hline Qloose & $\begin{array}{l}\text { Average permeate flow rate of the loose membrane when } \\
\text { filtering Milli-Q water }\end{array}$ \\
\hline $\mathrm{Q}_{\mathrm{p}}$ & Permeate flow \\
\hline
\end{tabular}




\begin{tabular}{|c|c|}
\hline $\mathrm{r}^{2}$ & Coefficient of determination \\
\hline $\mathrm{R}_{\mathrm{irr}}$ & Irreversible resistance \\
\hline $\mathrm{R}_{\text {loose }}$ & $\begin{array}{l}\text { Resistance of the loose membrane after filtering Milli-Q } \\
\text { water for } 2 \text { hours }\end{array}$ \\
\hline $\mathrm{R}_{\mathrm{m}}$ & Membrane resistance \\
\hline RMS & Root mean square \\
\hline rpm & Revolutions per minute \\
\hline $\mathrm{R}_{\mathrm{rev}}$ & Reversible resistance \\
\hline $\mathrm{R}_{\text {total }}$ & Total resistance \\
\hline SEC & Size exclusion chromatography \\
\hline SUVA & Specific ultraviolet absorbance (at $254 \mathrm{~nm}$ ) \\
\hline TMP & Transmembrane pressure \\
\hline $\mathrm{TMP}_{\text {mounted }}$ & $\begin{array}{l}\text { Transmembrane pressure for the mounted membrane after } \\
\text { filtering Milli-Q water for } 2 \text { hours }\end{array}$ \\
\hline TOC & Total organic carbon \\
\hline UF & Ultrafiltration \\
\hline UHP & Ultra-high purity \\
\hline$\mu \mathrm{L}$ & Microliters \\
\hline UV & Ultraviolet \\
\hline $\mathrm{UV}_{254}$ & UV absorbance at $254 \mathrm{~nm}$ \\
\hline WTP & Water treatment plant \\
\hline ZW500 & ZeeWeed $®-500$ membrane \\
\hline ZW1000 & ZeeWeed®-1000 membrane \\
\hline
\end{tabular}




\section{Introduction}

\subsection{Background}

Ultrafiltration (UF) is being increasingly employed in water treatment because of its ability to reduce the footprint of a facility and effectively remove contaminants of interest such as organic material and pathogenic microorganisms (Gao et al., 2011). However, the productivity of UF is limited by membrane fouling by natural organic matter (Shi et al., 2014).

Chemical and physical cleaning (backwashing and air sparging) are commonly applied to mitigate fouling. Repeated and frequent cleaning reduces the lifespan of UF membranes as the chemicals can alter membrane properties (Abdullah and Bérubé, 2013). Backwashing (reversal of flow) loosens the fouling cake layer from the membrane (Remize et al., 2010), but halts permeation production as well as consumes permeate water. Air sparging removes loose deposits and transports foulants away from the surface, thereby reducing the effect of concentration polarization and redeposition (Braak et al., 2011; Cabassud et al., 2001). Unlike wastewater treatment where air sparging is continuously applied, it is typically only used during backwashing in drinking water treatment. Recent bench-scale studies suggest that the benefits of air sparging during permeation outweigh the associated increased energy costs and lead to significant cost savings (Abdullah et al., 2015; Li et al., 2014).

In addition to chemical and hydraulic cleaning methods, pretreatment strategies such as coagulation can be applied to minimize fouling (Gao et al., 2011). Most studies on coagulationUF has focused on investigating the effect of coagulant type and dose as well as the flocculation parameters on UF fouling control (Barbot et al., 2008; Nan et al., 2016; Wray et al., 2016). Some

studies have explored using coagulant particles to pre-coat membranes prior to permeation (Park et al., 2002; Salinas-Rodriguez et al., 2016; Tabatabai et al., 2010). A recent bench-scale study suggested that coagulant only needs to be applied for the first half of each permeation cycle (phased coagulation) for effective fouling control (Pronk et al., 2016).

Bench-scale experiments is an important mean to efficiently test various pretreatment strategies and operational conditions that can be further evaluated at pilot-scale and possibly implemented at full-scale. However, the differences in packing density and the concentration 
factor at the solution-membrane interface between bench and full-scale systems may impact the mass transfer, fouling rate, and thereby the applicability of bench-scale systems.

\subsection{Objectives}

The main objectives of this research were:

- Assess the potential to increase the duration of a permeation cycle by providing air sparging during both permeation and backwashing when compared to sparging only during backwash

- Determine the effect of phased coagulation on the fouling rate

- Determine whether the removal of organic material would be influenced by changes in sparging and coagulation conditions described in the two objectives above

- Assess the impact of concentration factor on fouling at bench-scale, and compare to fullscale systems operated in deposition mode.

\subsection{Description of Chapters}

- Chapter 2: provides background information about ultrafiltration fouling mechanisms and fouling control methods including air sparging, biofiltration, and coagulation

- Chapter 3: describes the bench and pilot systems, experimental design, sampling procedures, and analytical and statistical methods

- Chapter 4: presents the results of UF pilot-scale filtration tests describing the effect of various air sparging and in-line coagulation conditions on membrane fouling control

- Chapter 5: presents the results of UF bench-scale filtration tests detailing the effect of concentration factor on membrane fouling

- Chapter 6: provides summary, conclusions and recommendations for further studies

- Chapter 7: lists the references consulted in this study

- Chapter 8: presents the appendices, including standard operating procedures, and results of experiments not included in the body of the thesis (i.e. Lakeview WTP pilot biofilters and pulse bubble sparging) 


\section{Literature Review}

\subsection{Ultrafiltration Overview}

Ultrafiltration (UF) is an increasingly employed water treatment technology because of its ability to reduce the footprint of a facility and readily remove organic matter, pathogenic microorganisms, and viruses (Gao 2011). The major constraint of UF is membrane fouling, which limits productivity and is energy-intensive and costly to overcome (Shi 2014). UF operational and maintenance costs has been reported to be approximately three times that of conventional treatment (Chew 2016). The higher costs are largely associated with strategies to minimize the impact of fouling on production, which include coagulation, hydraulic cleaning, chemical cleaning, and membrane replacement (Chew et al., 2016; Li et al., 2014; Wray et al., 2014).

\subsection{Membrane Foulants}

Natural organic matter (NOM), a naturally occurring complex mixture of organics, is considered the major UF foulant (Katsoufidou et al., 2007; Shi et al., 2014). NOM can be classified as particulate $(>0.45 \mu \mathrm{m})$ or dissolved $(<0.45 \mu \mathrm{m})$ organic carbon (i.e. POC or DOC). The dissolved component can be further fractionated to humic substances and biopolymers, which consists of proteins and polysaccharides. Biopolymers have been highly correlated $\left(\mathrm{r}^{2}>0.75\right)$ with UF fouling (Chen 2014, Rahman 2014, Peldzus 2011, Tian 2013). Other studies have identified particulates and humic substances as UF foulants (Zularisam et al., 2006).

\subsection{Fouling Mechanisms}

Fouling mechanisms include adsorption, pore blocking, cake and gel formation (Figure 2-1). Adsorption involves interactions, such as electrostatic attraction and hydrogen bonding, between the membrane and the particulates and solutes in feed water (Jones and O'Melia, 2000). Because the size of macromolecules is similar to the pore size of UF membranes, adsorption of macromolecules inside the membrane pores contribute substantially to the increase in resistance. Pore blockage, which is prominent in the early stages of filtration, is the partial or full obstruction of membrane pores by particulates (Field and $\mathrm{Wu}, 2011$ ). Cake formation occurs when particulates form layers on the surface of the membrane contributing to additional resistance to permeate flow. 
During the initial stages of filtration, the cake layer acts as a protective layer by preventing foulants from directly interacting with the membrane and otherwise increase resistance through adsorption or pore blocking (Hughes and Field, 2006). Gel formation is the consolidation of concentrated macromolecules, initiated by concentration polarization, on the surface of the membrane. Compared to the cake layer, the gel layer is more compressed, homogenous, and resistant to hydraulic cleaning (Ye et al., 2011). A combination of the four fouling mechanisms occur concurrently during filtration and the mechanisms' relative impact is dependent on the source water and UF operating conditions (Le-Clech et al., 2006; Shi et al., 2014).

Adsorption/Pore blocking

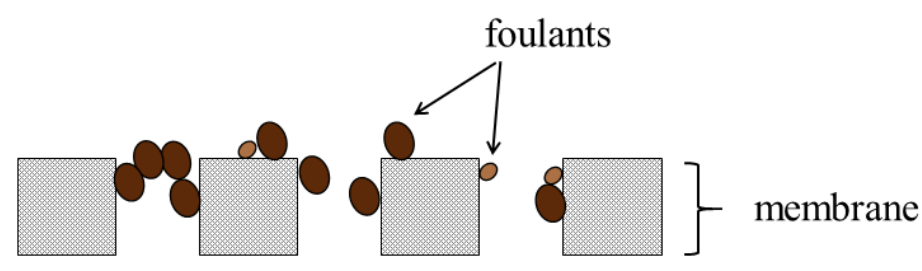

Cake layer formation

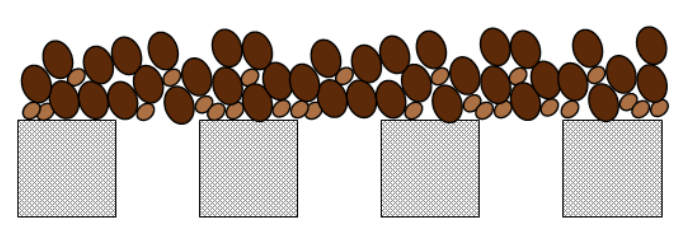

Gel layer formation

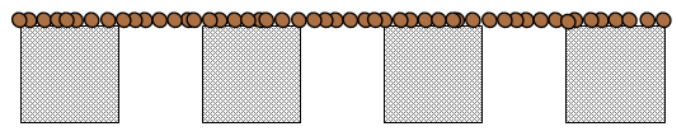

Figure 2-1: Schematic of the membrane fouling mechanisms

\subsection{Types of Fouling}

Membrane fouling can be classified as either reversible or irreversible fouling. The type of fouling can be further characterized by the cleaning method (i.e. hydraulic or chemical cleaning). Hydraulically reversible fouling, which can be removed by physical cleaning such as backwash and air sparging, is attributed to the formation of a surface cake layer on the membrane composed of particulates and higher molecular weight biopolymers (Amy, 2008; Taniguchi et al., 2003). Hydraulically irreversible fouling which cannot be removed by physical cleaning is due to pore adsorption or pore blocking (Huang et al., 2007) by biopolymers and humic substances (Chen et 
al., 2014; Rahman et al., 2014; Zularisam et al., 2006). The hydraulically irreversible foulants that can be removed by chemical cleaning are considered to be chemically reversible foulants.

Membrane fouling is often expressed as resistance to permeate flow. Resistance-in-series model is often used to model membrane fouling. Total resistance $\left(\mathrm{R}_{\text {total }}\right)$ is the sum of the intrinsic resistance of the membrane $\left(R_{m}\right)$ and resistance due to fouling which consists of reversible $\left(R_{\text {rev }}\right)$ and irreversible $\left(\mathrm{R}_{\text {irr }}\right)$ resistance. A representation of the various resistances is shown in Figure 2-2.

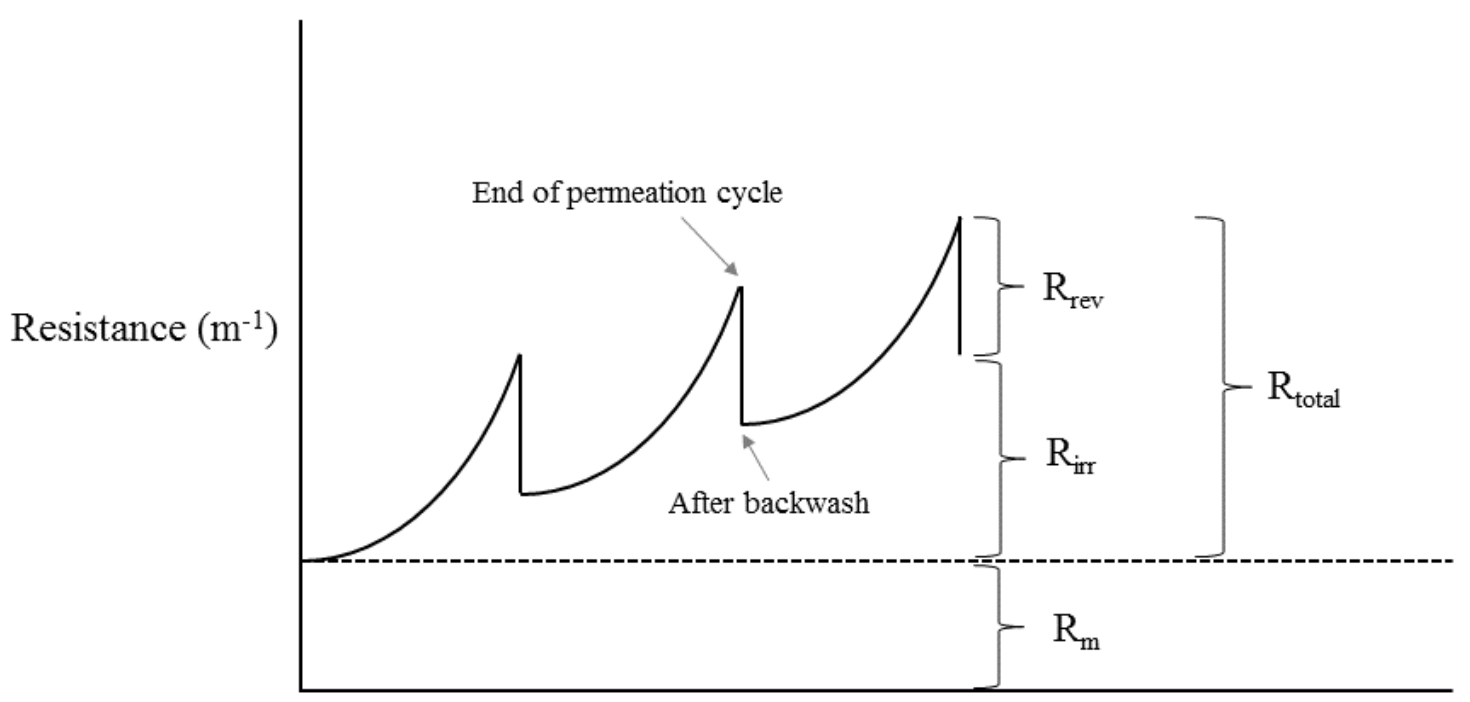

Time

Figure 2-2: Representation of contributions of intrinsic membrane resistance $\left(\mathrm{R}_{\mathrm{m}}\right)$, reversible resistance $\left(\mathrm{R}_{\mathrm{rev}}\right)$, and irreversible resistance $\left(\mathrm{R}_{\text {irr }}\right)$ with continuous permeation and backwash cycles.

\subsection{Fouling Control}

\subsubsection{Backwash}

Backwashing (reversal of flow) loosens the fouling cake layer from the membrane (Remize et al., 2010). The production of permeate is halted during backwashing and permeate is consumed, reducing the net yield of treated water. Because frequent backwashing is required, the water loss for UF (11-13\%) is double that reported for conventional treatment (6.6\%) (Chew et al., 2016). 


\subsubsection{Air Sparging}

Air sparging involves the injection of air bubbles from the base of the membrane which travel upwards propelled by buoyancy force. The bubbles and the resultant turbulence flow impart a shear force onto the membrane. While backwashing can only loosen foulants (Remize et al., 2010; Ye et al., 2011), air sparging removes loose deposits and transports foulants away from the surface , thereby reducing the effect of concentration polarization and deposition (Braak et al., 2011; Cabassud et al., 2001).

The extent of fouling control is generally proportional to the shear force imparted onto the membrane, which is dependent on the bubble size and frequency (Abdullah et al., 2015; Wray et al., 2013; Ye et al., 2014). Numerous studies have reported that pulse bubbles (>100 $\mathrm{mL})$ reduce membrane fouling more effectively when compared to coarse bubbles ( $<3 \mathrm{~mL}$ ) (Li et al., 2014; Wray et al., 2013; Ye et al., 2014). Intermittent sparging has also been reported to result in better fouling control when compared to continuous sparging (Chan et al., 2011; Li et al., 2014). Ye et al. (2014) found that the optimum bubble size and frequency was $150-250 \mathrm{~mL}$ and $0.5-0.6 \mathrm{~Hz}$, respectively, when filtering a $750 \mathrm{mg} / \mathrm{L}$ bentonite solution.

Membrane fouling control increases with increasing air flow rate up to an optimum flow rate. Further increase beyond the optimum flow rate results in increased fouling (Ye et al., 2014, $2011,2010)$. The increased fouling at high flow rates have been attributed to the removal of a cake layer, which acts as a protective fouling layer limiting the transport of foulants into the membrane pores causing irreversible fouling (Ye et al., 2011). Air sparging at high flow rates may also promote the rearrangement of foulants (Sur and Cui, 2001; Tabatabai et al., 2010) into a homogeneous, dense, gel-layer (Wang and Waite, 2008; Ye et al., 2011).

Unlike wastewater treatment where air sparging is continuously applied, it is typically only used during backwashing in drinking water treatment. As a result, costs associated with sparging are considered to be negligible and limited attention has focused on optimizing air sparging for drinking water treatment. Recent bench-scale studies suggest that the benefits of air sparging during permeation outweigh the associated increased energy costs and lead to significant cost savings (Abdullah et al., 2015; Li et al., 2014). 


\subsubsection{Biofiltration}

Biofiltration is an attractive UF pretreatment method that can remove biopolymers. Yearround, pilot-scale studies reported that biofilters reduced biopolymer concentration at the Grand River, ON, Canada from 0.36 to $0.17 \mathrm{mg} \mathrm{C} / \mathrm{L}$ (Halle et al. 2009, Peldszus et al. 2012) and at the Saugeen River, ON, Canada from 0.15 to $0.12 \mathrm{mg}$ C/L (Rahman et al. 2014) which resulted in reduction in both reversible and irreversible UF fouling. Furthermore, lengthening the EBCT from 5 to $15 \mathrm{~min}$ increased biopolymer removal by an average of $0.1 \mathrm{mg} / \mathrm{L}(35 \%)$ as well as reduced the rate of irreversible fouling (in terms of $\triangle \mathrm{TMP}$ ) by approximately $30 \mathrm{kPa}$ (Peldszus et al. 2012). A pilot-scale study conducted at the Lakeview WTP, ON, Canada showed that varying the EBCT (4, 8, 12, 16 minutes) had no impact on UF fouling control (Appendix Section 8.4).

\subsubsection{Coagulation}

Coagulation is the most common pretreatment method for UF (Gao et al., 2011). Typically, an inorganic coagulant such as aluminum or ferric salts are added prior to UF treatment for fouling control as well as to increase removal of organics. Coagulation increases the particle size of contaminants either by charge neutralization or sweep flocculation such that contaminants can be effectively removed by UF. Charge neutralization promotes particle growth by neutralizing the typically negatively charged natural organic matter. Sweep flocculation involves applying an excess coagulant amount such that metal hydroxide precipitates (e.g. aluminum and ferric hydroxides) are formed. In addition to increasing the particle size, coagulation decreases resistance by promoting the formation of a cake layer that prevents smaller foulants to penetrate into the membrane pores (Howe et al., 2007). Furthermore, the cake layer has been reported to be more porous in the presence of a coagulant which led to less resistance (Lee et al., 2000).

Unlike conventional treatment where coagulated and flocculated water undergo sedimentation, coagulants are directly injected into the UF feed stream for in-line coagulation. Consequently, the coagulation conditions ideal for conventional treatment does not necessarily apply to in-line coagulation (Choi and Dempsey, 2004a; Liu et al., 2011). While large flocs with high density and fractal dimension (a measure of complexity of the floc's external shape) are optimal for sedimentation, small-sized flocs with low density and fractal dimension are preferable for in-line coagulation (Yu et al., 2013). Small, irregular, and branched flocs form loosely- 
structured, highly porous cake layer which leads to low resistance (Barbot et al., 2008; Liu et al., 2011; Nan et al., 2016). Membrane flux has been reported to increase with increasing floc size and decreasing fractal dimension (Park et al., 2006; Sun et al., 2016). Studies have reported that minimal mixing time (Nan 2016) and the addition of coagulant in two stages (Liu 2011) can achieve the described floc characteristics such that the membrane resistance is minimized.

An optimal coagulant dose was previously reported to be $0.5 \mathrm{mg} / \mathrm{L}$ for biopolymer removal and UF fouling control (Wray et al., 2016; Wray and Andrews, 2014), which is substantially lower than dosages typically applied at full-scale systems (up to $15 \mathrm{mg} / \mathrm{L}$ ). Numerous studies have reported UF fouling to be minimized where charge neutralization (low coagulant dose, optimized $\mathrm{pH}$ ) is the dominant removal mechanism when compared to sweep flocculation (higher coagulant dose) (Choi and Dempsey, 2004b; Guigui et al., 2002; Lee et al., 2000). Under sweep flocculation conditions, precipitates of the coagulant attach to the membrane surface, as shown by Field Emission Scanning Electron Microscope analysis (Wray et al., 2016) and contribute to increased cake resistance (Jang et al., 2005; Ohno et al., 2010; Wray et al., 2016). Furthermore, sweep flocculation promotes the formation of a more compressible and less porous layer when compared to the foulant layer under charge neutralization conditions (Lee et al., 2000).

The addition of coagulant precipitates (Park et al., 2002; Salinas-Rodriguez et al., 2016) prior to permeation has been reported to minimize irreversible fouling. The precipitates pre-coat the membranes with a protective fouling layer, which prevents pore plugging (Park et al., 2002; Salinas-Rodriguez et al., 2016). Past studies have pre-coated the membrane with iron hydroxide particles (Park et al., 2002; Salinas-Rodriguez et al., 2016) or diatomite particles (Galjaard et al., 2003, 2001) before each permeation cycle.

\subsubsection{Chemical Cleaning}

Chemical cleaning reduces hydraulically irreversible fouling through daily to weekly application of an alkali solution such as sodium hypochlorite which removes persistent organics. Monthly application of an acidic solution such as citric acid is used to remove inorganic deposits (Gao et al., 2011). Repeated and frequent cleaning reduces the lifespan of UF membranes as the chemicals can alter membrane properties (Abdullah and Bérubé, 2013). Fouling control strategies that reduce the reliance and application of chemical cleans are expected to increase membrane service life and lead to substantial cost savings (Li et al., 2014; Wray et al., 2013). 


\subsection{Hydraulic Configurations}

The hydraulic configuration describes the process in which the feed water is treated by a UF system and largely determined by operational conditions such as backwash, air sparging, and concentrate and recycle flow (Membrane Filtration Guidance Manual, 2005). The hydraulic configuration determines the extent in which particulates are concentrated on the feed side of the membrane or the concentration factor (CF) (Eqn. 2-1).

$$
C F=\frac{C_{m}}{C_{f}}
$$

where:

$\mathrm{C}_{\mathrm{m}}=$ concentration of particulates on the feed side of the membrane

$\mathrm{C}_{\mathrm{f}}=$ concentration of particulates in the feed water

By definition, $\mathrm{CF}=1$ for a system in which the particulates do no concentration on the feed side of the membrane. For $\mathrm{CF}>1$, particles are resuspended in the membrane tank and the potential for pathogens and particulates to pass through the membrane increases as shown in Eqn. 2.2.

$$
L R V_{D I T}=\log \left(\frac{Q_{p}}{C F \cdot Q_{\text {breach }}}\right)
$$

where:

$\mathrm{LRV}_{\mathrm{DIT}}=$ maximum log removal value that can be verified by direct integrity test (DIT) (dimensionless)

$\mathrm{Q}_{\mathrm{p}}=$ permeate flow $(\mathrm{L} / \mathrm{min})$

$Q_{\text {breach }}=$ critical breach size $(\mathrm{L} / \mathrm{min})$, flow from the breach associated with the smallest integrity test response that can be reliably measured

$\mathrm{CF}=$ concentration factor (dimensionless)

Deposition mode and suspension mode are the two basic hydraulic configurations (Membrane Filtration Guidance Manual, 2005). Deposition mode (also known as dead-end mode or direct filtration) is analoguous to conventional granular media filtration such that the system has one feed and permeate stream with no concentrate stream. Suspended particulates in the feed stream accumulate on the membrane surface and hydraulic forces perpendicular to the membrane ensures that the particulates are not resuspended. As a result, a cake layer forms. In suspension mode, a shear force is applied tangential to the membrane surface continuously or intermittently 
using water or air. The shear force is applied to decrease the accumulation of particulates at the membrane surface and thereby reduce fouling. Examples of suspension mode systems include plug flow reactor (PFR) model, continuously stirred tank reactor (CSTR), cross flow filtration, and systems with continuous air sparging. The CF increases with time for CSTR, cross flow filtration and continuous air sparging while the CF increases in the direction of flow for PFR. The typical ranges of $\mathrm{CF}$ values for the various hydraulic configurations are shown in Table 2-1.

Table 2-1: Typical range of $\mathrm{CF}$ values for various hydraulic configurations (adapted from (Membrane Filtration Guidance Manual, 2005)

\begin{tabular}{|c|c|c|}
\hline Mode & Description & $\mathbf{C F}$ \\
\hline \multicolumn{2}{|r|}{ Deposition } & 1 \\
\hline \multirow{4}{*}{ Suspension } & PFR & $3-20$ \\
\hline & Cross flow & $4-20$ \\
\hline & CSTR & $4-21$ \\
\hline & Continuous air sparging & $4-22$ \\
\hline
\end{tabular}

\subsection{Research Gaps}

Previous studies conducted at bench-scale have compared conditions with no sparging to those with continuous sparging (sparging throughout permeation and backwash) (Li et al., 2014; Wray et al., 2013). However, most UF systems in drinking water applications only sparge during backwash. Continuous sparging has not been compared to the baseline condition that is prevalent in drinking water treatment plants.

Pronk et al (2016) suggested that applying coagulant for the first half of each permeation cycle, as opposed to continuous coagulation, has no negative impact on fouling and would reduce coagulant costs. However, the application of coagulant in phases within a permeation cycle has not been examined at pilot-scale. As such, the scalability of this method and the optimum duration is unclear.

A number of studies have investigated pretreatment methods and operational conditions to reduce membrane fouling. Much of this work has been based on the use of bench-scale systems that incorporate single membrane fibers (Chan et al., 2007; Katsoufidou et al., 2007; Li et al., 2014; Wray et al., 2014) and as such have substantially different loading characteristics when compared 
to full-scale systems; in particular, the specific membrane surface area or packing density within a given system volume. As a result, most bench-scale studies may have been performed at concentration factors (CF) that are much lower than those typical of full scale systems. Considering that fouling is impacted by the concentration of the constituents in the solution being filtered, it is possible that the outcomes of bench-scale studies are not representative of those at full-scale, especially considering that the $\mathrm{CF}$ in most bench-scale studies is approximately 1 . Unfortunately, limited information exists on the impact of $\mathrm{CF}$ on the outcomes of bench-scale studies. 


\section{Materials and Methods}

\subsection{Water Matrices and Water Treatment Plants}

The Barrie Surface WTP (Barrie, ON, Canada) treats Lake Simcoe water using coagulation, ultrafiltration, granular activated carbon, and chlorination. The Lakeview WTP (Mississauga, ON, Canada) treats Lake Ontario (2 $\mathrm{mg} / \mathrm{L} \mathrm{DOC}$ ) water using ozonation, biofiltration, ultrafiltration, UV, and chlorination. Both plants operate their membranes in dead-end mode with $95 \%$ recovery and use ZeeWeed®1000 (GE Water \& Process Technologies, Oakville, Ontario), which are outside-in, polyvinylidene difluoride (PVDF) hollow fiber UF membranes.

\subsection{Experimental Protocol}

\subsubsection{Air Sparging and In-line Coagulation Study}

At the Barrie Surface WTP, membranes are sparged only during backwash using coarse air bubbles at $60 \mathrm{~L} / \mathrm{min}$. For pilot-scale filtration tests, the air sparging (sparging duration and flow rate) and coagulation conditions were varied as presented in Table 3-1. Two-tailed t-tests were used to evaluate the impact of varying operating conditions on the rate of increase in membrane resistance. All analyses were evaluated at a 95\% significance level. Feed and permeate samples were collected at $0,24,48$ hours of each filtration test and analyzed for TOC, DOC, POC, and $\mathrm{UV}_{254}$.

\subsubsection{Concentration Factor Study}

UF feed and reject water (obtained at the end of a permeation cycle following air sparging and backwashing) were collected from the Barrie Surface and Lakeview WTP during a single sampling event and used as influent to a bench-scale system (Chan et al., 2007; Li et al., 2014) (Figure 3-1). The membrane resistance when filtering UF feed water and reject water at benchscale over a period of 24 hours were compared. Results obtained at bench-scale were also directly compared to full-scale systems (at the time when the feed and reject water were collected). A chemical recovery clean was performed on the full-scale system prior to data collection. 
Feed and permeate samples were collected every 8 hours during the 24-hour filtration tests and analyzed for total organic carbon (TOC), dissolved organic carbon (DOC), and particulate organic carbon (POC) was calculated by subtracting DOC from TOC.

Table 3-1: Description of the conditions for all pilot filtration tests

\begin{tabular}{|c|c|c|c|c|c|}
\hline \multirow{3}{*}{$\begin{array}{c}\text { Parameters } \\
\text { Examined }\end{array}$} & \multirow{3}{*}{ Deviation from base condition } & \multicolumn{3}{|c|}{ Sparging conditions } & \multirow{3}{*}{$\begin{array}{c}\begin{array}{c}\text { Coagulant } \\
\text { conditions }\end{array} \\
\text { Dose }(\mathrm{mg} / \mathrm{L})\end{array}$} \\
\hline & & \multirow{2}{*}{$\begin{array}{c}\text { Air } \\
\text { flow } \\
\text { (L/min) }\end{array}$} & \multicolumn{2}{|c|}{ Applied during: } & \\
\hline & & & Permeation & Backwash & \\
\hline $\begin{array}{c}\text { Base } \\
\text { condition }\end{array}$ & - & 60 & $x$ & $\checkmark$ & 4 \\
\hline \multirow{5}{*}{$\begin{array}{l}\text { Sparging } \\
\text { duration }\end{array}$} & Continuous sparging & 60 & $\checkmark$ & $\checkmark$ & 4 \\
\hline & Phased 60 min sparging ${ }^{b}$ & 60 & $\checkmark$ & $\checkmark$ & 4 \\
\hline & Phased 110 min sparging ${ }^{\mathrm{c}}$ & 60 & $\checkmark$ & $\checkmark$ & 4 \\
\hline & No sparging & 60 & $x$ & $x$ & 4 \\
\hline & Continuous sparging, no coag. & 60 & $\checkmark$ & $\checkmark$ & 0 \\
\hline \multirow{4}{*}{$\begin{array}{l}\text { Lower } \\
\text { intensity } \\
\text { sparging }\end{array}$} & Continuous sparging $5 \mathrm{~L} / \mathrm{min}$ & 5 & $\checkmark$ & $\checkmark$ & 4 \\
\hline & Continuous sparging $20 \mathrm{~L} / \mathrm{min}$ & 20 & $\checkmark$ & $\checkmark$ & 4 \\
\hline & Intermittent sparging ${ }^{d} 5 \mathrm{~L} / \mathrm{min}$ & 5 & $\checkmark$ & $\checkmark$ & 4 \\
\hline & Intermittent sparging ${ }^{\mathrm{d}} 20 \mathrm{~L} / \mathrm{min}$ & 20 & $\checkmark$ & $\checkmark$ & 4 \\
\hline \multirow{2}{*}{$\begin{array}{c}\text { Phased } \\
\text { coagulation }\end{array}$} & Phased 60 min coagulation ${ }^{\mathrm{e}}$ & 60 & $x$ & $\checkmark$ & 4 \\
\hline & Phased 10 min coagulation ${ }^{\mathrm{f}}$ & 60 & $x$ & $\checkmark$ & 4 \\
\hline
\end{tabular}

${ }^{a}$ Sparging during backwash only

${ }^{\mathrm{b}}$ No sparging was applied for the first 60 minutes of each permeation cycle. Sparging was applied for the last 60 minutes of each cycle

${ }^{\mathrm{c}}$ No sparging was applied for the first 10 minutes of each permeation cycle. Sparging was applied for the last 110 minutes of each cycle

${ }^{\mathrm{d}}$ Sparging for 10 seconds followed by 10 seconds of rest

${ }^{\text {e }}$ Coagulant was applied for the first 60 minutes of each permeation cycle. No coagulant was applied for the last 60 minutes of each cycle

${ }^{\mathrm{f}}$ Coagulant was applied for the first 10 minutes of each permeation cycle. No coagulant was applied for the last 110 minutes of each cycle 


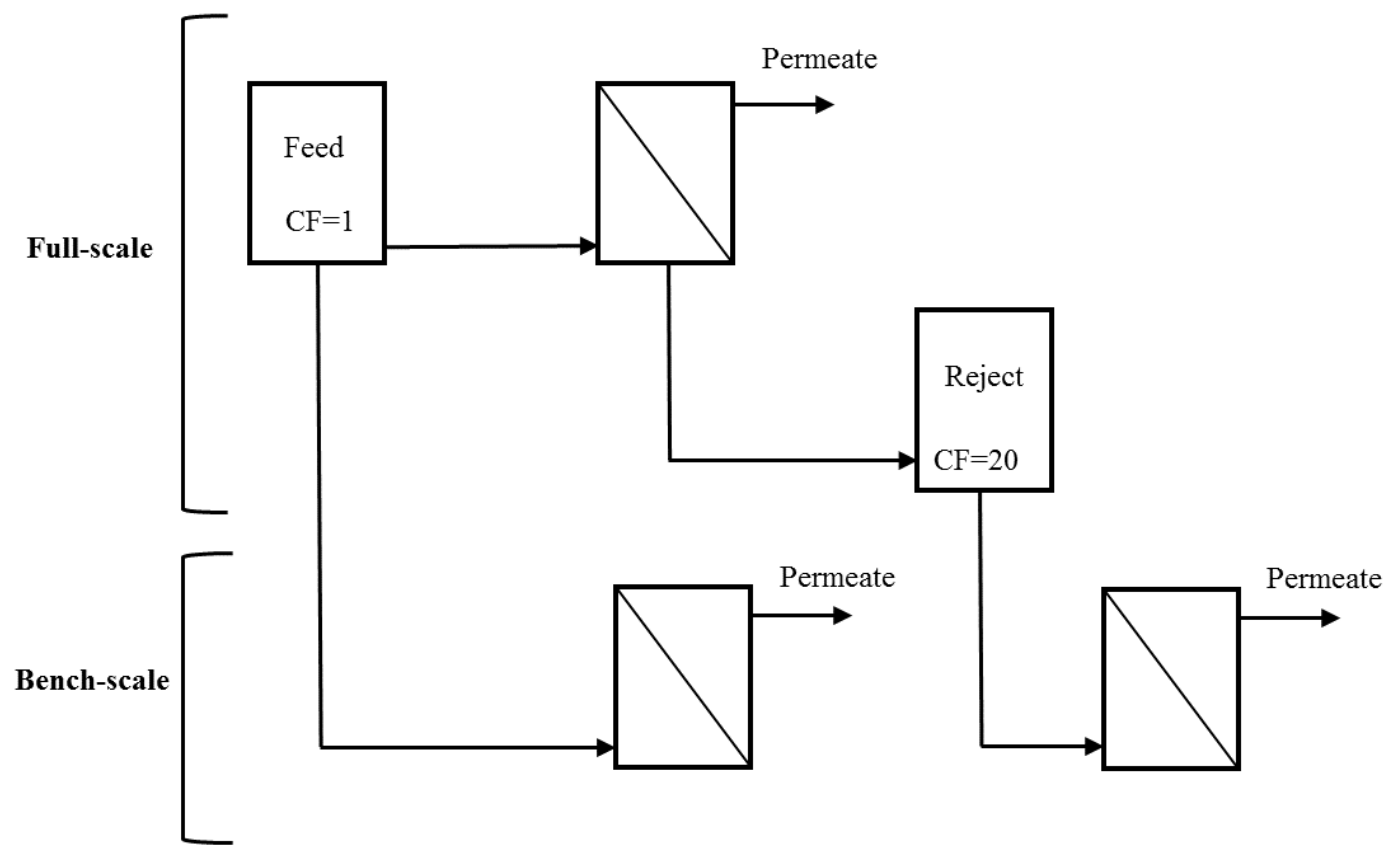

Figure 3-1: Schematic of the experiments for the concentration factor study. Theoretical CF values for membranes operated at $95 \%$ recovery are shown.

\subsection{Fouling Quantification}

Fouling was quantified using a resistance-in-series approach (Busch et al., 2007; Cho et al., 2004) (Eqn. 3.1), normalized to the intrinsic resistance of the membrane at the start of each filtration test and a temperature of $20^{\circ} \mathrm{C}$ (Zheng et al., 2010).

$$
R=\frac{\Delta P}{J \mu}
$$

where: $\mathrm{R}$ is the resistance $\left(\mathrm{m}^{-1}\right), \Delta \mathrm{P}$ is the transmembrane pressure $(\mathrm{Pa}), \mathrm{J}$ is the flux $(\mathrm{m} / \mathrm{s})$ and $\mu$ is the fluid viscosity $(\mathrm{kg} / \mathrm{m} \cdot \mathrm{s})$.

\subsection{Membrane Filtration Apparatus}

\subsubsection{Pilot Apparatus}

Pilot-scale filtration tests were conducted at Barrie, ON, Canada using a full ZeeWeed® 1000 membrane module (Figure 3-2) as previously described (Wray et al., 2016). The pilot was 
fully automated to mimic full-scale treatment including in-line coagulation using $4 \mathrm{mg} / \mathrm{L}$ polyaluminium chloride (PACl) (PAX-XL1900, Kemira Water Solutions Canada, Inc.), backwashing, and air sparging. Transmembrane pressure, feed and permeate turbidity, temperature, $\mathrm{pH}$ and particle counts were monitored every 5 minutes throughout 48 -hour filtration tests. A membrane integrity test (pressure hold test) was also performed before every filtration test. At the end of each filtration test, the membrane module was chemically cleaned as recommended by the manufacturer (soaked with $500 \mathrm{mg} / \mathrm{L} \mathrm{NaOCl}$ and $200 \mathrm{mg} / \mathrm{L}$ citric acid for 12 hours). If the transmembrane pressure reached $40 \mathrm{kPa}$ prior to 48 hours, the filtration test was terminated and a chemical clean was initiated. Permeation duration was extended from 30 minutes (full-scale operation) to 2 hours in order to accelerate fouling during the pilot-scale tests. As performed at full-scale, following each backwash, the pilot-scale membrane tank was drained.

(a)

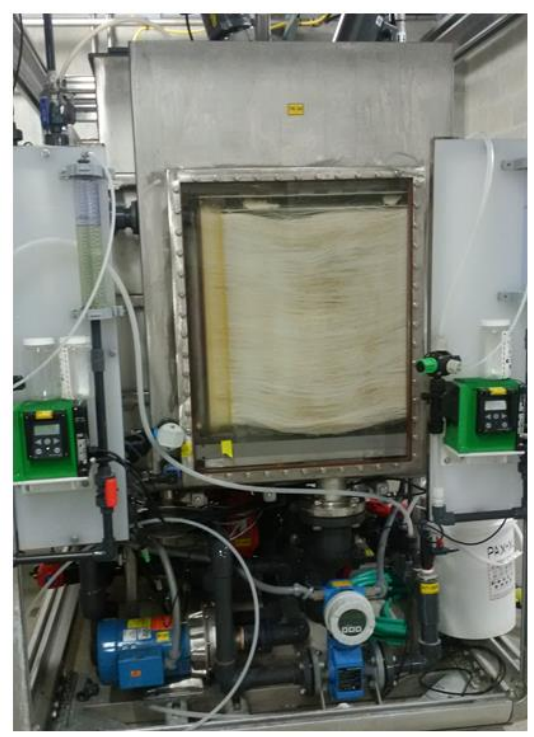

(b)

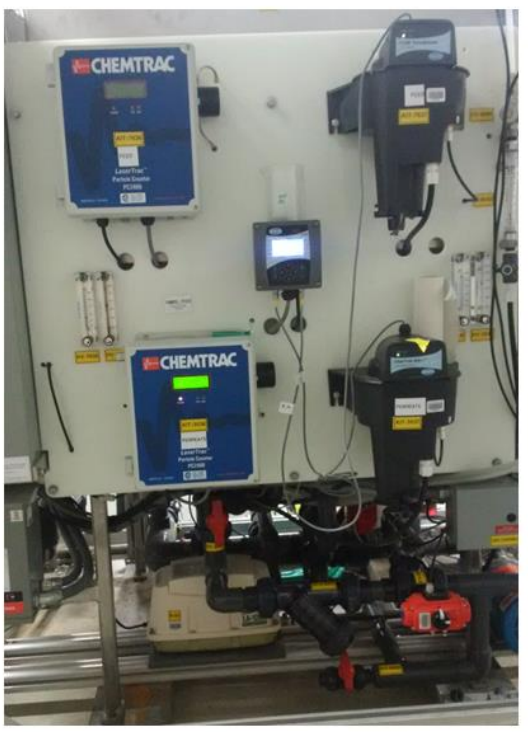

(c)

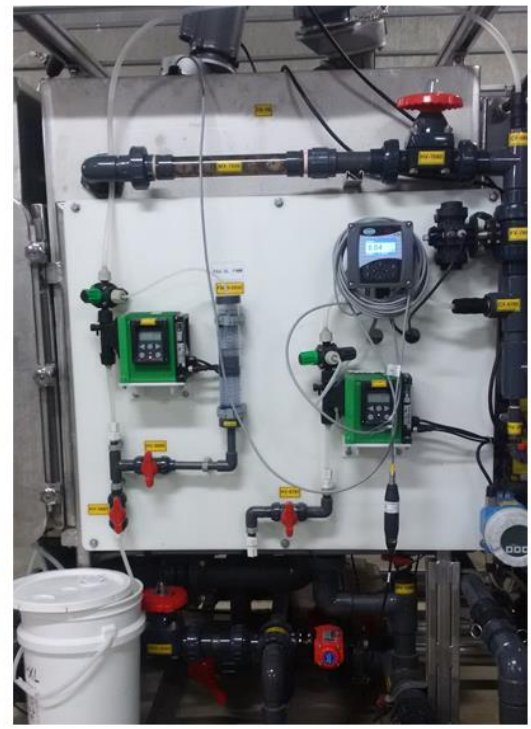

Figure 3-2: ZW pilot unit at the Barrie Surface WTP. (a) membrane module and chemical cleaning dosing, (b) particle counters and turbidity analyzers for raw and permeate water, (c) coagulant dosing and flow meter

\subsubsection{Single-Fiber Apparatus}

The bench-scale setup consisted of four identical systems such that up to four different experiments could be conducted simultaneously. Each system (Figure 3-3) had a feed tank, single 
UF hollow fiber mounted in a stainless steel holder in the inner wall of a membrane tank, shear apparatus, peristaltic pump, and solenoid valves to control the filling and draining of the membrane tanks by gravity. The solenoid valves and the pumps were controlled by a PLC program (WinLDR V6, IDEC Corporation), which allowed for automated filtration and backwash cycles. Transmembrane pressure (TMP) on the permeate side of the membrane was monitored using a pressure gauge and collected using a pressure transducer (Omega PX240, Omega Engineering, Montreal, QC) connected to a data logger (National Instruments USB-6009) and recorded automatically every 30 s using Labview software (version 10.0, National Instruments, VaudreuilDorion, QC). The permeate flow was monitored using a scale (Cole Parmer Symmetry Topbalance, Montreal, Quebec).

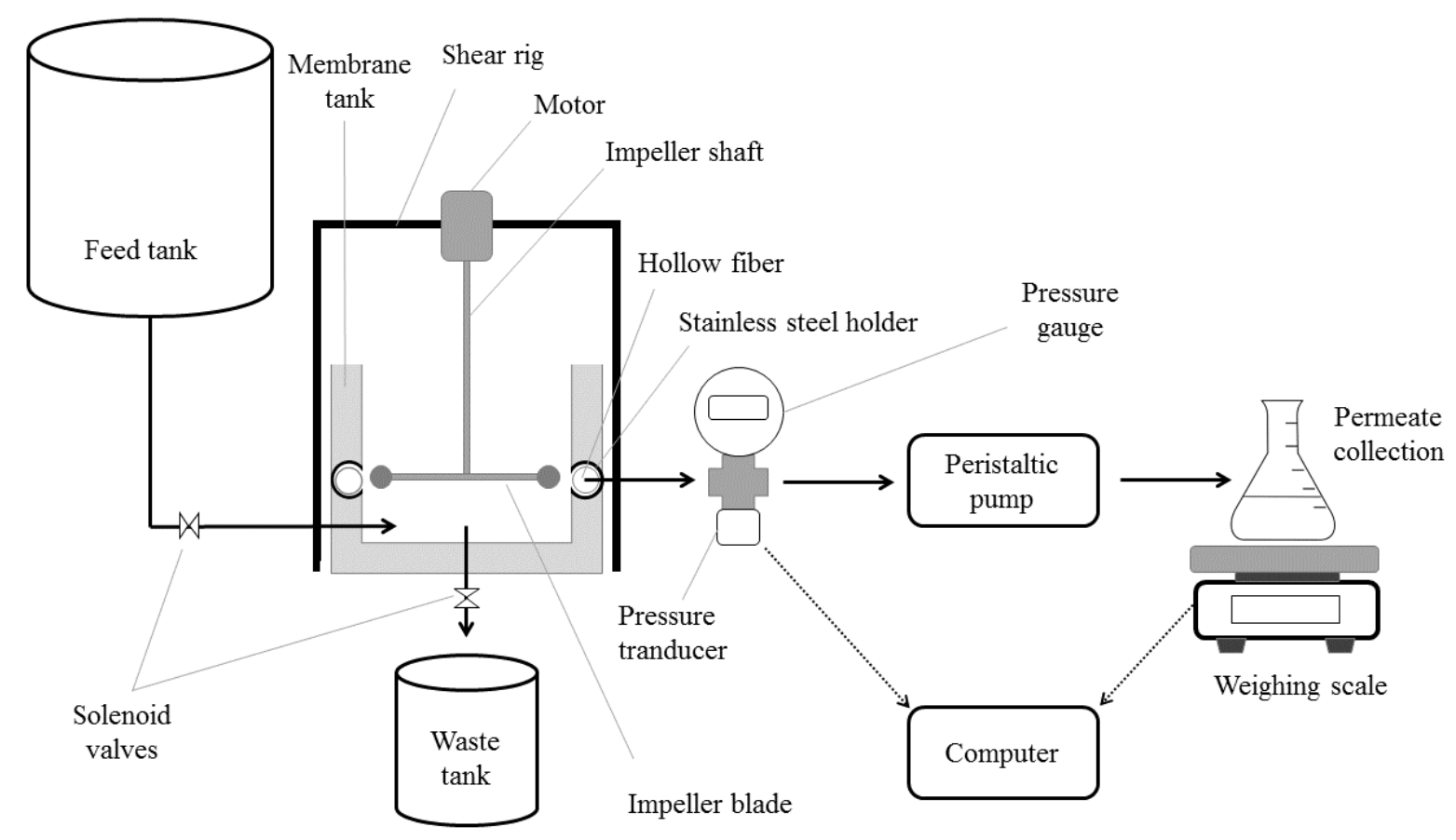

Figure 3-3: Schematic of bench-scale UF apparatus (only one of the four systems is shown)

The outside-in, polyvinylidene difluoride (PVDF) hollow fiber UF membranes (ZeeWeed®500, GE Water and Process Technologies, Oakville, Ontario) were used in this study. The membrane fibers were composed of polyvinylidene fluoride (PVDF) and were of the same compositional chemistry (CP5) (Table 3-2) as hollow fiber ZeeWeed®-1000 (ZW1000) membranes in both the Barrie Surface and Lakeview WTP. 
Table 3-2: Properties of the single-fiber bench scale membrane (GE Water \& Process Technologies, Oakville, ON)

\begin{tabular}{|c|c|}
\hline Hollow fiber type & ZW500 \\
\hline Fiber chemistry & CP5 \\
\hline Nominal pore size $(\mu \mathrm{m})$ & 0.04 \\
\hline $\begin{array}{c}\text { Pure water permeability } \\
\left(\mathrm{L}^{-2} \mathrm{~m}^{-2} \cdot \mathrm{h}^{-1} \cdot \mathrm{kPa}^{-1}\right)\end{array}$ & $2.15( \pm 0.25)$ \\
\hline $\begin{array}{c}\text { Intrinsinc membrane resistance } \\
\left(\mathrm{x} 10^{12} \mathrm{~m}^{-1}\right)\end{array}$ & $1.02( \pm 0.11)$ \\
\hline Membrane area $\left(\mathrm{m}^{2}\right)$ & 0.0006 \\
\hline Typical operating TMP $(\mathrm{kPa})$ & -10 to -50 \\
\hline
\end{tabular}

A $25-\mathrm{cm}$ length of virgin outside-in, hollow fiber UF membrane (approximately $1250 \mathrm{~mm}^{2}$ of permeable area) was used for each filtration test. Fibers were first soaked in $750 \mathrm{mg} / \mathrm{L}$ sodium hypochlorite solution for $24 \mathrm{~h}$ to remove residual shipping preservative and then stored in a 50 $\mathrm{mg} / \mathrm{L}$ sodium hypochlorite solution until use. Membrane integrity was tested at the start of each experiment using a bubble test at a pressure of 5 psi (34.5 kPa). Membranes were discarded if air bubbles escaped during the integrity test. Immediately prior to the experiments, fibers were cleaned by filtering $750 \mathrm{mg} / \mathrm{L}$ sodium hypochlorite solution twice for 1 hour each followed by Milli-Q water for 2 hours, during which the clean water resistance of the virgin, loose membrane was quantified. The loose membrane was then mounted onto a stainless steel holder which was recessed into the wall of the membrane tank and secured using silicone. Milli-Q water was then filtered through the fiber for an additional 2 hours (Appendix Figure 8-12). The change in resistance between the loose and mounted fibers was used to estimate the actual permeable membrane area (Appendix Section 8.2). The permeate flow was adjusted to $501 / \mathrm{m}^{2} \cdot \mathrm{hr}$, which is representative of full-scale operation.

The system was specifically designed to mimic the hydrodynamic conditions and filtration/backwash cycles present at full-scale systems. The permeation and backwash cycles were 30 and 3 minutes, respectively. Air sparging, using the shear apparatus, was only applied during backwash (permeation in deposition mode). The shear apparatus was developed by (Chan et al., 2011) and consisted of an impeller, a rig which secured the impeller, and a motor which provided impeller rotation (Figure 3-3). The impeller rotational speed was 8.5, which is representative of high peak shear conditions (Chan et al., 2011). 


\subsection{Analytical Methods}

\subsubsection{Dissolved Organic Carbon}

DOC was measured based on standard method 5310 D using an O-I Corporation Model 1010 Analytical TOC Analyzer with a Model 1051 Vial Multi-Sampler (APHA, 2005). Samples were filtered into $40 \mathrm{~mL}$ amber vials through a $0.45 \mu \mathrm{m}$ glass fiber filter, and acidified to $\mathrm{pH} \leq 2 \mathrm{using}$ concentrated sulfuric acid if samples were not analyzed immediately after preparation. The vials were sealed with Teflon $®$-lined septum screw caps and stored at $4{ }^{0} \mathrm{C}$. All samples were prepared on the day of collection and tested within 7 days. A summary of the instrument conditions are presented in Table 3-2. DOC concentrations in water were quantified using anhydrous potassium hydrogen phthalate (KHP) in Milli-Q ${ }^{\circledR}$ water as a calibration solution. The calibration solutions were prepared at a concentration of $10 \mathrm{mg} / \mathrm{L}$ and diluted by the instrument to concentrations of 0 , $0.625,1.25,2.5$ and $5 \mathrm{mg} / \mathrm{L}$ for a 6 point calibration curve. A $10 \mathrm{mg} / \mathrm{L}$ calibration sample was prepared, diluted and analyzed before each sample set. Check standards $(\mathrm{C}=2.5 \mathrm{mg} / \mathrm{L})$ were tested after every 10 samples, and at the end of every sample set. Additionally, a minimum of three blank samples were tested after calibration, and before every check standard sample. The reagent list is presented in

Table 3-4. Sample preparation and the method outline details are presented in Appendix Table 8-4.

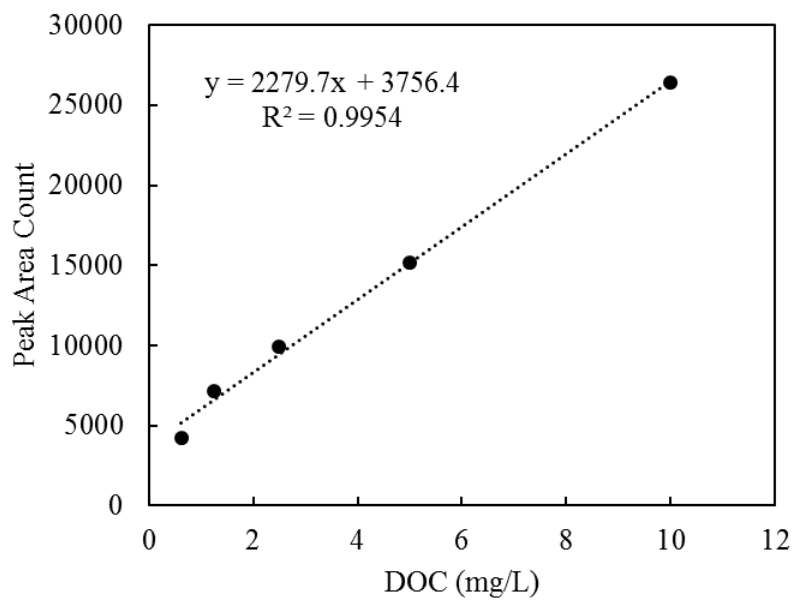

Figure 3-4: Sample Calibration Curve - DOC (November 2016) 
Table 3-3: DOC analyzer conditions

\begin{tabular}{|l|l|}
\hline Parameter & Description \\
\hline Acid volume & $200 \mu \mathrm{L}$ of $5 \%$ phosphoric acid \\
\hline Oxidant volume & $1000 \mu \mathrm{L}$ of $100 \mathrm{~g} / \mathrm{L}$ sodium persulphate \\
\hline Sample volume & $15 \mathrm{~mL}$ \\
\hline Rinses per sample & 1 \\
\hline Volume per rinse & $15 \mathrm{~mL}$ \\
\hline Replicates per sample & 3 \\
\hline Reaction time (min:sec) & TIC 2:00; TOC 2:30 \\
\hline Detection time (min:sec) & TIC $2: 40 ;$ TOC $2: 00$ \\
\hline Purge gas & Nitrogen \\
\hline Loop size & $5 \mathrm{~mL}$ \\
\hline
\end{tabular}

Table 3-4: DOC Analysis Reagents

\begin{tabular}{|l|l|}
\hline Reagent & Supplier and purity \\
\hline Milli-Q® water & Prepared in the laboratory \\
\hline Sulphuric acid, $\mathrm{H}_{2} \mathrm{SO}_{4}$ & VWR International, 98\%+ \\
\hline Sodium persulphate, $\mathrm{Na}_{2}\left(\mathrm{SO}_{4}\right)$ & Sigma Aldrich, 98\%+, anhydrous \\
\hline $\begin{array}{l}\text { Potassium hydrogen phthalate }(\mathrm{KHP}), \\
\mathrm{C}_{8} \mathrm{H}_{5} \mathrm{KO}_{4}\end{array}$ & Sigma Aldrich, 98\%+ \\
\hline Phosphoric acid, $\mathrm{H}_{3} \mathrm{PO}_{4}$ & Caledon, $>85 \%$ \\
\hline Nitrogen gas, $\mathrm{N}_{2}$ & Praxair, Ultra high purity (UHP) \\
\hline
\end{tabular}

\subsubsection{UV 254}

UV254 is a measure of ultraviolet absorbance at wavelengths of $254 \mathrm{~nm}$, and can be used to approximate the concentration of organic materials in a water sample (Kitis et al., 2002). Samples were placed in $1 \mathrm{~cm}$ quartz cell (Hewlett Packard, Mississagua) and measured using a CE 3055 Single Beam Cecil UV/Visible Spectrophotometer (Cambridge, England). The device was zeroed with Milli-Q ${ }^{\circledR}$ water. The cells were rinsed with Milli-Q ${ }^{\circledR}$ water twice between sampling and rinsed again with the sample water before analysis to minimize contamination. 


\section{Optimization of Air Sparging and In-line Coagulation for Ultrafiltration Fouling Control}

\subsection{Introduction}

Ultrafiltration (UF) is being increasingly employed in water treatment because of its ability to reduce the footprint of a facility and effectively remove contaminants of interest such as organic material and pathogenic microorganisms (Gao et al., 2011). While capital costs of UF and conventional treatment are comparable, UF operation and maintenance costs per $1000 \mathrm{~m}^{3}$ of water produced have been reported to be three times that of conventional treatment (Chew et al., 2016). Higher operation and maintenance costs are largely associated with strategies to minimize the impact of fouling on production, which include coagulation, hydraulic cleaning, chemical cleaning, and membrane replacement (Chew et al., 2016; Li et al., 2014; Wray et al., 2014).

Chemical and physical cleaning (backwashing and air sparging) are commonly applied to mitigate fouling. Chemical cleaning reduces hydraulically irreversible fouling through daily to weekly application of an alkali solution such as sodium hypochlorite which removes persistent organics. Periodic application of an acidic solution such as citric acid is also sometimes used to remove inorganic deposits (Gao et al., 2011). Repeated and frequent cleaning reduces the lifespan of UF membranes as the chemicals can alter membrane properties (Abdullah and Bérubé, 2013). Fouling control strategies that reduce the reliance and application of chemical cleans are expected to increase membrane service life and lead to substantial cost savings ( $\mathrm{Li}$ et al., 2014). Backwashing (reversal of flow) loosens the fouling cake layer from the membrane (Remize et al., 2010). The production of permeate is halted during backwashing and permeate is consumed, reducing the net yield of treated water. Because frequent backwashing is required, the water loss for UF (11-13\%) is typically double that reported for conventional treatment (6.6\%) (Chew et al., 2016). Extending the duration between backwashes would not only lead to higher production but also contribute to reduced costs ( $\mathrm{Li}$ et al., 2014).

Unlike wastewater treatment where air sparging is continuously applied, it is typically only used during backwashing in drinking water treatment. As a result, costs associated with sparging are considered to be negligible and limited attention has focused on optimizing air sparging for drinking water treatment. Recent bench-scale studies suggest that the benefits of air sparging 
during permeation outweigh the associated increased energy costs and lead to significant cost savings (Abdullah et al., 2015; Li et al., 2014). Air sparging removes loose deposits and transports foulants away from the surface, thereby reducing the effect of concentration polarization and redeposition (Braak et al., 2011; Cabassud et al., 2001).

Previous studies conducted at bench-scale have compared conditions with no sparging to those with continuous sparging (sparging throughout permeation and backwash) (Li et al., 2014; Wray et al., 2013). However, most UF systems in drinking water applications only sparge during backwash. As such, continuous sparging has not been compared to the baseline condition (sparging only during backwash) that is prevalent in drinking water treatment plants.

In addition to chemical and hydraulic cleaning methods, pretreatment strategies such as coagulation can be applied to minimize fouling (Gao et al., 2011). Numerous bench-scale studies have demonstrated that pre-coating membranes with coagulant or diatomite prior to permeation reduces fouling when compared to direct permeation (Galjaard et al., 2003, 2001; Park et al., 2002; Salinas-Rodriguez et al., 2016; Tabatabai et al., 2010). A recent bench-scale study suggested that applying coagulant for the first half of each permeation cycle could maintain the original permeation production rate and reduce the use of coagulant (Pronk et al., 2016). Furthermore, decreased use of coagulant when applied only during part of a permeation cycle would reduce costs associated with sludge disposal (Dassanayake et al., 2015). However, the application of a coagulant in phases within a permeation cycle has not been examined at pilot-scale. As such, the scalability of this method and the impact of the duration over which coagulation is applied needs to be investigated.

The main objectives of the present research were to:

- Assess the potential to increase the duration of a permeation cycle by providing air sparging during both permeation and backwashing when compared to sparging only during backwash

- Determine the effect of phased coagulation on the fouling rate

- Determine whether the removal of organic material would be influenced by changes in sparging and coagulation conditions as described in the two objectives above 


\subsection{Materials and Methods}

Filtration tests were conducted at the Barrie Surface Water Treatment Plant (Barrie, Ontario, Canada). The full-scale plant treats Lake Simcoe water using coagulation, ultrafiltration (submerged hollow fiber UF membranes, ZW1000, GE Water \& Process Technologies, Oakville, Ontario), followed by filtration through biological granular activated carbon. Pilot-scale filtration tests were conducted using a full ZeeWeed® 1000 membrane module as previously described (Wray et al., 2016). The pilot was fully automated to mimic full-scale treatment including in-line coagulation using $4 \mathrm{mg} / \mathrm{L}$ polyaluminium chloride (PACl) (PAX-XL1900, Kemira Water Solutions Canada, Inc.), backwashing, and air sparging. Transmembrane pressure, feed and permeate turbidity, temperature, $\mathrm{pH}$ and particle counts were monitored every 5 minutes throughout 48-hour filtration tests. The average flux, temperature, and $\mathrm{pH}$ during testing ranged between $37-49 \mathrm{Lm}^{-1} \mathrm{~h}^{-1}, 8-17^{\circ} \mathrm{C}$, and 7.3-8.4, respectively (representative of full-scale operation). At the end of each filtration test, the membrane module was chemically cleaned as recommended by the manufacturer (soaked with $500 \mathrm{mg} / \mathrm{L} \mathrm{NaOCl}$ and then in $200 \mathrm{mg} / \mathrm{L}$ citric acid for 6 hours each). If the transmembrane pressure reached $40 \mathrm{kPa}$ prior to 48 hours, the filtration test was terminated and a chemical clean was initiated.

Permeation duration was extended from 30 minutes (full-scale operation) to 2 hours in order to accentuate fouling during the permeation cycle for the pilot-scale tests. As performed at full-scale, following each backwash, the pilot-scale membrane tank was drained. At full-scale, the membranes are sparged only during backwash using coarse air bubbles at $60 \mathrm{~L} / \mathrm{min}$. For the pilotscale filtration tests, the air sparging (sparging duration and flow rate) and coagulation conditions were varied as presented in (Table 3-1). Fouling was quantified using a resistance-in-series approach (Busch et al., 2007; Cho et al., 2004), normalized to the intrinsic resistance of the membrane at the start of each filtration test and a temperature of $20^{\circ} \mathrm{C}$ (Zheng et al., 2010). Twotailed t-tests were used to evaluate the impact of varying operating conditions on the rate of increase in membrane resistance. All analyses were evaluated at a 95\% significance level.

Feed and permeate samples were collected at 0,24, 48 hours of each filtration test. Samples were subsequently filtered using a $0.45 \mu \mathrm{m}$ filter (Gelman Supor, Gelman Sciences, Ann Arbor, MI) prior to dissolved organic carbon (DOC) analyses. Samples for total organic carbon (TOC) analysis were unfiltered. Particulate organic carbon (POC) was calculated by subtracting DOC 
from TOC. Organic carbon was measured using a wet oxidation method based on Standard Method 5310 D (APHA, 2012). The analysis was conducted using an O-I Corporation Model 1010 TOC Analyzer with a Model 1051 Vial Multi-Sampler (College Station, Texas). Ultraviolet absorbance at $254 \mathrm{~nm}$ (UV254) was measured for filtered samples using a CE 3055 Single Beam Cecil UV/Visible Spectrophotometer (Cambridge, England) equipped with $1 \mathrm{~cm}$ quartz cells (Hewlett Packard, Mississauga).

\subsection{Results and Discussion}

\subsubsection{Continuous sparging}

Typical of many drinking water treatment plants, the Barrie Surface WTP applies air sparging only during backwash. Continuous sparging (throughout permeation and backwashing) was compared to this base condition (sparging during only backwash) to evaluate whether increased sparging could be used to extend the permeation cycle.

The resistance associated with the base condition during typical successive permeation cycles is presented in Figure 4-1. Total fouling was quantified by the resistance at the end of each permeation cycle; irreversible fouling was quantified by the resistance at the beginning of each permeation cycle. Reversible fouling was quantified as the difference between total and irreversible resistance. The raw resistance graphs for each filtration test conducted in this study are shown in Appendix Section 8.1.

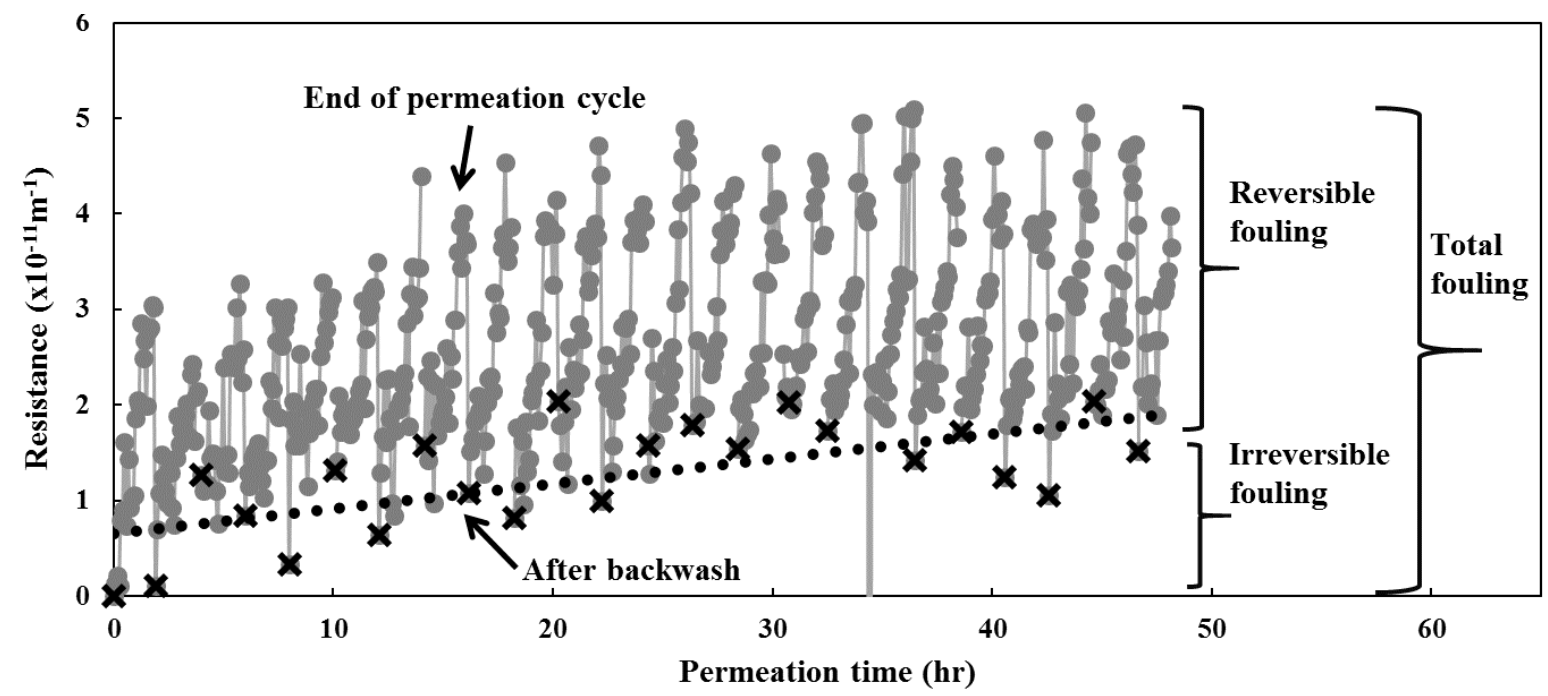

Figure 4-1: Typical resistance increase as a function of permeation time (results presented for the base condition) 
The increase in irreversible resistance was significantly greater $(\mathrm{P}<0.05)($ Table 4-1) for continuous sparging $\left(0.136 \times 10^{-11} \mathrm{~m}^{-1} \mathrm{~h}^{-1}\right)$ when compared to the base condition $\left(0.029 \times 10^{-11} \mathrm{~m}^{-1} \mathrm{~h}^{-}\right.$ ${ }^{1}$ ) (Figure 4-2a). This suggests that sparging during permeation altered the fouling layer promoting greater irreversible fouling (Ye et al., 2011).

Table 4-1: Statistical comparison of irreversible resistance between the base condition (4 mg/L continuous coagulation and sparging only during backwash) and various operating conditions. Bold values indicate statistically significant difference at $95 \%$ significance level $(\mathrm{P}<0.05)$

\begin{tabular}{|c|l|c|}
\hline Parameters examined & \multicolumn{1}{|c|}{ Deviation from base condition } & p-value \\
\hline \multirow{5}{*}{ Sparging duration } & Continuous sparging & $\mathbf{1 . 1 E - 1 1}$ \\
& Phased 60 min sparging & 0.14 \\
& Phased 110 min sparging & $\mathbf{0 . 0 2}$ \\
& No sparging & $\mathbf{1 . 2 E - 1 5}$ \\
& Continuous sparging, no coag. & $\mathbf{3 . 5 E}-\mathbf{0 3}$ \\
\hline \multirow{3}{*}{ Lower intensity } & Continuous sparging $5 \mathrm{~L} / \mathrm{min}$ & $\mathbf{1 . 5 E}-20$ \\
sparging & Continuous sparging $20 \mathrm{~L} / \mathrm{min}$ & $\mathbf{3 . 6 E}-16$ \\
& Intermittent sparging $5 \mathrm{~L} / \mathrm{min}$ & $\mathbf{1 . 7 E - 1 0}$ \\
& Intermittent sparging $20 \mathrm{~L} / \mathrm{min}$ & $\mathbf{1 . 9 E - 0 7}$ \\
\hline
\end{tabular}

Although numerous studies have examined the effect of increasing the air flow rate on fouling control (Akhondi et al., 2014; Ye et al., 2014, 2011, 2010), few have investigated the effect of increased sparging time during a permeation cycle for drinking water applications. However, analogous to sparging at high air flow rates, sparging during permeation may remove the protective cake layer and promote irreversible fouling (Wu et al., 2008; Ye et al., 2011). In a bench-scale study conducted by Ye et al. (2010) (Ye et al., 2010), the total fouling rate was reported to decrease with the air sparging flow rate. However, it increased at greater air flow rates. In another study, Ye et al. (2011) (Ye et al., 2011) observed that the cake layer thickness decreased with increasing air flow rates. The increase in fouling at high air flow rates was attributed to the removal of a cake layer, which acts as a protective fouling layer limiting the transport of foulants into the membrane pores causing irreversible fouling. Air sparging may also promote the rearrangement of foulants (Sur and Cui, 2001; Tabatabai et al., 2010) into a homogenous, dense, and resistant cake layer (Tabatabai et al., 2010; Wang and Waite, 2008; Ye et al., 2011). A schematic of the proposed fouling layer for the base condition and continuous sparging is shown in Figure 4-3. 
i)
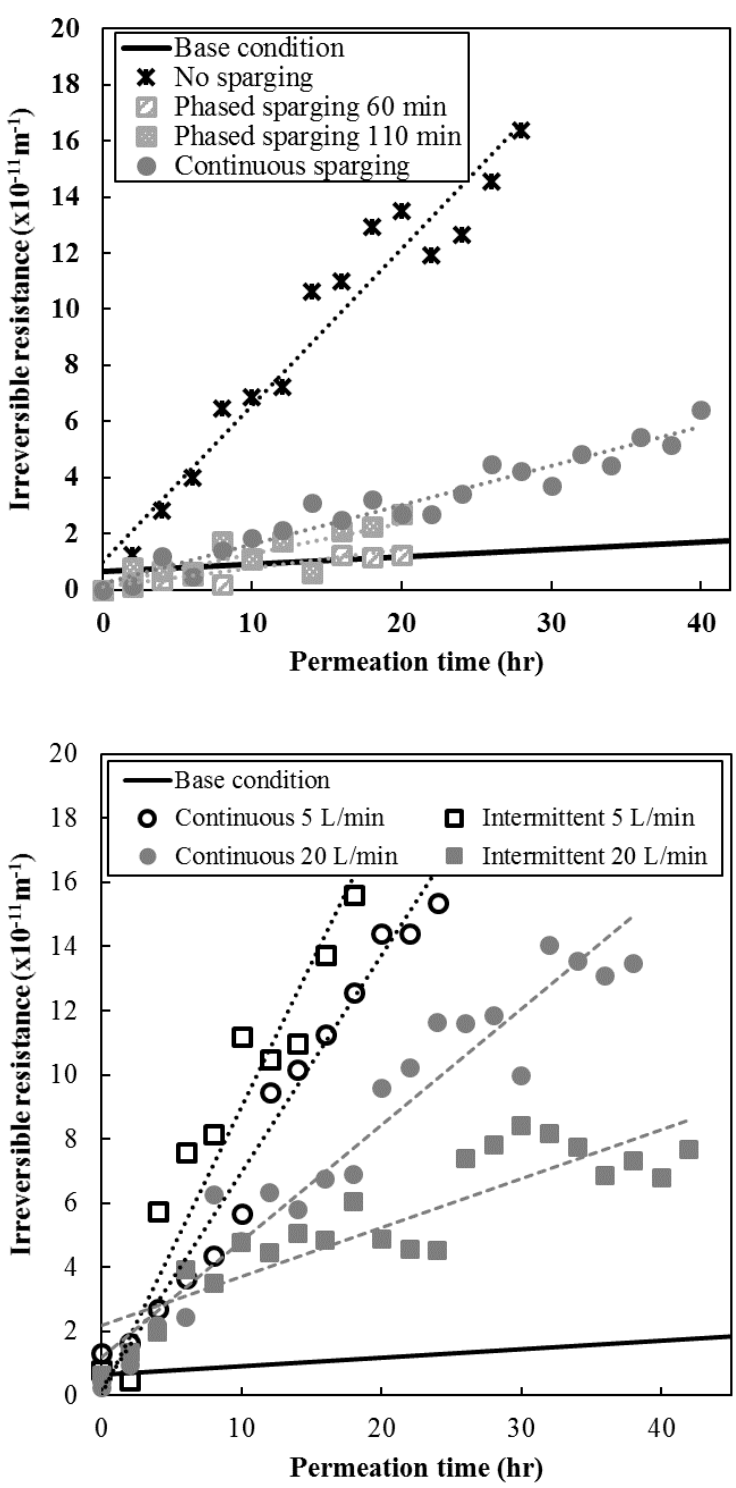

c)

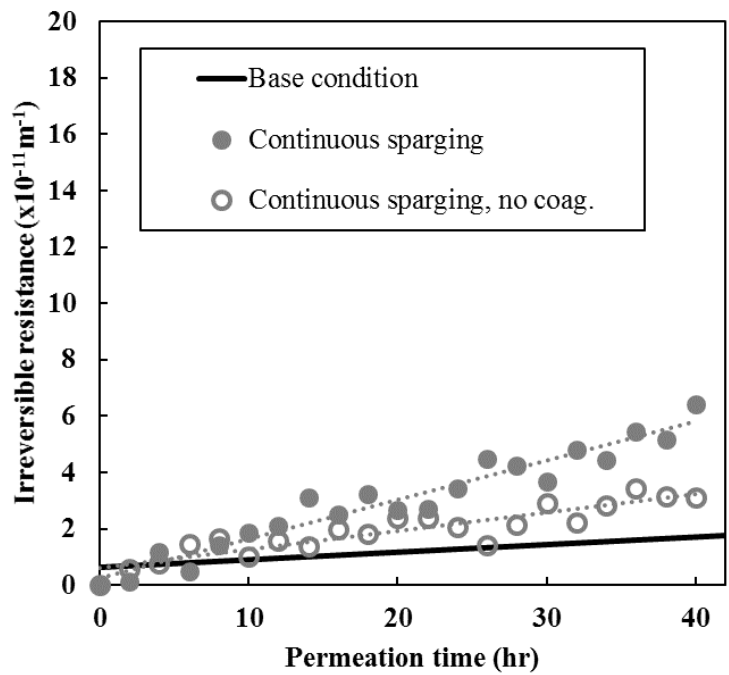

ii)

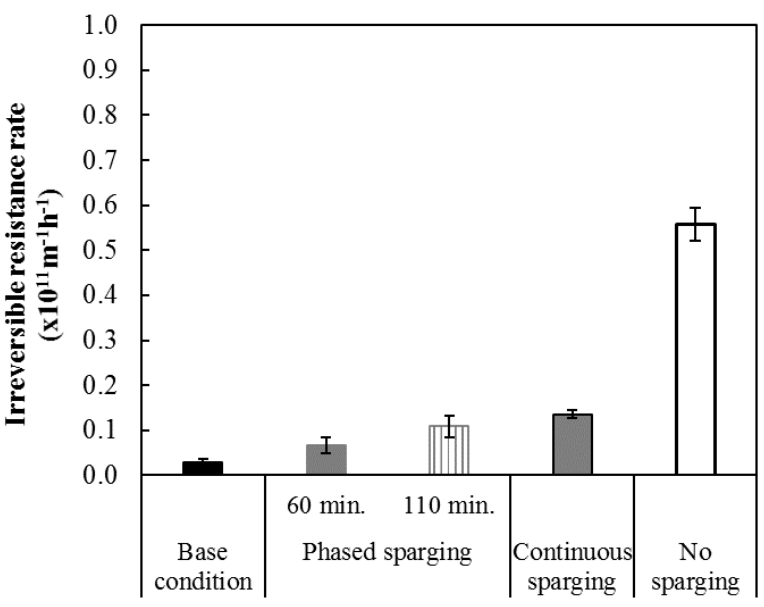

Experimental conditions

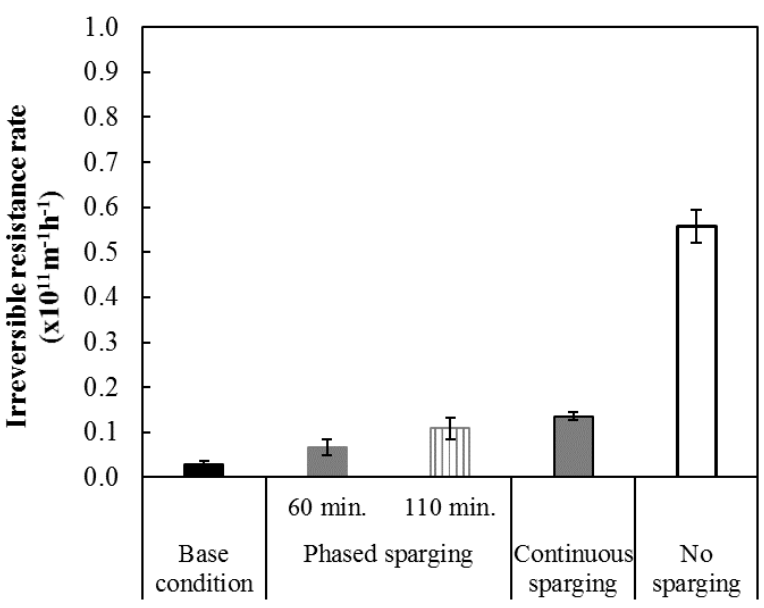

Experimental conditions

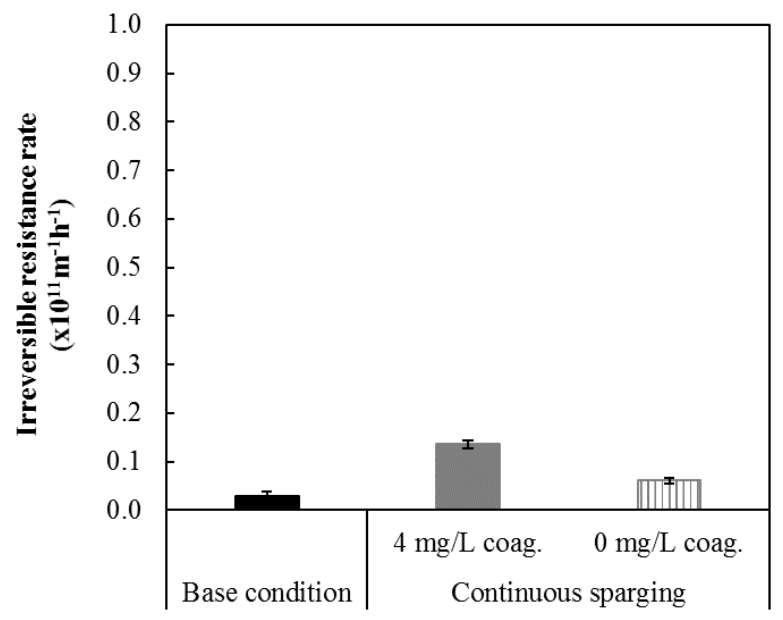

Experimental conditions

Figure 4-2: (i) Irreversible resistance vs. time and, (ii) irreversible resistance rates for (a) varying sparging duration, (b) reduced sparging intensity (c) varying sparging duration and coagulant dose. Vertical bars correspond to the $95 \%$ confidence interval associated with the estimated slope. 


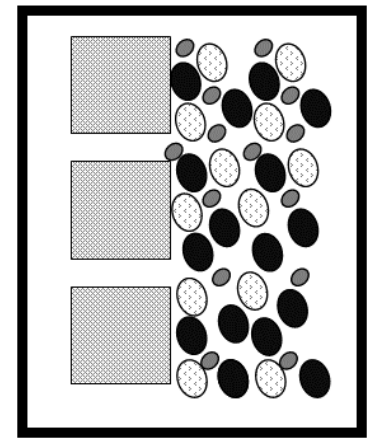

Base condition

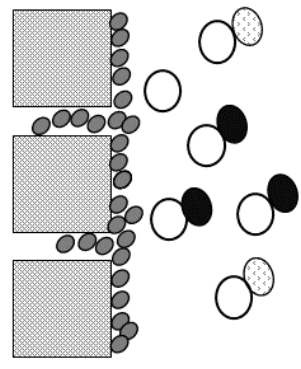

Continuous sparging

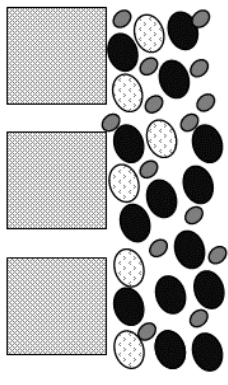

Phased coagulation $60 \mathrm{~min}$

(Sparging only during backwash, continuous coagulation)

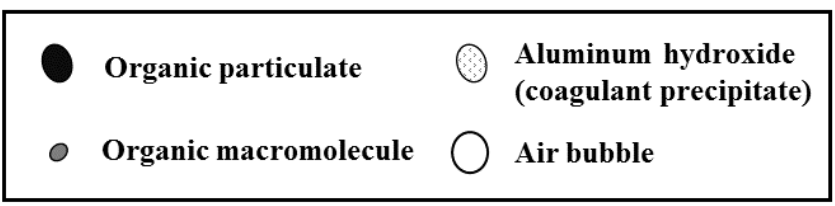

Figure 4-3: Proposed schematic of the fouling layer for various conditions during permeation

No sparging during both permeation and backwash were compared to the base condition. The rate of increase in the irreversible resistance was greatest for the condition with no sparging, demonstrating the importance of sparging during backwash for fouling control. As an alternative to continuous sparging during permeation, sparging only during the latter part of a permeation cycle (i.e. phased sparging), to allow for the establishment of a protective foulant layer during the initial part of a permeation cycle was considered. Irreversible resistance increased more rapidly when sparging for the latter $60 \mathrm{~min}$. of 120-minute permeation cycles $\left(0.066 \times 10^{-11} \mathrm{~m}^{-1} \mathrm{~h}^{-1}\right)$ when compared to the base condition (Figure 4-2a). However, the difference was not statistically significant (Table 4-2). Irreversible resistance when sparging for the latter 110 minutes of a 120minute permeation cycle $\left(0.108 \times 10^{-11} \mathrm{~m}^{-1} \mathrm{~h}^{-1}\right)$ was significantly $(\mathrm{P}<0.05)$ greater than when sparging only during backwash. These results indicate that the amount of fouling increases slightly with the duration of sparging during permeation (Figure 4-2a). Sparging with reduced intensity and intermittently applied during permeation were also examined. Continuous and intermittent sparging (sparging for 10 seconds followed by 10 seconds of rest) at $5 \mathrm{~L} / \mathrm{min}$ resulted in rates of increase in irreversible resistance that were at least 20 times greater than the base condition (Figure 4-2b). Continuous and intermittent sparging at $20 \mathrm{~L} / \mathrm{min}$ resulted in rates of increase in irreversible resistance that were respectively, 12 and 5 times higher than the base condition. Evidently, sparging at lower flow rates $(5,20 \mathrm{~L} / \mathrm{min})$ and intermittently did not improve fouling mitigation 
when compared to the base case. Pulse bubble sparging conducted at 5 and $20 \mathrm{~L} / \mathrm{min}$ are shown in the Appendix (Figure 8-13).

Air sparging at high flow rates has been reported to lead to floc breakup and the formation of small flocs with high fractal dimension (Liu et al., 2014), which increases fouling by promoting pore adsorption and narrowing as well as forming a dense foulant layer (Barbot et al., 2008; Citulski et al., 2008; Liu et al., 2014). To assess if the difference observed in Figure 4-2a was due to floc break-up, continuous sparging with coagulation was compared to continuous sparging without coagulation. Continuous sparging with no coagulation resulted in a lower increase in irreversible resistance (Figure 4-2c) when compared to continuous sparging with coagulation, but still had significantly a $(\mathrm{P}<0.05)$ higher $($ Table $4-1)$ increase in irreversible resistance when compared to the base condition.

Results from a series of experiments (shown in Figure 4-2) suggest that the benefits of air sparging are most prominent when combined with backwashing. Not only is air sparging during permeation more energy-intensive and costly, but continuous sparging also increases fouling relative to sparging only during backwash.

\subsubsection{Phased Coagulation}

Typically, coagulant is applied continuously during permeation. As an alternative to continuous coagulation, coagulant was applied for a fraction (initial $10 \mathrm{~min}$ or $60 \mathrm{~min}$ ) of each 120-min permeation cycle to establish a pre-coat layer; coagulant addition was then ceased for the remainder of the permeation cycle. Increases of irreversible resistance for these phased coagulation filtration tests were compared to the base condition (continuous coagulation).

The increase in irreversible resistance for phased $60 \mathrm{~min}$. coagulation was similar to the base condition (Figure 4-4). Under both conditions, irreversible resistance increased rapidly for the first 15 hours of permeation and reached a steady-state. However, the irreversible resistance for phased 10 min. coagulation continued to increase after the first 15 hours. Results suggest that aluminum hydroxide precipitates may have aided the establishment of a steady, persistent protective fouling layer (Salinas-Rodriguez et al., 2016) after 60 minutes of coagulation within a cycle. Following 60 minutes, further coagulation is not necessary and may increase the cake resistance by adding a more compressive and less porous layer (Lee et al., 2000) as presented in Figure 4-3. Similarly, 
Pronk et al. (2016) reported that dosing ferric chloride coagulant for the initial $50 \%$ of a permeation cycle stabilized irreversible fouling rates after 5 cycles (Pronk et al., 2016).

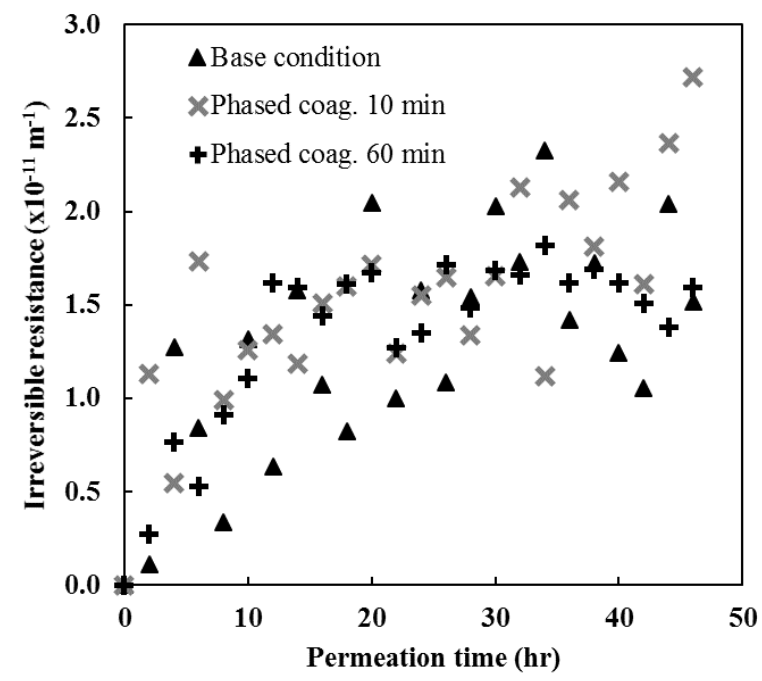

Figure 4-4: Irreversible resistance for the base condition and phased coagulation.

Coagulating for 60 minutes of each 120-minute cycle does not increase resistance when compared to the base case, and could potentially save approximately $\$ 10,000$ in annual coagulant costs for a full-scale 16 MLD facility such as the one considered in this study.

\subsubsection{Removal of Particulate and Dissolved Organics}

While the feed turbidity between filtration tests varied to a small degree (0.21-0.42 NTU), average permeate turbidities remained consistent (0.01-0.02 NTU) (Appendix Table 8-3). Similarly, particle counts in the feed varied from $210-1100$ counts $/ \mathrm{mL}$ for $2-5 \mu \mathrm{m}$ and $13-160$ counts $/ \mathrm{mL}$ for 5-10 $\mu \mathrm{m}$; the permeate consistently contained $100-190$ counts $/ \mathrm{mL}$ and $\leq 1$ counts $/ \mathrm{mL}$ of $2-5 \mu \mathrm{m}$ and 5-10 $\mu \mathrm{m}$ particles, respectively. The POC in all measured permeate samples was not statistically different (95\% confidence) among filtration tests. DOC removal ranged from 0.3-0.6 $\mathrm{mg} / \mathrm{L}$ and SUVA was reduced by 0.02-0.07 L/mg/m (Appendix Table 8-2). Thus, the changes in sparging duration and coagulant application had no significant impact on particulate or dissolved organic removal. 


\subsection{Conclusions}

Sparging during both backwash and permeation for various durations $(60,110$, and 120 minutes of the permeation cycle), intermittently (sparging for 10 seconds followed by 10 seconds of rest), and at reduced air flow rates $(5,20 \mathrm{~L} / \mathrm{min})$ did not improve fouling control when compared to a base condition of sparging at $60 \mathrm{~L} / \mathrm{min}$ only during backwash. Increased irreversible resistance rates associated with the application of air sparging during permeation is likely due to the removal of a protective fouling layer and the promotion of pore blocking.

Provision of coagulant for the first half of each permeation cycle did not increase irreversible resistance when compared to the base condition. This was attributed to the formation of a persistent, protective fouling layer that minimizes pore blocking during the first half the permeation cycle. Phased coagulation may be a promising, long-term fouling mitigation strategy that requires minimal process modifications to implement and reduces coagulant and sludge removal costs.

Changes in sparging and coagulant conditions had no impact on particulate and dissolved organics removal when compared to the base condition. 


\section{The Effect of Concentration Factor on Membrane Fouling}

\subsection{Introduction}

Hollow fiber ultrafiltration (UF) systems are increasingly being employed in drinking water treatment applications because of their ability to produce high quality water and reduce the footprint of a facility (Gao et al., 2011). The main drawback of UF is membrane fouling, which reduces productivity and increases operational costs of the systems (Gao et al., 2011). A number of studies have investigated pretreatment methods and operational conditions to reduce membrane fouling. Much of this work has been based on the use of bench-scale systems that incorporate single membrane fibers (Chan et al., 2007; Katsoufidou et al., 2007; Li et al., 2014; Wray et al., 2014) and as such have substantially different loading characteristics when compared to full-scale systems; in particular, the specific membrane surface area or packing density within a given system volume. As a result, most bench-scale studies may have been performed at concentration factors (CF) that are much lower than those typical of full-scale systems. Considering that fouling is impacted by the concentration of the constituents in the solution being filtered, it is possible that the outcomes of bench-scale studies are not representative of those at full-scale, especially considering that the $\mathrm{CF}$ in most bench-scale studies is approximately 1 . However, when operating in deposition mode (no turbulence induced onto the membrane by cross-flow or air sparging during permeation), the $\mathrm{CF}$ in full-scale systems are theoretically not expected to change during a filtration cycle (Membrane Filtration Guidance Manual, 2005). Unfortunately, limited information exists on the impact of CF on the outcomes of bench-scale studies. The objective of the present study was to assess the impact of concentration factor on fouling (i.e. change in membrane resistance over time) at bench-scale, and compare to full-scale systems operated in deposition mode.

\subsection{Materials and Methods}

UF feed and reject water (obtained at the end of a permeation cycle following air sparging and backwashing) were collected from two full-scale water treatment plants (WTPs) during a single sampling event and used as influent to a bench-scale system (Chan et al., 2007; Li et al., 2014) (Figure 3-1). The reject water corresponds to the maximum bulk CF that would be expected in the full-scale system. The reject water for membranes operated at $95 \%$ recovery is expected to 
have a CF of 20. Because the systems are operated in deposition mode, the theoretical concentration of foulants in the bulk liquid is expected to be equivalent to that in the feed (Membrane Filtration Guidance Manual, 2005). However, the actual concentration of foulants at the membrane surface is expected to be greater than in the feed. The membrane resistance when filtering UF feed water and reject water at bench-scale over a period of 24 hours were compared. Results obtained at bench-scale were also directly compared to full-scale systems (at the time when the feed and reject water were collected).

The Lakeview WTP (Mississauga, ON, Canada) treats Lake Ontario (2 mg/L DOC) water using ozonation, biofiltration, ultrafiltration, UV, and chlorination. The Barrie Surface WTP (Barrie, ON, Canada) treats Lake Simcoe water using coagulation, ultrafiltration, granular activated carbon, and chlorination. Both plants operate their membranes in deposition mode with 95\% recovery and use ZeeWeed®1000 (GE Water \& Process Technologies, Oakville, Ontario), which are outside-in, polyvinylidene difluoride (PVDF) hollow fiber UF membranes. A chemical recovery clean was performed on the full-scale system prior to data collection.

The single-fiber bench-scale system used in this study was similar to that previously described (Chan et al., 2011; Li et al., 2014). The system was specifically designed to mimic the hydrodynamic conditions and filtration/backwash cycles present at full-scale systems. The permeation and backwash cycles were 30 and 3 minutes, respectively. Air sparging, used to induce turbulence onto the membranes, was only applied during backwash (permeation in deposition mode). A $25-\mathrm{cm}$ length of virgin outside-in, hollow fiber UF membrane (ZeeWeed®500, GE Water and Process Technologies, Oakville, Ontario) (approximately $1250 \mathrm{~mm}^{2}$ of permeable area) was used for each filtration test. Fibers were first soaked in $750 \mathrm{mg} / \mathrm{L}$ sodium hypochlorite solution for $24 \mathrm{~h}$ to remove residual shipping preservative and then stored in a $50 \mathrm{mg} / \mathrm{L}$ sodium hypochlorite solution until use. Immediately prior to the experiments, fibers were cleaned by filtering $750 \mathrm{mg} / \mathrm{L}$ sodium hypochlorite solution twice for 1 hour each followed by Milli-Q water for 2 hours, during which the clean water resistance of the virgin, loose membrane was quantified. The loose membrane was then mounted onto a stainless steel holder which was recessed into the wall of the membrane tank and secured using silicone. Milli-Q water was then filtered through the fiber for an additional 2 hours. The change in resistance between the loose and mounted fibers was used to estimate the actual permeable membrane area. The permeate flow was monitored using a scale 
(Cole Parmer Symmetry Topbalance, Montreal, Quebec) and adjusted to $501 / \mathrm{m}^{2} \cdot \mathrm{hr}$ (i.e. identical to the flux at full-scale).

Feed and permeate samples were collected every 8 hours during the 24 -hour filtration tests and analyzed for total organic carbon (TOC) using a O-I Corporation Model 1010 TOC Analyzer with a Model 1051 Vial Multi-Sampler (College Station, Texas), based on Standard Method 5310D (APHA, 2012). Samples for dissolved organic carbon (DOC) were filtered using a $0.45 \mu \mathrm{m}$ filter (Gelman Supor, Gelman Sciences, Ann Arbor, MI) prior to analysis. Particulate organic carbon (POC) was calculated by subtracting DOC from TOC.

\subsection{Results and Discussion}

The DOC concentration in the UF reject water collected from the Barrie Surface WTP was twice that of the feed water (Table 5-1). However, the POC concentration in the UF reject water was 7.5 times greater. The DOC and POC concentrations in the UF reject water at the Lakeview WTP increased by a factor of 2.6 and 2.7 , respectively. The POC concentration in the reject water for both systems was not 20 times greater than in the feed, as would be anticipated based on a $95 \%$ recovery rate.

Table 5-1: DOC and POC concentration in feed and reject water collected from Barrie and Lakeview WTP

\begin{tabular}{|c|c|c|c|c|c|c|}
\hline \multirow{2}{*}{$\begin{array}{c}\text { Sampling } \\
\text { location }\end{array}$} & \multicolumn{3}{|c|}{ DOC (mg/L) } & \multicolumn{3}{c|}{ POC (mg/L) } \\
\cline { 2 - 7 } & Feed & Reject & CF & Feed & Reject & CF \\
\hline Barrie WTP & $3.6 \pm 0.1$ & $7.5 \pm 0.1$ & 2.1 & $0.40 \pm 0.06$ & $3.0 \pm 0.07$ & 7.5 \\
\hline Lakeview WTP & $1.9 \pm 0.1$ & $5.0 \pm 0.1$ & 2.6 & $0.14 \pm 0.08$ & $0.38 \pm 0.06$ & 2.7 \\
\hline
\end{tabular}

Bench-scale filtration results indicated that the resistance observed with reject water was greater than when using feed water for both Barrie Surface and Lakeview WTP (Figure 5-2). However, the difference between the results were more pronounced for the Barrie Surface WTP. The greater difference between the resistance observed between feed and reject water for the Barrie Surface WTP could be attributed to the higher concentration of organic material. As illustrated in Figure 5-3, a positive relationship was observed between the concentration of organic matter in the solution being filtered and the resistance. As such, the results suggest that the concentration of 
the solution being filtered largely determines the membrane resistance, which is consistent with previous studies (Tian et al., 2015; Zularisam et al., 2006).
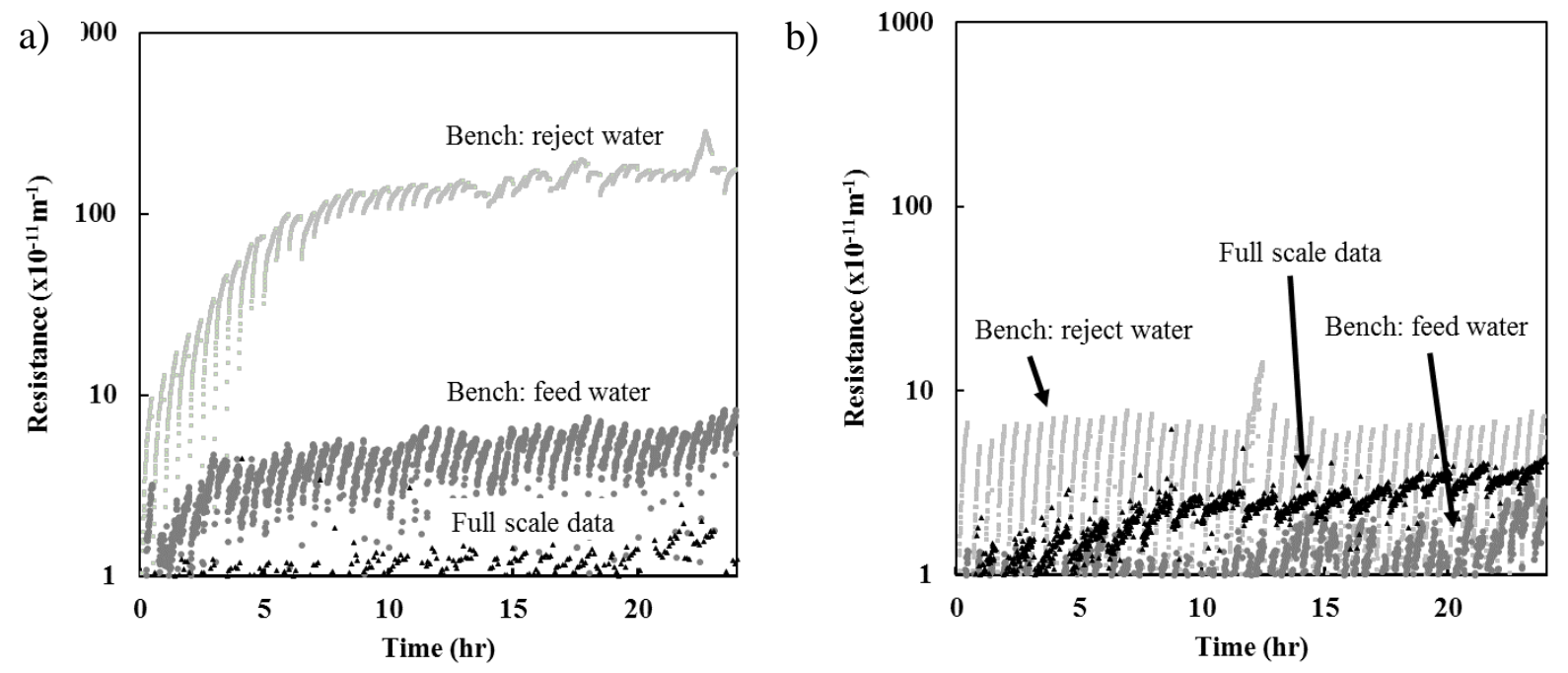

Figure 5-1: Results from filtration tests (a) Barrie Surface WTP, and (b) Lakeview WTP. Fullscale resistance data are plotted for comparison.

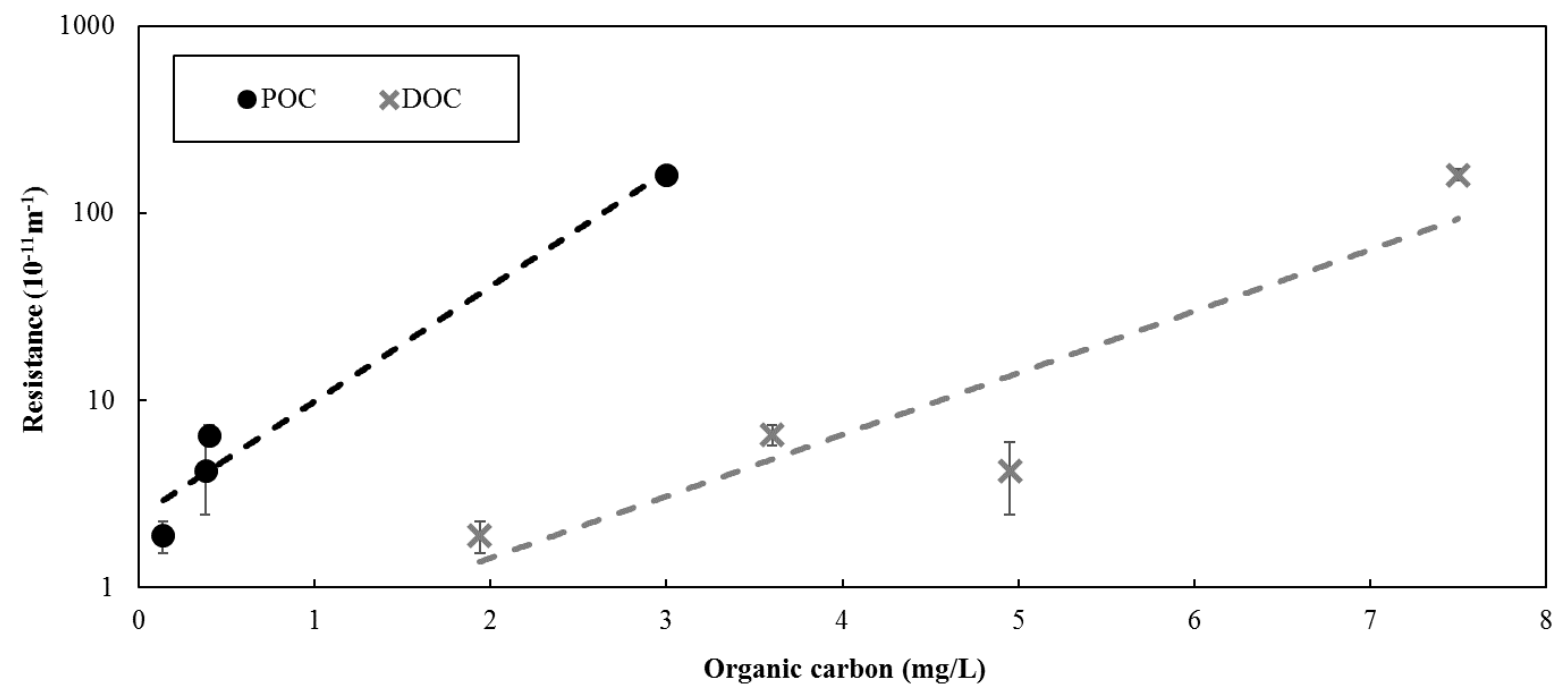

Figure 5-2: Resistance (averaged over the entire last permeation cycle) for each of the bench-scale filtration tests vs. organic carbon concentration (POC, DOC) in the solution filtered. The error bars represent the standard error associated with the resistance of the last permeation cycle. Exponential relationship was fitted to the data presented to illustrate the overall trend.

While the organic carbon was not measured at full-scale for the data presented, the POC and DOC at full-scale range between 0.2-0.4 mg/L and 3.8-4.2 mg/L, respectively, at Barrie Surface WTP and 0.1-0.2 mg/L and 1.8-2.2 mg/L, respectively, at Lakeview WTP. Based on the relationships shown in Figure 5-3, the full-scale resistance is expected to range between 3.2-5.7 x 
$10^{-11} \mathrm{~m}^{-1}$ for Barrie Surface WTP, which is slightly above the actual full-scale resistance presented in Figure 5-2. The expected full-scale resistance for Lakeview WTP ranges from 1.2-3.2 x 10-11 $\mathrm{m}^{-}$ ${ }^{1}$, which is consistent with actual full-scale resistance (Figure 5-2).

Results for both Barrie and Lakeview WTP suggest that bench-scale studies using fullscale feed water $(\mathrm{CF}=1)$ is more representative of the actual resistance obtained at full-scale when compared to using full-scale reject water (CF>1) (Figure 5-1).

When filtering feed water, the permeate quality in terms of DOC, and POC was similar at bench and full-scale (based on 95\% confidence interval) (Table 5-2) . However, when filtering reject water at bench-scale, the permeate DOC was significantly greater than observed at full-scale. Similar to the resistance data, results for both plants suggest that bench-scale studies using fullscale feed water $(\mathrm{CF}=1)$ is more representative in terms of rejection of organic matter when compared to using full-scale reject water $(\mathrm{CF}>1)$

Table 5-2: Permeate DOC and POC concentrations at full and bench-scale

\begin{tabular}{|c|c|c|c|c|c|}
\hline \multirow{2}{*}{ Permeate sample } & \multicolumn{2}{c|}{ Barrie WTP } & \multicolumn{2}{c|}{ Lakeview WTP } \\
\cline { 2 - 6 } & DOC & POC & DOC & POC \\
\hline \multicolumn{2}{|c|}{ Full-scale } & $3.6 \pm 0.1$ & $0.11 \pm 0.06$ & $1.8 \pm 0.1$ & $0.05 \pm 0.06$ \\
\hline \multirow{2}{*}{ Bench-scale } & Feed water & $3.6 \pm 0.1$ & $0.10 \pm 0.08$ & $1.9 \pm 0.1$ & $0.07 \pm 0.05$ \\
\cline { 2 - 6 } & Reject water & $4.1 \pm 0.1$ & $0.10 \pm 0.07$ & $2.2 \pm 0.1$ & $0.05 \pm 0.06$ \\
\hline
\end{tabular}

\subsection{Conclusions}

The expected elevated concentration at the membrane surface in densely packed or full-scale systems does not appear to largely influence resistance in UF systems operated in deposition mode. The results of the present study confirm the validity of using full-scale feed water $(\mathrm{CF}=1)$ in benchscale studies to evaluate membrane fouling. 


\section{Summary, Conclusions, and Recommendations}

\subsection{Summary}

The potential to increase the duration of a permeation cycle by providing air sparging during both permeation and backwashing when compared to sparging only during backwash was assessed at pilot-scale. In addition, the effect of phased in-line coagulation on the fouling rate was investigated. The removal of organic material were compared between various sparging and coagulation conditions.

The applicability of bench-scale systems using the same feed water as full-scale was examined. The present study compared membrane resistance when considering raw water $(\mathrm{CF}=1)$ and reject water $(\mathrm{CF}>1)$ as feed in UF systems operated in deposition mode.

\subsection{Conclusions}

Sparging at $60 \mathrm{~L} / \mathrm{min}$ applied only during backwash resulted in a rate of increase in irreversible resistance of $0.029 \times 10^{-11} \mathrm{~m}^{-1} \mathrm{~h}^{-1}$. Unexpectedly, sparging during permeation resulted in a significantly $(\mathrm{P}<0.05)$ higher rate of increase in irreversible resistance (i.e. 0.066, 0.108, and $\left.0.136 \times 10^{-11} \mathrm{~m}^{-1} \mathrm{~h}^{-1}\right)$. Lower irreversible fouling observed without sparging during permeation was attributed to the formation of a protective layer on the membrane. Sparging at reduced air flow rates $(5,20 \mathrm{~L} / \mathrm{min})$, and intermittently (10 seconds on followed by 10 seconds of rest), during the permeation cycle did not improve the irreversible resistance rate when compared to sparging only during backwash at $60 \mathrm{~L} / \mathrm{min}$. Coagulating for only the first half of the permeation cycle (phased coagulation) did not negatively impact membrane performance in terms of irreversible resistance and organics removal. Phased coagulation, which would lead to reduced coagulant and sludge disposal costs, appears to be a promising fouling control strategy.

Single-fiber, bench-scale experiments showed a positive relationship between the concentration of the organic matter in the solution being filtered and resistance. Bench-scale trials conducted with $\mathrm{CF}=1$ water were more representative of full-scale operation than trials conducted with elevated CFs when considering membrane resistance and permeate quality. As such, the results of this study indicate that the use of the same feed water as used at full-scale $(\mathrm{CF}=1)$ is appropriate to evaluate fouling in UF systems operated in deposition mode. 


\subsection{Recommendations}

Based on the present study, further research is warranted in the following areas:

- In this work, air sparging duration and flow rate were considered. However, the bubble type was not extensively investigated. Previous research have suggested that pulse bubble sparging is more effective at fouling control when compared to coarse bubble sparging. Pulse bubble sparging only during backwash should be compared coarse bubble sparging only during backwash in terms of membrane fouling control.

- The present study demonstrated that phased coagulation is a promising and cost-effective membrane fouling control strategy. Further research is recommended to gain further understanding of the benefits and the limitations of this method.

- The current work investigated phased coagulation for 10 and 60 minutes of a 120min. permeation cycle. The results suggest that 10 minutes of coagulation is not sufficient while 60 minutes resulted in comparable fouling control as continuous coagulation. More phased coagulation tests (e.g. coagulating for the first 25, 35, 45 minutes of a 120-min permeation cycle) would help determine the optimum coagulation time in terms of fouling control and cost

- This work evaluated phased coagulation over 48 hours. Long-term experiments (e.g. week-long) should be conducted to fully evaluate the benefits of phased coagulation

- Phased coagulation is thought to establish a protective fouling layer. Further work should be completed to characterize the membrane fouling layer during phased coagulation to confirm the fouling control mechanism.

- Field Emission Scanning Electron Microscopy (FESEM) analysis should be used to qualitatively determine the changes in cake layer properties during a phased coagulation filtration test

- Fluorescence excitation-emission matrix (FEEM) analysis should be conducted on the composition and concentration of the membrane foulant layer 


\section{References}

Abdullah, S.Z., Bérubé, P.R., 2013. Assessing the effects of sodium hypochlorite exposure on the characteristics of PVDF based membranes. Water Res. 47, 5392-5399.

Abdullah, S.Z., Wray, H.E., Bérubé, P.R., Andrews, R.C., 2015. Distribution of surface shear stress for a densely packed submerged hollow fiber membrane system. Desalination 357, $117-120$.

Akhondi, E., Wicaksana, F., Fane, A.G., 2014. Evaluation of fouling deposition, fouling reversibility and energy consumption of submerged hollow fiber membrane systems with periodic backwash. J. Membr. Sci. 452, 319-331.

Amy, G., 2008. Fundamental understanding of organic matter fouling of membranes. Desalination $231,44-51$.

Barbot, E., Moustier, S., Bottero, J.Y., Moulin, P., 2008. Coagulation and ultrafiltration: Understanding of the key parameters of the hybrid process. J. Membr. Sci. 325, 520-527. doi:10.1016/j.memsci.2008.07.054

Braak, E., Alliet, M., Schetrite, S., Albasi, C., 2011. Aeration and hydrodynamics in submerged membrane bioreactors. J. Membr. Sci. 379, 1-18.

Busch, J., Cruse, A., Marquardt, W., 2007. Modeling submerged hollow-fiber membrane filtration for wastewater treatment. J. Membr. Sci. 288, 94-111.

Cabassud, C., Laborie, S., Durand-Bourlier, L., Laine, J.M., 2001. Air sparging in ultrafiltration hollow fibers: relationship between flux enhancement, cake characteristics and hydrodynamic parameters. J. Membr. Sci. 181, 57-69.

Chan, C.C.V., Bérubé, P.R., Hall, E.R., 2011. Relationship between types of surface shear stress profiles and membrane fouling. Water Res. 45, 6403-6416.

Chan, C.C.V., Bérubé, P.R., Hall, E.R., 2007. Shear profiles inside gas sparged submerged hollow fiber membrane modules. J. Membr. Sci. 297, 104-120. 
Chen, F., Peldszus, S., Peiris, R.H., Ruhl, A.S., Mehrez, R., Jekel, M., Legge, R.L., Huck, P.M., 2014. Pilot-scale investigation of drinking water ultrafiltration membrane fouling rates using advanced data analysis techniques. Water Res. 48, 508-518.

Chew, C.M., Aroua, M.K., Hussain, M.A., Ismail, W.M.Z.W., 2016. Evaluation of ultrafiltration and conventional water treatment systems for sustainable development: an industrial scale case study. J. Clean. Prod. 112, 3152-3163.

Cho, J.W., Ahn, K.-H., Lee, Y.H., Lim, B.-R., Kim, J.Y., 2004. Investigation of biological and fouling characteristics of submerged membrane bioreactor process for wastewater treatment by model sensitivity analysis. Water Sci. Technol. 49, 245-254.

Choi, K.Y., Dempsey, B.A., 2004a. In-line coagulation with low-pressure membrane filtration. Water Res. 38, 4271-4281.

Choi, K.Y., Dempsey, B.A., 2004b. In-line coagulation with low-pressure membrane filtration. Water Res. 38, 4271-4281.

Citulski, J., Farahbakhsh, K., Kent, F., Zhou, H., 2008. The impact of in-line coagulant addition on fouling potential of secondary effluent at a pilot-scale immersed ultrafiltration plant. J. Membr. Sci. 325, 311-318.

Dassanayake, K.B., Jayasinghe, G.Y., Surapaneni, A., Hetherington, C., 2015. A review on alum sludge reuse with special reference to agricultural applications and future challenges. Waste Manag. 38, 321-335.

Field, R.W., Wu, J.J., 2011. Modelling of permeability loss in membrane filtration: Reexamination of fundamental fouling equations and their link to critical flux. Desalination $283,68-74$.

Galjaard, G., Buijs, P., Beerendonk, E., Schoonenberg, F., Schippers, J.C., 2001. Pre-coating (EPCE®) UF membranes for direct treatment of surface water. Desalination 139, 305-316. 
Galjaard, G., Kruithof, J.C., Scheerman, H., Verdouw, J., Schippers, J.C., 2003. Enhanced precoat engineering (EPCE®) for micro-and ultrafiltration: steps to full-scale application. Water Sci. Technol. Water Supply 3, 125-132.

Gao, W., Liang, H., Ma, J., Han, M., Chen, Z., Han, Z., Li, G., 2011. Membrane fouling control in ultrafiltration technology for drinking water production: a review. Desalination 272, 18.

Guigui, C., Rouch, J.C., Durand-Bourlier, L., Bonnelye, V., Aptel, P., 2002. Impact of coagulation conditions on the in-line coagulation/UF process for drinking water production. Desalination 147, 95-100.

Howe, K.J., Marwah, A., Chiu, K.-P., Adham, S.S., 2007. Effect of membrane configuration on bench-scale MF and UF fouling experiments. Water Res. 41, 3842-3849.

Huang, H., Lee, N., Young, T., Gary, A., Lozier, J.C., Jacangelo, J.G., 2007. Natural organic matter fouling of low-pressure, hollow-fiber membranes: effects of NOM source and hydrodynamic conditions. Water Res. 41, 3823-3832.

Hughes, D., Field, R.W., 2006. Crossflow filtration of washed and unwashed yeast suspensions at constant shear under nominally sub-critical conditions. J. Membr. Sci. 280, 89-98.

Jang, N.-Y., Watanabe, Y., Minegishi, S., 2005. Performance of ultrafiltration membrane process combined with coagulation/sedimentation. Water Sci. Technol. 51, 209-219.

Jones, K.L., O’Melia, C.R., 2000. Protein and humic acid adsorption onto hydrophilic membrane surfaces: effects of pH and ionic strength. J. Membr. Sci. 165, 31-46.

Katsoufidou, K., Yiantsios, S.G., Karabelas, A.J., 2007. Experimental study of ultrafiltration membrane fouling by sodium alginate and flux recovery by backwashing. J. Membr. Sci. $300,137-146$.

Le-Clech, P., Chen, V., Fane, T.A., 2006. Fouling in membrane bioreactors used in wastewater treatment. J. Membr. Sci. 284, 17-53. 
Lee, J.-D., Lee, S.-H., Jo, M.-H., Park, P.-K., Lee, C.-H., Kwak, J.-W., 2000. Effect of coagulation conditions on membrane filtration characteristics in coagulation-microfiltration process for water treatment. Environ. Sci. Technol. 34, 3780-3788.

Li, L., Wray, H.E., Andrews, R.C., Bérubé, P.R., 2014. Ultrafiltration fouling: Impact of backwash frequency and air sparging. Sep. Sci. Technol. 49, 2814-2823.

Liu, J., Liu, B., Liu, T., Bai, Y., Yu, S., 2014. Coagulation-bubbling-ultrafiltration: Effect of floc properties on the performance of the hybrid process. Desalination 333, 126-133.

Liu, T., Chen, Z., Yu, W., Shen, J., Gregory, J., 2011. Effect of two-stage coagulant addition on coagulation-ultrafiltration process for treatment of humic-rich water. Water Res. 45, 42604268.

Membrane Filtration Guidance Manual, 2005. . United States Environmental Protection Agency, Office of Water.

Nan, J., Yao, M., Li, Q., Zhan, D., Chen, T., Wang, Z., Li, H., 2016. The role of shear conditions on floc characteristics and membrane fouling in coagulation/ultrafiltration hybrid process - the effect of flocculation duration and slow shear force. RSC Adv. 6, 163-173. doi:10.1039/C5RA18328F

Nemani, V.A., Taylor-Edmonds, L., Peleato, N.M., Andrews, R.C., 2016. Impact of operational parameters on biofiltration performance: organic carbon removal and effluent turbidity. Water Sci. Technol. Water Supply ws2016093.

Ohno, K., Matsui, Y., Itoh, M., Oguchi, Y., Kondo, T., Konno, Y., Matsushita, T., Magara, Y., 2010. NF membrane fouling by aluminum and iron coagulant residuals after coagulationMF pretreatment. Desalination 254, 17-22.

Park, N., Kwon, B., Kim, S.-D., Cho, J., 2006. Characterizations of the colloidal and microbial organic matters with respect to membrane foulants. J. Membr. Sci. 275, 29-36. 
Park, P., Lee, C., Choi, S.-J., Choo, K.-H., Kim, S.-H., Yoon, C.-H., 2002. Effect of the removal of DOMs on the performance of a coagulation-UF membrane system for drinking water production. Desalination 145, 237-245.

Pronk, W., Traber, J., Kaminska, G., 2016. Optimization of process parameters of the coagulation/ultrafiltration process for the reduction of membrane fouling, in: Advances in Particle Science and Separation: Meeting Tomorrow's Challenges. Presented at the IWA Specialist conference: Particle Separatoin, The International Water Association, Oslo, Norway, pp. 198-205.

Rahman, I., Ndiongue, S., Jin, X., Van Dyke, M.I., Anderson, W.B., Huck, P.M., 2014. Fouling of low-pressure membranes during drinking water treatment: effect of NOM components and biofiltration pretreatment. Water Sci. Technol. Water Supply 14, 453-460.

Remize, P.J., Guigui, C., Cabassud, C., 2010. Evaluation of backwash efficiency, definition of remaining fouling and characterisation of its contribution in irreversible fouling: Case of drinking water production by air-assisted ultra-filtration. J. Membr. Sci. 355, 104-111.

Salinas-Rodriguez, S.G., Prabowo, A., Abushaban, A., Battes, F., Schippers, J.C., Kennedy, M.D., 2016. Pre-coating of outside-inside capillary UF membranes with iron hydroxide particles to limit non-backwashable fouling during seawater algal blooms. Desalination Water Treat. $1-11$.

Shi, X., Tal, G., Hankins, N.P., Gitis, V., 2014. Fouling and cleaning of ultrafiltration membranes: a review. J. Water Process Eng. 1, 121-138.

Sun, W., Nan, J., Yao, M., Xing, J., Tian, J., 2016. Effect of aluminum speciation on fouling mechanisms by pre-coagulation/ultrafiltration process with different NOM fractions. Environ. Sci. Pollut. Res. 1-15.

Sur, H.W., Cui, Z., 2001. Experimental study on the enhancement of yeast microfiltration with gas sparging. J. Chem. Technol. Biotechnol. 76, 477-484. 
Tabatabai, S.A.A., Wei, J., Kennedy, M.D., Amy, G.L., Schippers, J.C., 2010. Examining Coagulation and Precoating for Seawater UF/RO System Pretreatment. IDA J. Desalination Water Reuse 2, 58-62.

Taniguchi, M., Kilduff, J.E., Belfort, G., 2003. Modes of natural organic matter fouling during ultrafiltration. Environ. Sci. Technol. 37, 1676-1683.

Tian, J., Yu, H., Shen, Y., Shi, W., Liu, D., Gao, S., Cui, F., 2015. Identification of irreversible UF membrane foulants by fluorescence excitation-emission matrix coupled with parallel factor analysis. Desalination Water Treat. 1-12.

Wang, X.-M., Waite, T.D., 2008. Impact of gel layer formation on colloid retention in membrane filtration processes. J. Membr. Sci. 325, 486-494.

Wray, H.E., Andrews, R.C., 2014. Optimization of coagulant dose for biopolymer removal: impact on ultrafiltration fouling and retention of organic micropollutants. J. Water Process Eng. 1, $74-83$.

Wray, H.E., Andrews, R.C., Bérubé, P.R., 2016. Coagulation optimization for DOC removal: pilot-scale analysis of UF fouling and disinfection byproduct formation potential. Water Sci. Technol. Water Supply 16, 473-480.

Wray, H.E., Andrews, R.C., Berube, P.R., 2014. Ultrafiltration organic fouling control: Comparison of air-sparging and coagulation. Journal-American Water Works Assoc. 106, $41-42$.

Wray, H.E., Andrews, R.C., Bérubé, P.R., 2013. Surface shear stress and membrane fouling when considering natural water matrices. Desalination 330, 22-27.

Wu, J., Le-Clech, P., Stuetz, R.M., Fane, A.G., Chen, V., 2008. Novel filtration mode for fouling limitation in membrane bioreactors. Water Res. 42, 3677-3684.

Ye, D., Saadat-Sanei, S., Bérubé, P.R., 2014. Pulse bubble sparging for the control of hydraulically reversible fouling in submerged hollow fiber membrane systems. Sep. Purif. Technol. 123, $153-163$. 
Ye, Y., Chen, V., Le-Clech, P., 2011. Evolution of fouling deposition and removal on hollow fibre membrane during filtration with periodical backwash. Desalination 283, 198-205.

Ye, Y., Sim, L.N., Herulah, B., Chen, V., Fane, A.G., 2010. Effects of operating conditions on submerged hollow fibre membrane systems used as pre-treatment for seawater reverse osmosis. J. Membr. Sci. 365, 78-88.

Yu, W.-Z., Liu, H.-J., Liu, T., Liu, R.-P., Qu, J.-H., 2013. Comparison of submerged coagulation and traditional coagulation on membrane fouling: Effect of active flocs. Desalination 309, 11-17.

Zheng, X., Ernst, M., Huck, P.M., Jekel, M., 2010. Biopolymer fouling in dead-end ultrafiltration of treated domestic wastewater. Water Res. 44, 5212-5221. doi:10.1016/j.watres.2010.06.039

Zularisam, A.W., Ismail, A.F., Salim, R., 2006. Behaviours of natural organic matter in membrane filtration for surface water treatment - a review. Desalination 194, 211-231. 


\section{Appendices}

\subsection{Raw Experimental data for Air sparging and In-line coagulation Study}

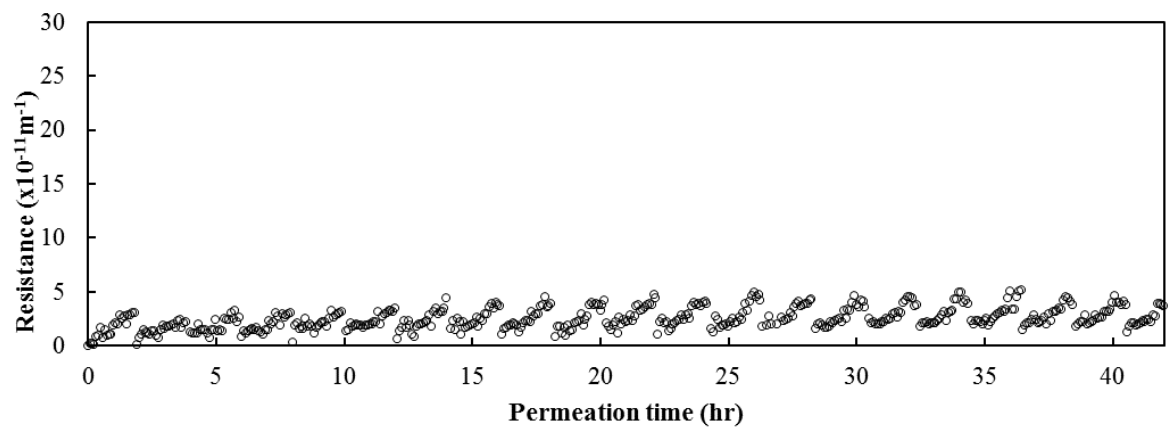

Figure 8-1: Resistance vs. time for the base condition

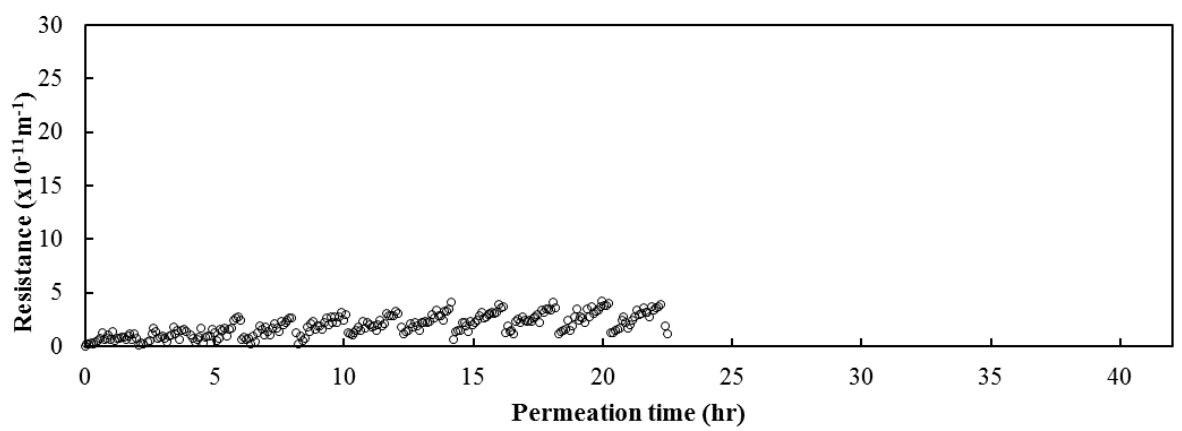

Figure 8-2: Resistance vs. time for phased $60 \mathrm{~min}$. sparging

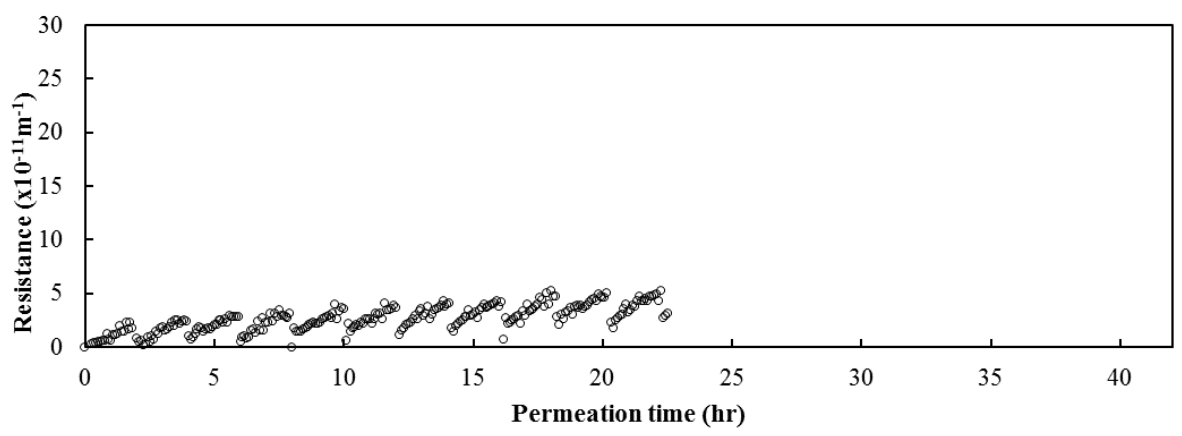

Figure 8-3: Resistance vs. time for phased 110 min. sparging 


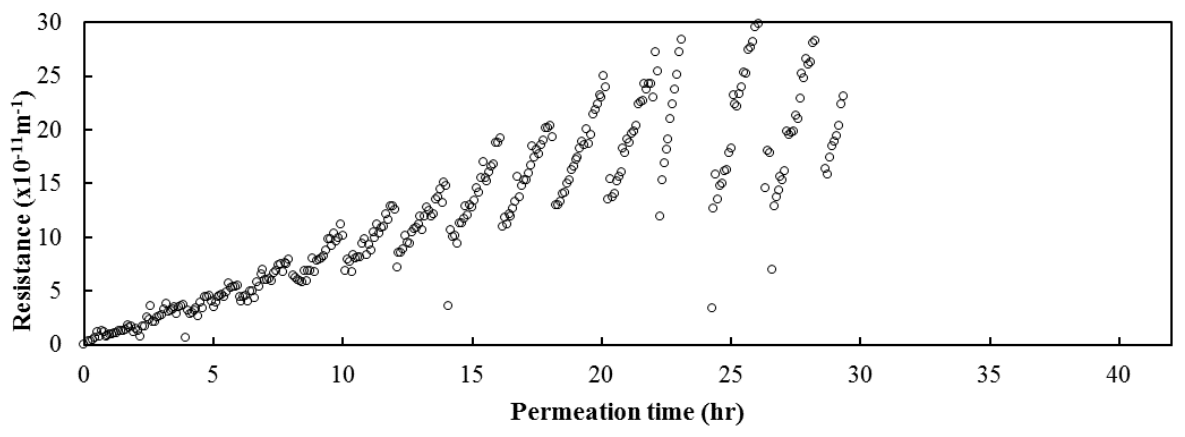

Figure 8-4: Resistance vs. time for no sparging

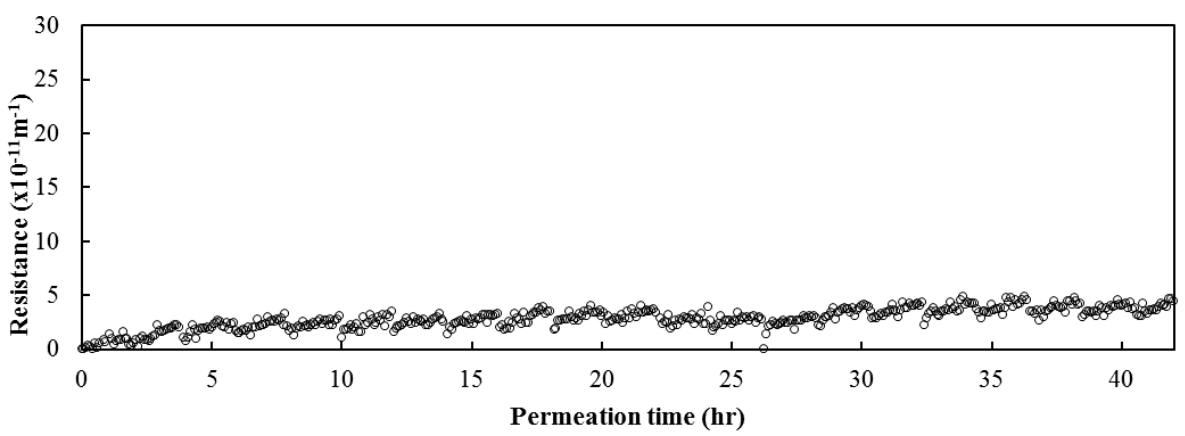

Figure 8-5: Resistance vs. time for no coag., continuous sparging

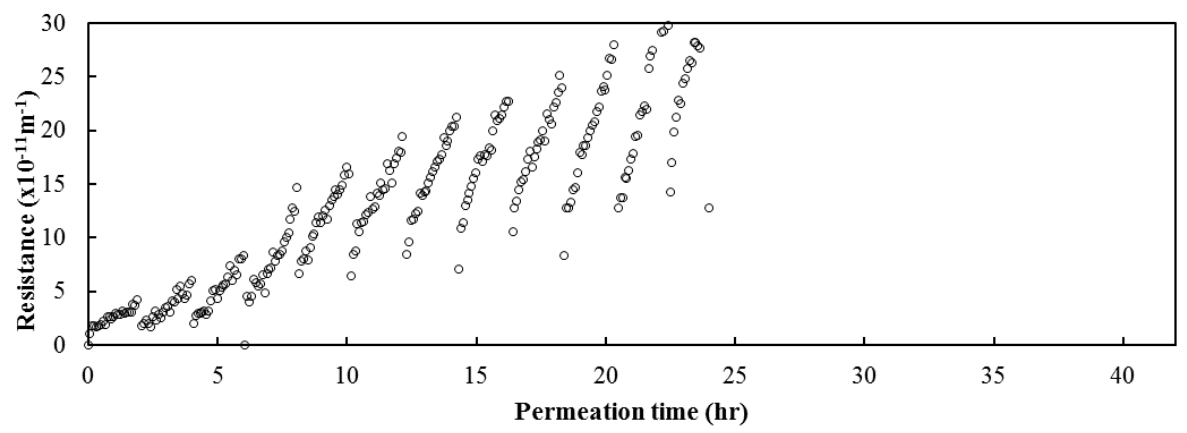

Figure 8-6: Resistance vs. time for continuous sparging $5 \mathrm{~L} / \mathrm{min}$

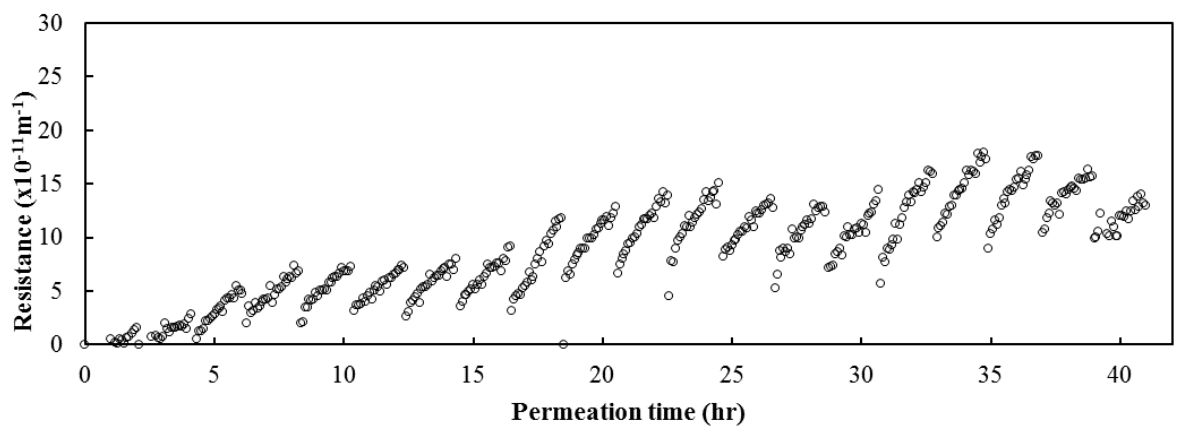

Figure 8-7: Resistance vs. time for continuous sparging $20 \mathrm{~L} / \mathrm{min}$ 


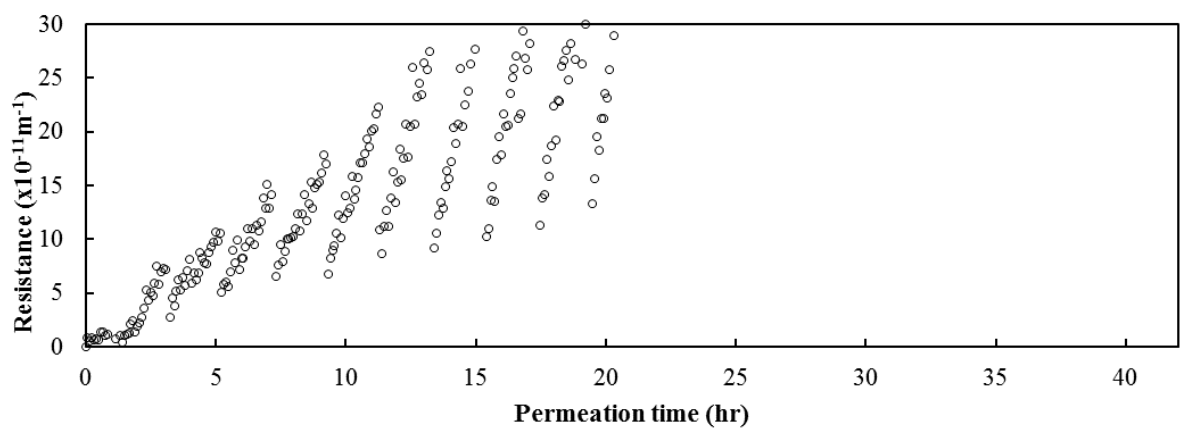

Figure 8-8: Resistance vs. time for intermittent sparging $5 \mathrm{~L} / \mathrm{min}$

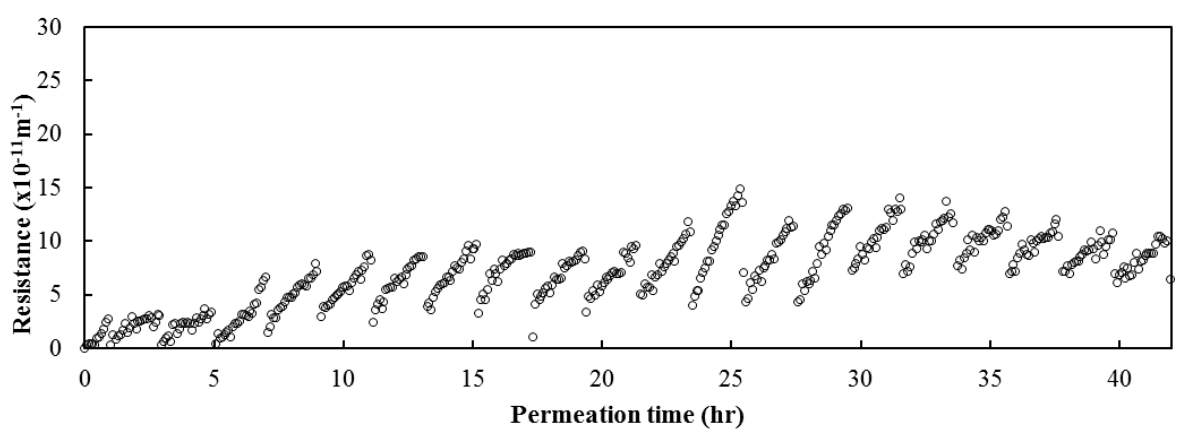

Figure 8-9: Resistance vs. time for intermittent sparging $20 \mathrm{~L} / \mathrm{min}$

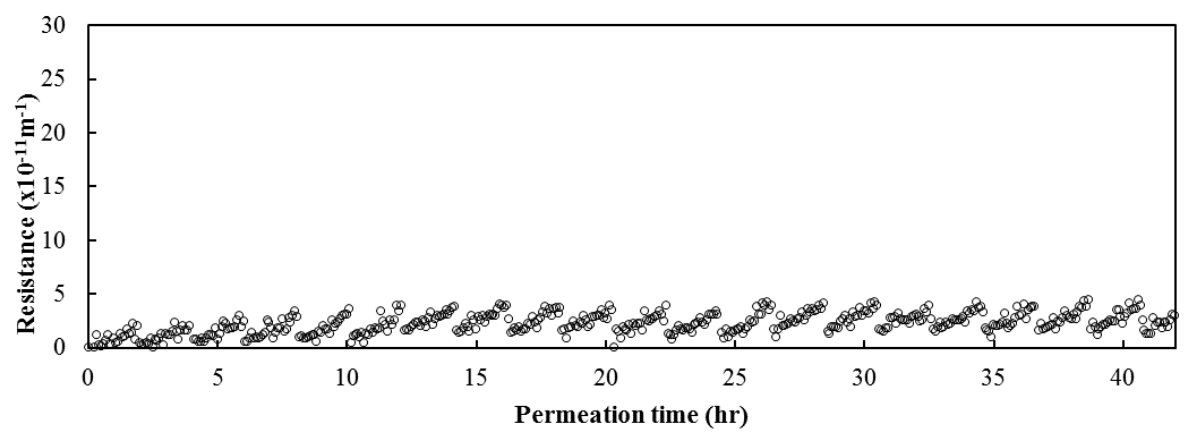

Figure 8-10: Resistance vs. time for phased 60 min. coagulation

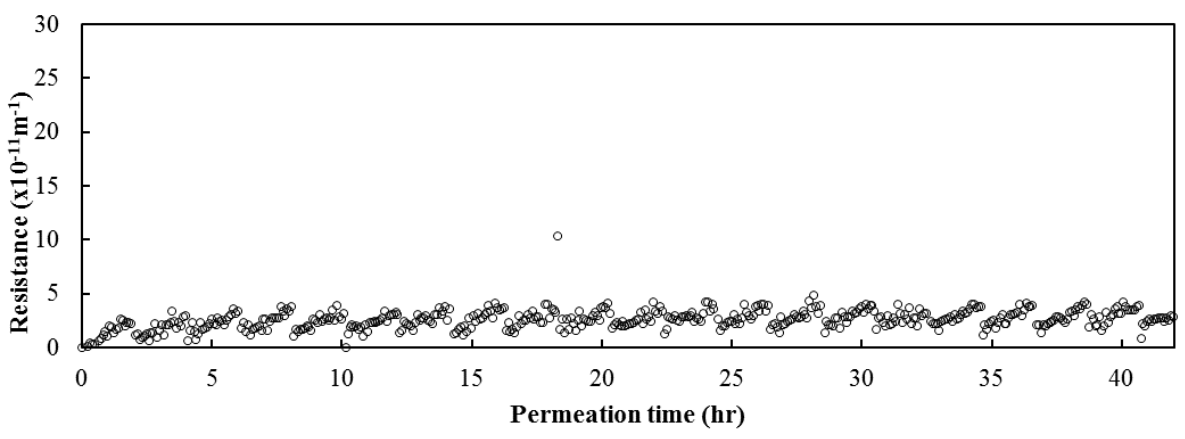

Figure 8-11: Resistance vs. time for phased 10 min. coagulation 
Table 8-1: Flux, temperature, and $\mathrm{pH}$

\begin{tabular}{|c|l|ccc|}
\hline $\begin{array}{c}\text { Parameters } \\
\text { Examined }\end{array}$ & Deviation from base condition & $\begin{array}{c}\text { Flux } \\
\left(\mathrm{Lm}^{-2} \mathrm{~h}^{-1}\right)\end{array}$ & $\begin{array}{c}\text { Temperature } \\
\left({ }^{\circ} \mathrm{C}\right)\end{array}$ & $\mathrm{pH}$ \\
\hline Base condition & \multicolumn{1}{|c|}{-} & $37 \pm 7$ & $7.8 \pm 0.4$ & $7.73 \pm 0.07$ \\
\hline \multirow{5}{*}{ Sparging duration } & Continuous sparging & $38 \pm 5$ & $8 \pm 1$ & $7.68 \pm 0.04$ \\
& Phased 60 min sparging & $38 \pm 4$ & $12 \pm 1$ & $7.27 \pm 0.02$ \\
& Phased 110 min sparging & $38 \pm 6$ & $11.4 \pm 0.2$ & $7.28 \pm 0.01$ \\
& No sparging & $38 \pm 3$ & $12 \pm 2$ & $7.39 \pm 0.03$ \\
& Continuous sparging, no coag. & $38 \pm 3$ & $12 \pm 2$ & $7.61 \pm 0.05$ \\
\hline \multirow{3}{*}{ Lower intensity } & Continuous sparging 5 L/min & $41 \pm 8$ & $8.3 \pm 0.2$ & $8.3 \pm 0.2$ \\
sparging & Continuous sparging 20 L/min & $42 \pm 6$ & $8.1 \pm 0.1$ & $8.1 \pm 0.1$ \\
& Intermittent sparging 5 L/min & $49 \pm 10$ & $8 \pm 1$ & $8.4 \pm 0.2$ \\
& Intermittent sparging 20 L/min & $43 \pm 5$ & $7 \pm 2$ & $8.3 \pm 0.2$ \\
\hline \multirow{2}{*}{ Phased } & Phased 60 min coagulation & $38 \pm 4$ & $17 \pm 3$ & $7.7 \pm 0.1$ \\
coagulation & Phased 10 min coagulation & $38 \pm 4$ & $13 \pm 1$ & $7.59 \pm 0.01$ \\
\hline
\end{tabular}

Table 8-2: Feed and permeate DOC, UV254, and SUVA

\begin{tabular}{|c|c|c|c|c|c|c|c|}
\hline \multirow{2}{*}{$\begin{array}{c}\text { Parameters } \\
\text { Examined }\end{array}$} & \multirow{2}{*}{ Deviation from base condition } & \multicolumn{3}{|c|}{ Feed } & \multicolumn{3}{|c|}{ Permeate } \\
\hline & & $\begin{array}{c}\mathrm{DOC} \\
(\mathrm{mg} / \mathrm{L})\end{array}$ & UV254 & $\begin{array}{c}\text { SUVA } \\
(\mathrm{L} / \mathrm{mg} \cdot \mathrm{m})\end{array}$ & $\begin{array}{c}\text { DOC } \\
(\mathrm{mg} / \mathrm{L})\end{array}$ & UV254 & $\begin{array}{c}\text { SUVA } \\
(\mathrm{L} / \mathrm{mg} \cdot \mathrm{m})\end{array}$ \\
\hline $\begin{array}{c}\text { Base } \\
\text { condition }\end{array}$ & - & 3.9 & 5.4 & 0.73 & 3.4 & 4.9 & 0.69 \\
\hline \multirow{4}{*}{$\begin{array}{l}\text { Sparging } \\
\text { duration }\end{array}$} & Continuous sparging & 3.8 & 5.3 & 0.71 & 3.1 & 4.5 & 0.69 \\
\hline & $\begin{array}{l}\text { Phased } 60 \text { min sparging } \\
\text { Phased } 110 \text { min sparging }\end{array}$ & $\begin{array}{c}\text { Not } \\
\text { sampled }\end{array}$ & $\begin{array}{c}\text { Not } \\
\text { sampled }\end{array}$ & $\begin{array}{l}\text { Not } \\
\text { sampled }\end{array}$ & $\begin{array}{c}\text { Not } \\
\text { sampled }\end{array}$ & $\begin{array}{c}\text { Not } \\
\text { sampled }\end{array}$ & Not sampled \\
\hline & No sparging & 4.8 & 5.6 & 0.85 & 4.3 & 5.0 & 0.86 \\
\hline & Continuous sparging, no coag. & 3.8 & 5.2 & 0.74 & 3.5 & 5.2 & 0.67 \\
\hline \multirow{2}{*}{$\begin{array}{c}\text { Phased } \\
\text { coagulation }\end{array}$} & Phased 60 min coagulation & 3.8 & 5.4 & 0.71 & 3.3 & 5.0 & 0.66 \\
\hline & Phased 10 min coagulation & 3.9 & 5.3 & 0.73 & 3.6 & 5.2 & 0.68 \\
\hline
\end{tabular}


Table 8-3: Feed and permeate turbidity, particle counts, and POC

\begin{tabular}{|c|c|c|c|c|c|c|c|c|c|}
\hline \multirow{2}{*}{$\begin{array}{c}\text { Parameters } \\
\text { Examined }\end{array}$} & \multirow{2}{*}{ Deviation from base condition } & \multicolumn{4}{|c|}{ Feed } & \multicolumn{4}{|c|}{ Permeate } \\
\hline & & $\begin{array}{l}\text { Turbidity } \\
\text { (NTU) }\end{array}$ & $\begin{array}{c}2-5 \mu \mathrm{m} \\
\text { (counts } / \mathrm{mL} \text { ) }\end{array}$ & $\begin{array}{c}5-10 \mu \mathrm{m} \\
(\text { counts } / \mathrm{mL})\end{array}$ & $\begin{array}{c}\mathrm{POC} \\
(\mathrm{mg} / \mathrm{L})\end{array}$ & $\begin{array}{l}\text { Turbidity } \\
\text { (NTU) }\end{array}$ & $\begin{array}{c}2-5 \mu \mathrm{m} \\
(\text { counts } / \mathrm{mL})\end{array}$ & $\begin{array}{c}5-10 \mu \mathrm{m} \\
(\text { counts } / \mathrm{mL})\end{array}$ & $\begin{array}{c}\mathrm{POC} \\
(\mathrm{mg} / \mathrm{L})\end{array}$ \\
\hline $\begin{array}{c}\text { Base } \\
\text { condition }\end{array}$ & & $0.26 \pm 0.01$ & $280 \pm 100$ & $13 \pm 2$ & 0.05 & $0.02 \pm 0.07$ & $190 \pm 20$ & $0.17 \pm 0.08$ & 0.04 \\
\hline \multirow{5}{*}{$\begin{array}{l}\text { Sparging } \\
\text { duration }\end{array}$} & Continuous sparging & $0.35 \pm 0.05$ & $760 \pm 170$ & $80 \pm 20$ & 0.08 & $0.02 \pm 0.03$ & $190 \pm 30$ & $0.6 \pm 8$ & 0.03 \\
\hline & Phased 60 min sparging & $0.38 \pm 0.08$ & $1000 \pm 300$ & $90 \pm 70$ & Not & $0.02 \pm 0.05$ & $170 \pm 30$ & $1 \pm 12$ & Not \\
\hline & Phased 110 min sparging & $0.42 \pm 0.06$ & $1100 \pm 200$ & $160 \pm 60$ & sampled & $0.01 \pm 0.01$ & $160 \pm 50$ & $0.19 \pm 0.16$ & sampled \\
\hline & No sparging & $0.21 \pm 0.09$ & $210 \pm 160$ & $14 \pm 13$ & 0.1 & $0.02 \pm 0.07$ & $100 \pm 70$ & $1 \pm 12$ & 0.05 \\
\hline & Continuous sparging, no coag. & $0.34 \pm 0.05$ & $370 \pm 240$ & $20 \pm 10$ & 0.16 & $0.01 \pm 0.001$ & $190 \pm 20$ & $0.17 \pm 0.05$ & 0.05 \\
\hline \multirow{4}{*}{$\begin{array}{l}\text { Lower } \\
\text { intensity } \\
\text { sparging }\end{array}$} & Continuous sparging $5 \mathrm{~L} / \mathrm{min}$ & $0.14 \pm 0.02$ & \multirow{4}{*}{$\begin{array}{c}\text { Not } \\
\text { sampled }\end{array}$} & \multirow{4}{*}{$\begin{array}{c}\text { Not } \\
\text { sampled }\end{array}$} & \multirow{4}{*}{$\begin{array}{c}\text { Not } \\
\text { sampled }\end{array}$} & $0.01 \pm 0.001$ & \multirow{4}{*}{ Not sampled } & \multirow{4}{*}{$\begin{array}{c}\text { Not } \\
\text { sampled }\end{array}$} & \multirow{4}{*}{$\begin{array}{c}\text { Not } \\
\text { sampled }\end{array}$} \\
\hline & Continuous sparging $20 \mathrm{~L} / \mathrm{min}$ & $0.17 \pm 0.02$ & & & & $0.01 \pm 0.001$ & & & \\
\hline & Intermittent sparging $5 \mathrm{~L} / \mathrm{min}$ & $0.16 \pm 0.01$ & & & & $0.01 \pm 0.001$ & & & \\
\hline & Intermittent sparging $20 \mathrm{~L} / \mathrm{min}$ & $0.25 \pm 0.06$ & & & & $0.01 \pm 0.001$ & & & \\
\hline \multirow{2}{*}{$\begin{array}{c}\text { Phased } \\
\text { coagulation }\end{array}$} & Phased 60 min coagulation & $0.38 \pm 0.05$ & $1250 \pm 220$ & $70 \pm 10$ & 0.142 & $0.01 \pm 0.02$ & $190 \pm 20$ & $0.59 \pm 8$ & 0.04 \\
\hline & Phased 10 min coagulation & $0.26 \pm 0.01$ & $1260 \pm 360$ & $120 \pm 40$ & 0.242 & $0.05 \pm 0.01$ & $190 \pm 20$ & $0.17 \pm 0.04$ & 0.04 \\
\hline
\end{tabular}




\subsection{Bench-scale Membrane Surface Area and Flow Rate Calculations}

\section{Step 1:}

The change in resistance between the loose and mounted fibers was used to estimate the actual permeable membrane area (Eqn.. 8-1).

$$
A_{\text {mounted }}=\frac{R_{\text {loose }} \times Q_{\text {loose }} \times \mu}{T M P_{\text {mounted }}}
$$

where:

$\mathrm{A}_{\text {mounted }}=$ permeable surface area of mounted membrane

$\mathrm{R}_{\text {loose }}=$ resistance $\left(\mathrm{m}^{-1}\right)$ of the loose membrane after filtering Milli- $\mathrm{Q}$ water for two hours

$\mathrm{Q}_{\text {loose }}=$ average permeate flow rate $(\mathrm{L} / \mathrm{h})$ of the loose membrane when filtering Milli- $\mathrm{Q}$ water $\mu=$ viscosity of water at $20^{\circ} \mathrm{C}(\mathrm{kg} / \mathrm{m} / \mathrm{s})$

$\mathrm{TMP}_{\text {mounted }}=$ transmembrane pressure $(\mathrm{TMP})(\mathrm{Pa})$ for the mounted membrane after filtering Milli-Q water for two hours

\section{Step 2:}

The flow rate required to achieve a flux of $50 \mathrm{l} / \mathrm{m}^{2} \cdot \mathrm{hr}$ was calculated based on the calculated membrane surface area in Step 1 (Eqn. 8-2).

$Q_{\text {target }}=J \times A_{\text {mounted }}$ Eqn. 8-2

where: $\mathrm{J}=$ flux $\left(/ \mathrm{m}^{2} \cdot \mathrm{hr}\right)$

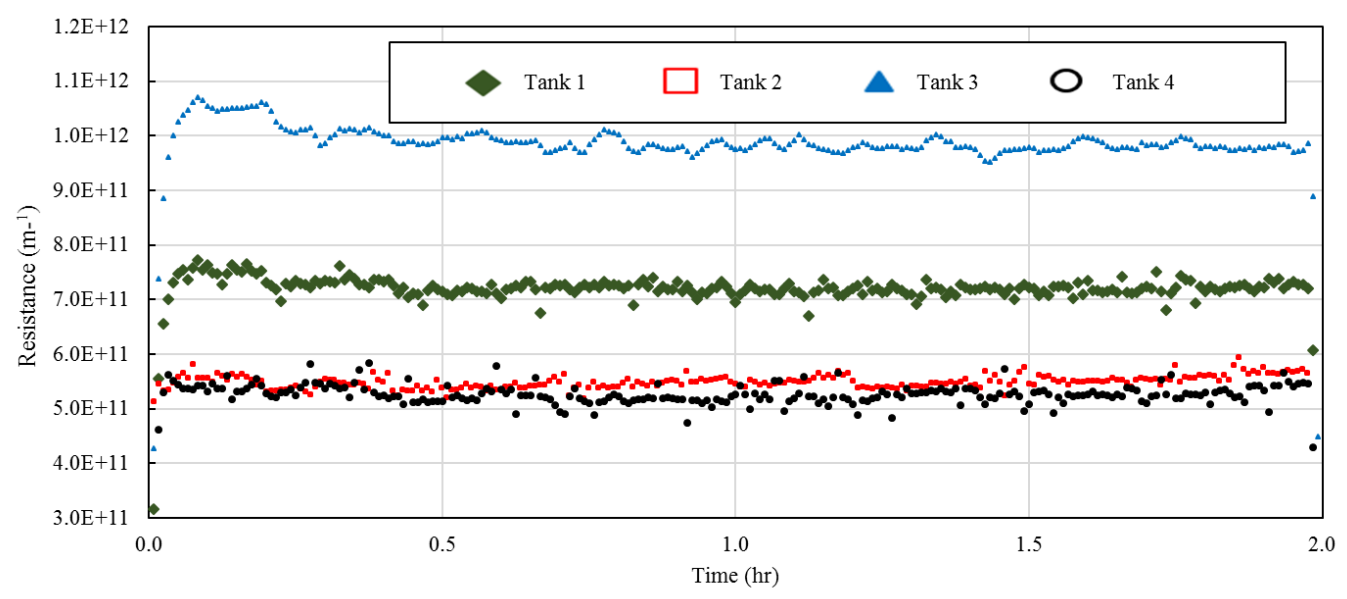

Figure 8-12: Sample Milli-Q water permeation test for mounted membranes 


\subsection{Pulse Sparging}

\subsubsection{Objective}

Compare pulse sparging to intermittent coarse and continuous coarse bubble sparging in terms of UF fouling control.

\subsubsection{Methods}

The pilot apparatus and experimental protocol used for this study are described in Section 3.4.1. Pulse, intermittent coarse, and continuous bubble sparging were conducted at $5,20 \mathrm{~L} / \mathrm{min}$.

\subsubsection{Results}

At a $5 \mathrm{~L} / \mathrm{min}$ air flow rate, continuous pulse bubbles, intermittent coarse bubbles, and continuous coarse bubbles impart shear stress of 0.39, 0.24, and 0.14 RMS, respectively (Abdullah et al., 2015). Accordingly, at a flow rate of $5 \mathrm{~L} / \mathrm{min}$, continuous pulse bubbles had the lowest irreversible fouling rate $\left(0.39 \times 10^{-11} \mathrm{~m}^{-1} \mathrm{~h}^{-1}\right)$ when compared to continuous coarse $\left(0.68 \times 10^{-11} \mathrm{~m}^{-}\right.$ $\left.{ }^{1} \mathrm{~h}^{-1}\right)$ and intermittent coarse $\left(0.80 \times 10^{-11} \mathrm{~m}^{-1} \mathrm{~h}^{-1}\right)$ (Figure 8-13: ). However, the benefits of pulse bubble sparging was less evident at a higher flow rate of $20 \mathrm{~L} / \mathrm{min}$.

a)

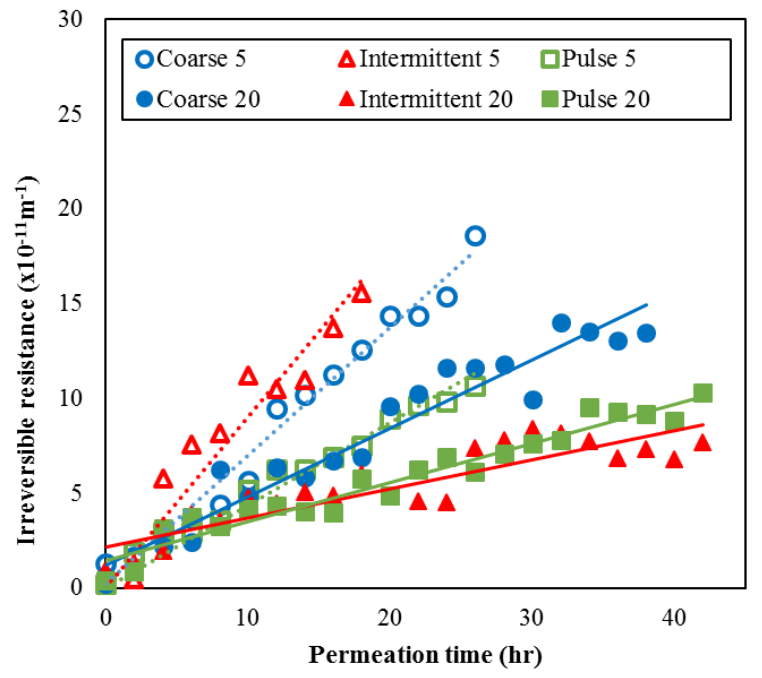

b)

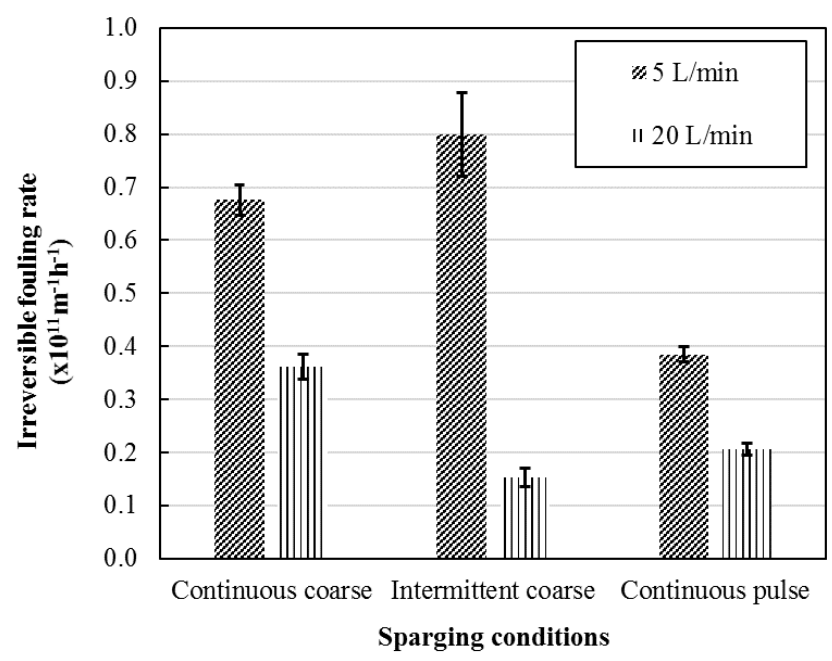

Figure 8-13: (a) Irreversible resistance over time and (b) irreversible resistance rates for continuous coarse, intermittent coarse, and continuous pulse bubble sparging at 5 and $20 \mathrm{~L} / \mathrm{min}$. Vertical bars correspond to the $95 \%$ confidence interval associated with the estimated slope. 


\subsection{Effect of EBCT on Biofiltration Performance and Membrane Fouling}

\subsubsection{Introduction}

Biofiltration is an attractive UF pretreatment method that can remove biopolymers. Yearround, pilot-scale studies reported that biofilters reduced biopolymer concentration at the Grand River, ON, Canada from 0.36 to $0.17 \mathrm{mg} \mathrm{C} / \mathrm{L}$ (Halle et al. 2009, Peldszus et al. 2012) and at the Saugeen River, ON, Canada from 0.15 to $0.12 \mathrm{mg} \mathrm{C/L}$ (Rahman et al. 2014) which resulted in reduction in both reversible and irreversible UF fouling. Furthermore, lengthening the EBCT from 5 to $15 \mathrm{~min}$ increased biopolymer removal by an average of $0.1 \mathrm{mg} / \mathrm{L}(35 \%)$ as well as reduced the rate of irreversible fouling (in terms of $\triangle \mathrm{TMP}$ ) by approximately $30 \mathrm{kPa}$ (Peldszus et al. 2012). There still exist areas for further optimization of biofilters for UF fouling control. Peldzsus et al. (2012) observed that EBCT of 5 vs. 10 min reduced biopolymer concentration by $0.1 \mathrm{mg} / \mathrm{L}$ (35\%) with concomitant decrease in UF fouling. However, more data points are needed to determine the optimal EBCT.

The minimum design EBCT for the biologically activated carbon contactors (BACCs) at Lakeview WTP (described in Section 3.2) is 4 minutes. However, the actual EBCT varies typically between 4-16 minutes depending on the water demand.

\subsubsection{Objectives}

1. Determine the impact of EBCT on biofilter performance in terms of the removal of dissolved organics at full-scale and pilot-scale

2. Determine the impact of biofilter EBCT on UF foulant removal and membrane resistance

\subsubsection{Materials and Methods}

\subsubsection{Biofilter Pilot Experimental Protocol}

The pilot consisted of four parallel filter columns made of acrylic ( $D=7.62 \mathrm{~cm}(3 \mathrm{in}))$. Each filter contained $100 \mathrm{~cm}$ of media harvested from the biologically active carbon contactors (BACCs) of the full-scale facility. The media (Calgon Filtrasorb-300, effective size 1.3-1.5 mm, uniformity coefficient 1.4) had been in service for 3 years prior to commencement of the study, 
and all adsorptive capacity was assumed to be exhausted. The filters were fed from a constant head tank that received ozonated water (post quenching of any residual). Pilot influent DOC varied between 2and $2.5 \mathrm{mg} / \mathrm{L}$ during the study, while turbidity, $\mathrm{pH}$ and temperature ranged between 0.1 1.5 NTU, 6.-8 and $9-23^{\circ} \mathrm{C}$ respectively. All four columns were operated at 4 minute EBCT on a 5day backwash cycle for 8 months to establish a baseline. The columns were then operated at different EBCTs of 4, 8, 12, 16 minutes on a 7-day backwash cycle for 5 months (Figure 8-14). A 7-day backwash cycle was selected for logistical reasons. Previous research using the same biofilter pilot has shown that biofilter performance when operated on a 5-day backwash cycle did not differ when compared to the performance when operated a 10-day backwash cycle (Nemani et al., 2016).

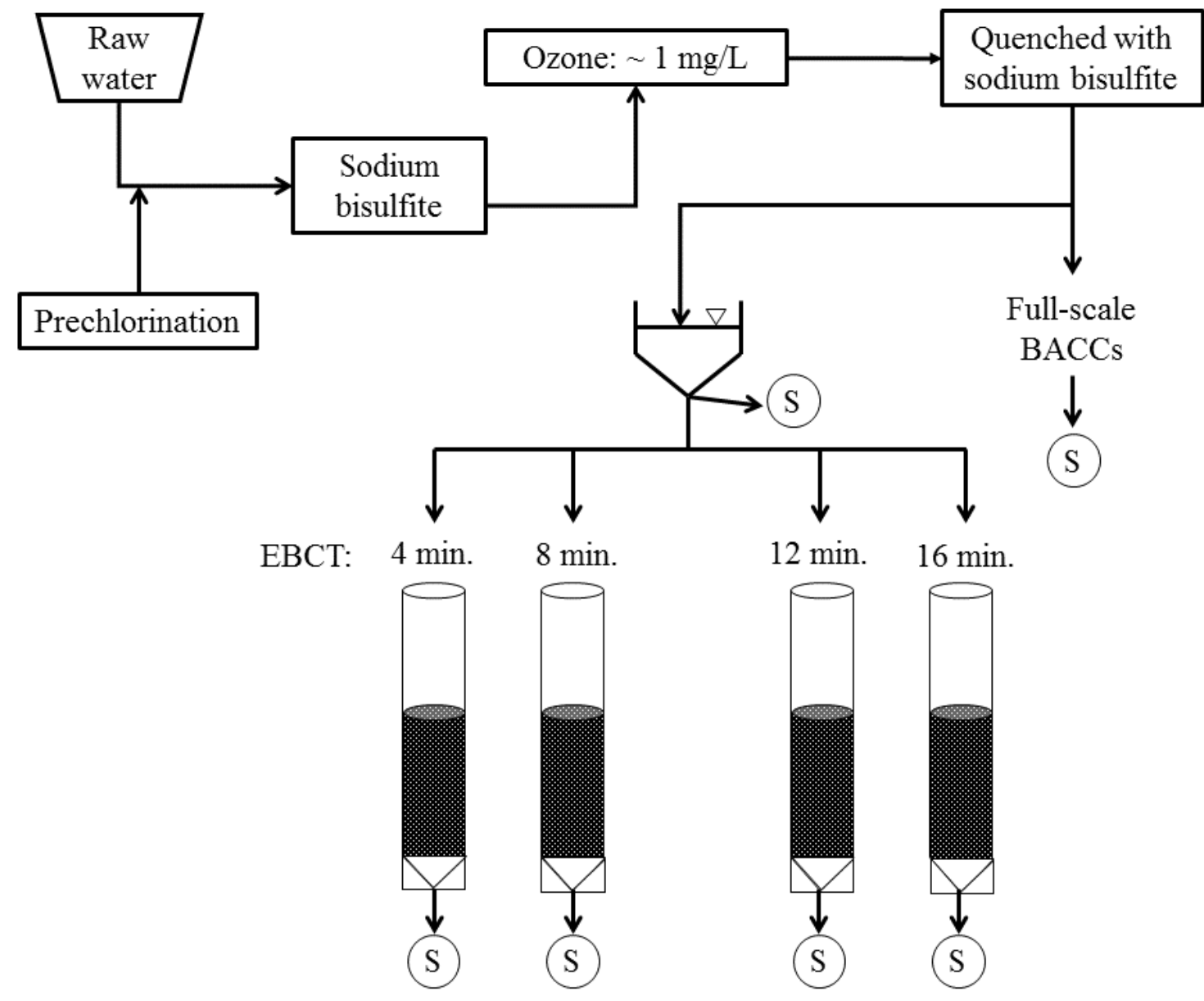

Figure 8-14: Schematic of Lakeview WTP pilot. S indicates sampling location. 
Water quality parameters including $\mathrm{pH}$, temperature, dissolved oxygen (DO), UV 254 absorbance (described in Section 3.5.1), and DOC (described in Section 3.5.1) were measured on grab samples collected from the influent (post ozone and quenching), pilot and full-scale effluents (as shown in Figure 8-14). All samples were collected immediately prior to a backwash. BACC effluent from the full-scale plant was also monitored. Active biomass was quantified using ATP analysis performed on media obtained from the top $5 \mathrm{~cm}$ of the pilot-scale biofilters.

\subsubsection{Bench-scale UF Fouling Study}

Membrane resistance for the 4 minute EBCT pilot effluent was measured at bench-scale. Bench-scale setup and experimental procedure are described in Section 3.4.2.

\subsubsection{ATP Analysis}

Adenosine triphosphate (ATP) analysis was completed using a Luminultra analysis kit (DSA-100C). Media samples were obtained from the top of the biofilter and analyzed following the manufacturer's instructions provided in Appendix Table 8-5.

\subsubsection{Liquid Chromatograph-Organic Carbon Detection (LC-OCD)}

Liquid chromatography-organic carbon detection (LC-OCD) characterized the organic compounds found in raw and treated water samples. LC-OCD identifies five different fractions of DOC including: biopolymers, humic substances, building blocks, low molecular weight neutrals and low molecular weight acids.

Water samples were filtered using a $0.45 \mu \mathrm{m}$ glass fiber filter (Gelman Supor, Gelman Sciences, Ann Arbor, MI) and collected in $40 \mathrm{~mL}$ amber glass vials with Teflon ${ }^{\circledR}$ lined silicon septa and screw caps (VWR International, Mississauga, ON). The samples were stored at $4^{\circ} \mathrm{C}$ until being shipped to the University of Waterloo (Waterloo, ON) for analysis. Based on a method by Huber et al., (2011), the samples are first separated chromatographically using a weak cation exchange column (250 mm x $20 \mathrm{~mm}$, Tosoh, Japan). The mobile phase used was a phosphate buffer exposed to UV irradiation in an annular UV reactor, delivered at a flow rate of $1.1 \mathrm{~mL} / \mathrm{min}$ to an autosampler (MLE, Dresden, Germany, 1 mL injection volume). Chromatographic separation was followed by UV254 detection, and organic carbon detection (OCD). The solution was 
acidified to form carbonic acid from carbonates at the OCD inlet. Total DOC for each sample was measured using a column bypass. Calibration was completed using a potassium hydrogen phthalate (KHP) solution. Data processing and acquisition was completed using a custom ChromCALC software package (Karlsruhe, Germany).

\subsubsection{Results}

Daily average EBCT at Lakeview WTP fluctuated between 4 and 21 minutes between June $17^{\text {th }}$ to November $30^{\text {th }}, 2016$ (Figure 8-15). Within a day, the EBCT typically fluctuated by 0.5-6 minutes (Figure 8-16). No relationship was observed between the full-scale EBCT and \% DOC removal (Figure 8-17). Similarly, the effluent of the pilot biofilter columns operated at 4, 8, 12, and 16 minute EBCT did not differ significantly in terms of DOC (Figure 8-18), UV254 (Figure 8-19), biopolymers, and humic substances (Figure 8-20).

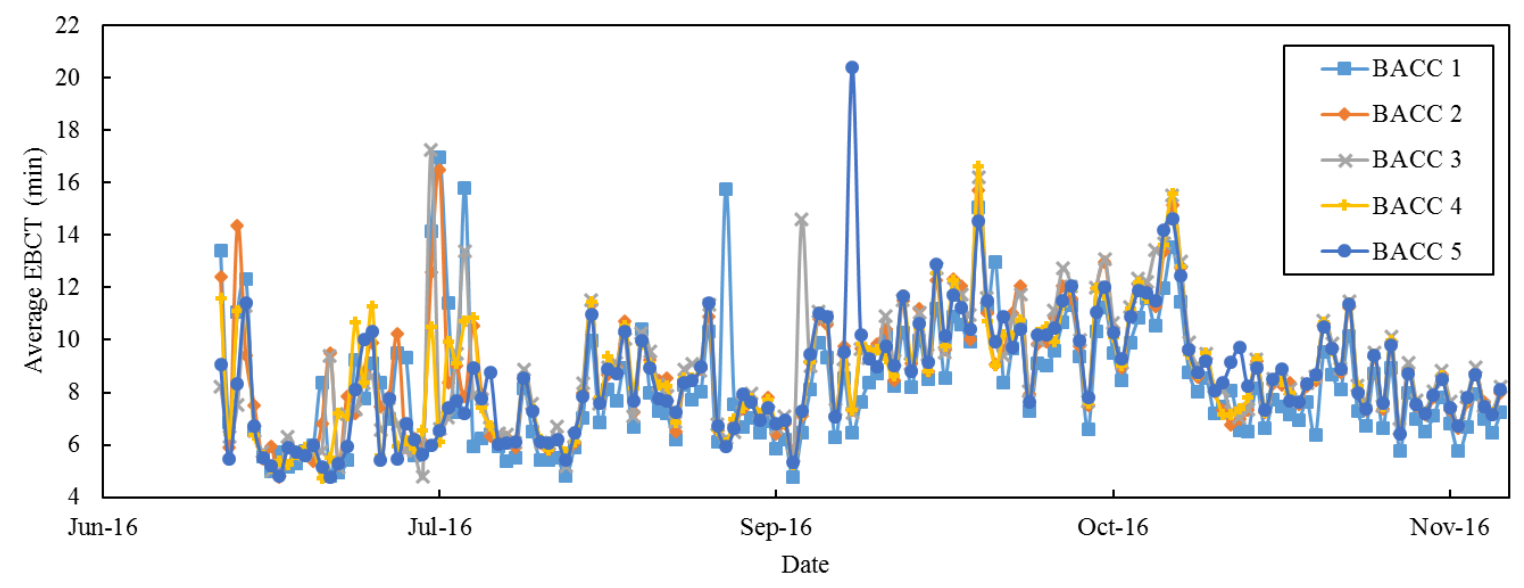

Figure 8-15: Daily average EBCT for Lakeview WTP's full-scale BACCs

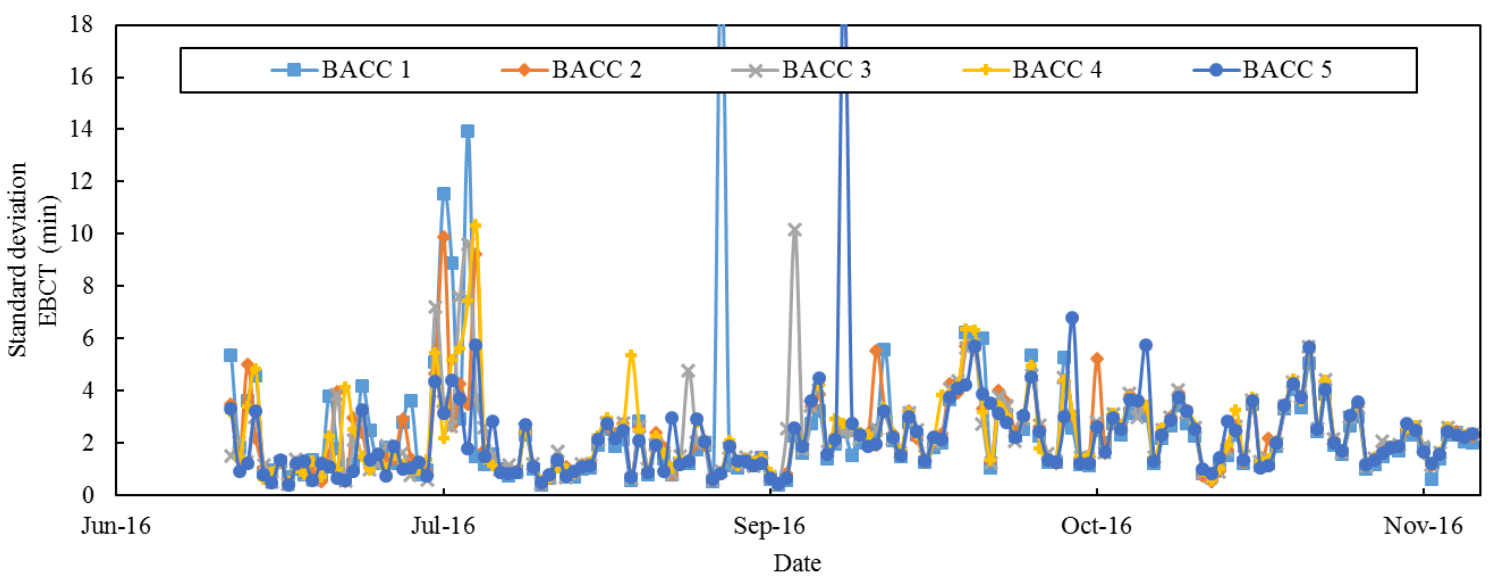

Figure 8-16: Standard deviation of the daily EBCT averages shown in Figure 8-15 


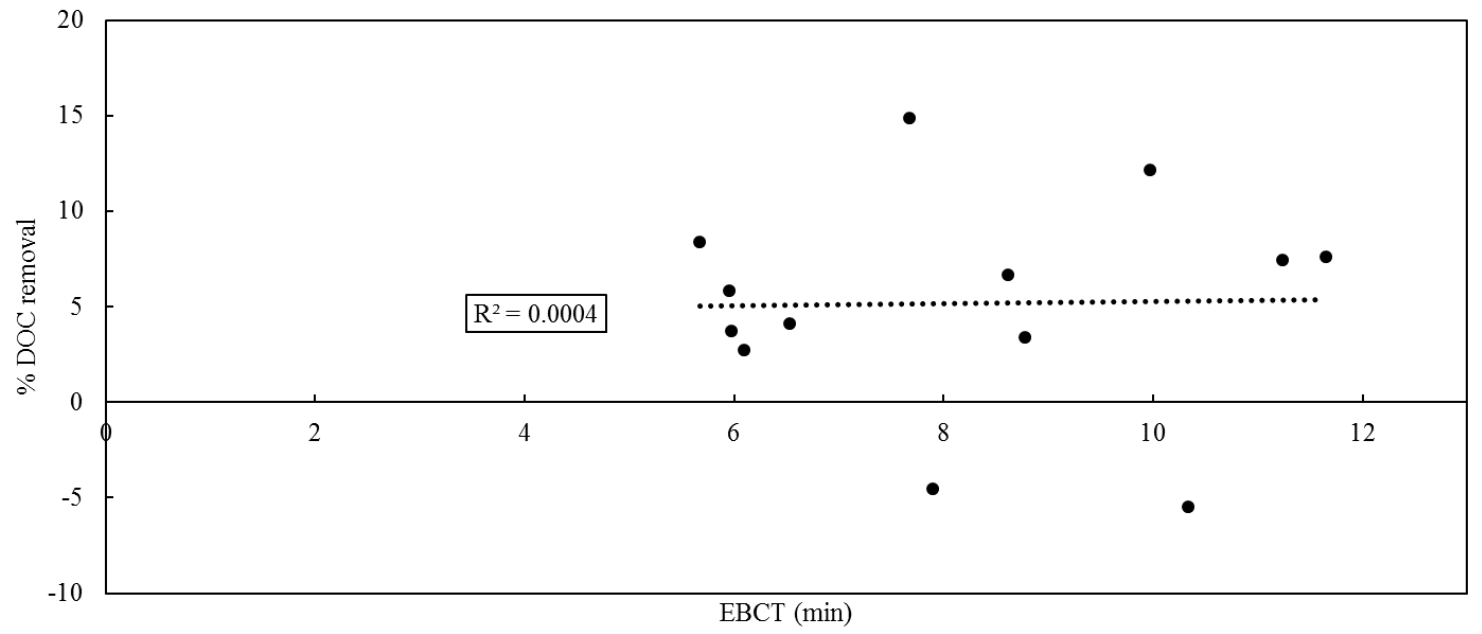

Figure 8-17: Relationship between EBCT and Lakeview WTP full-scale BACCs' \% DOC removal

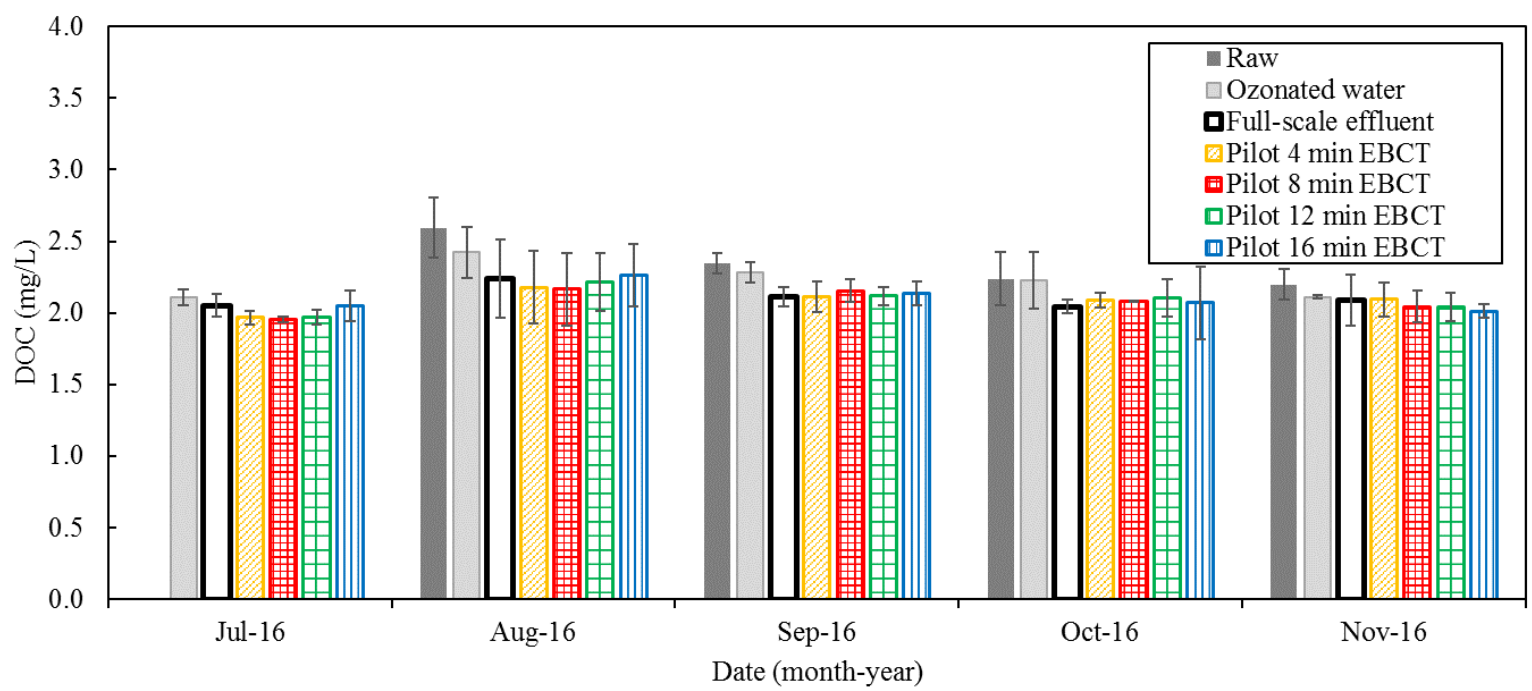

Figure 8-18: Monthly average DOC for full-scale raw water, ozonated water, BACC effluent and pilot biofilter effluents. Vertical bars represent the standard deviation. 


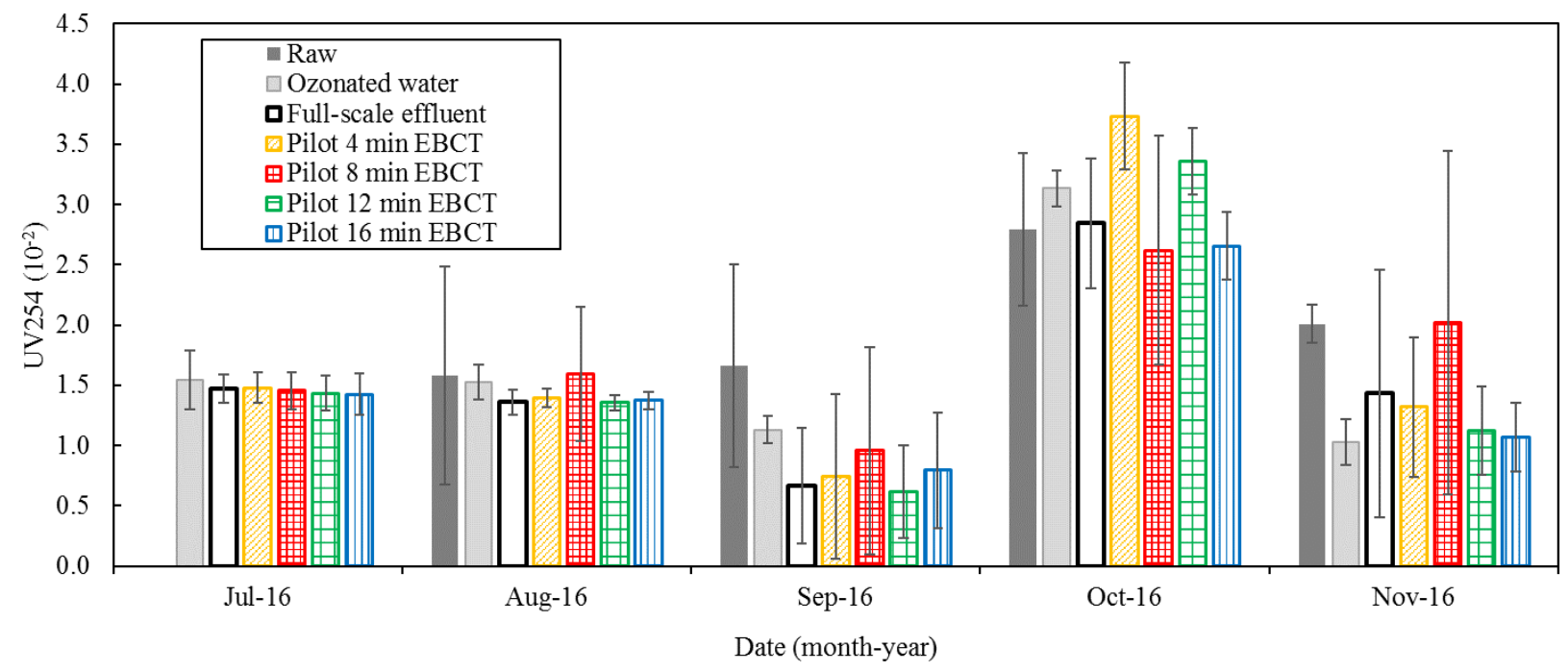

Figure 8-19: Monthly average $\mathrm{UV}_{254}$ values for full-scale raw water, ozonated water, BACC effluent and pilot biofilter effluents. Vertical bars represent the standard deviation.

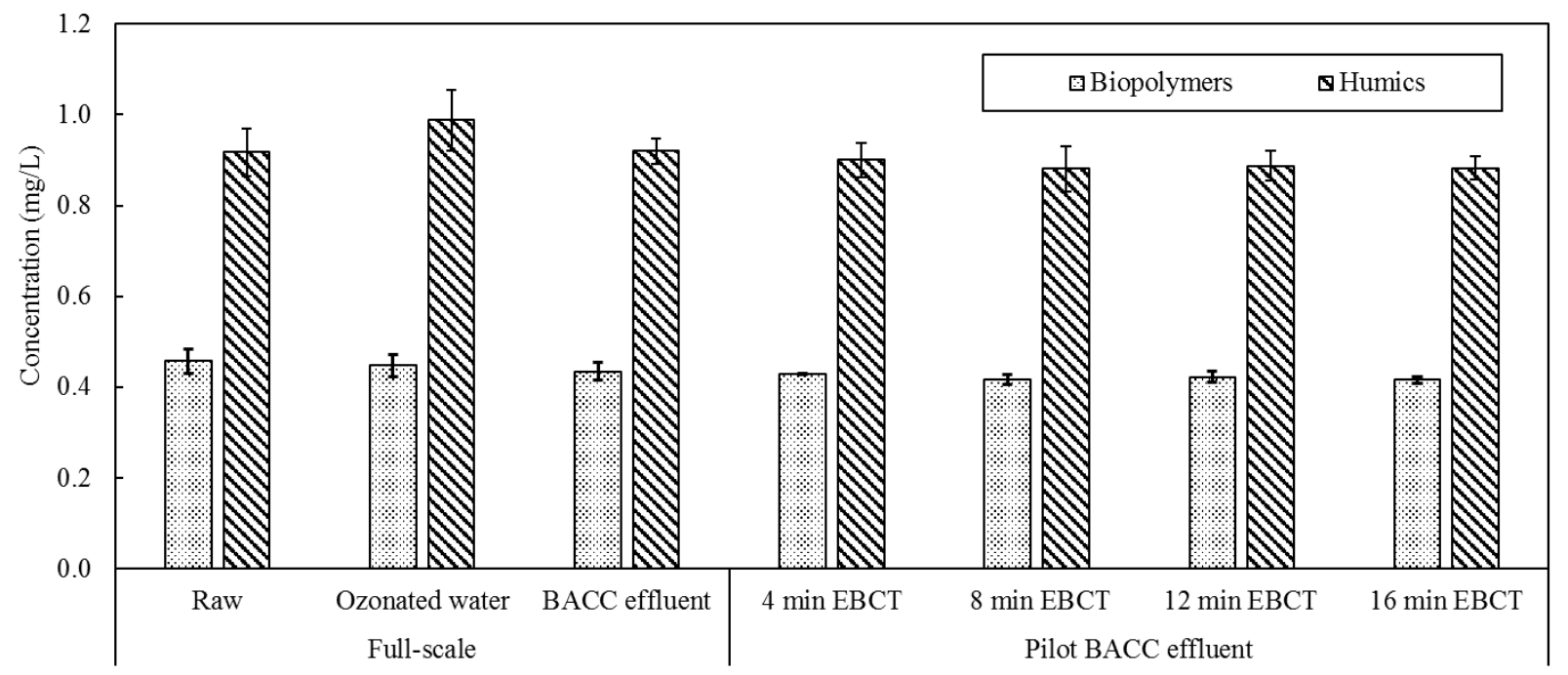

Figure 8-20: Biopolymers and humics for full-scale raw water, ozonated water, BACC effluent and pilot biofilter effluents. LC-OCD analysis was conducted twice in August 2016. Vertical bars represent the standard deviation.

The membrane resistance for the effluent of the pilot biofilter columns operated at 4 minutes was measured at bench-scale (Figure 8-21). Since no resistance increase was observed for the 4 minute EBCT pilot effluent, no resistance increase would be expected for the pilot columns operated at longer EBCTs. 


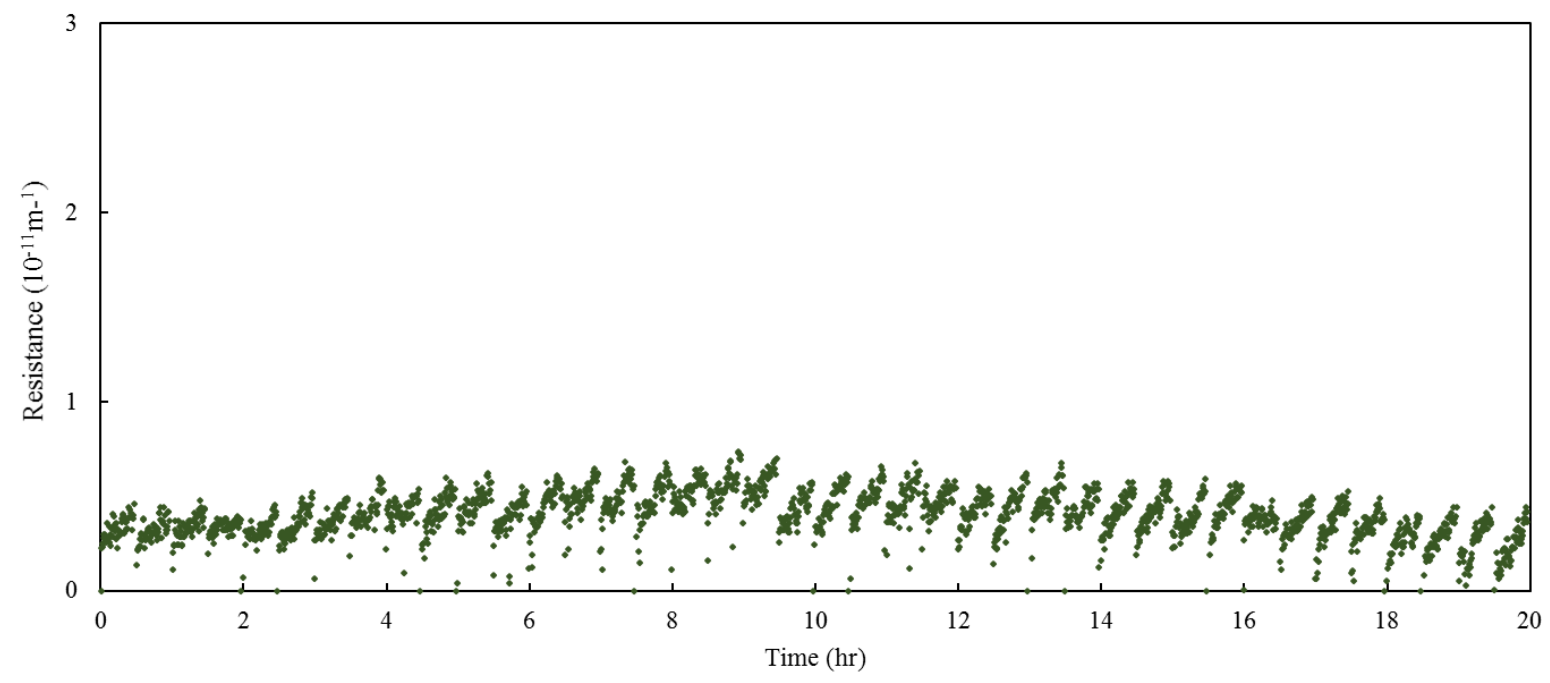

Figure 8-21: Typical resistance vs. time graph for 4 minute EBCT pilot effluent

\subsubsection{Conclusions}

EBCT (4-16 minutes) had no impact on biofilter performance in terms of dissolved organics removal. Bench-scale studies showed no increase of membrane resistance for the 4 minute EBCT pilot effluent.

\subsection{Standard Operating Procedure Outlines}

The following tables describe the basic procedure that was used for sample preparation and analysis throughout the study. Information for the analysis of ATP (Table 8-5) and DOC (Table $8-4)$. 
Table 8-4: DOC method

\section{Blanks}

Use $40 \mathrm{~mL}$ of Milli-Q®

\section{Stock Solution}

Mix $2.13 \mathrm{~g}$ potassium hydrogen phthalate in $1 \mathrm{~L}$ Milli- ${ }^{\circledR}$ water. Store at $\mathrm{pH} \leq 2$ by acidifying with $\mathrm{H}_{2} \mathrm{SO}_{4}$.

\section{Calibration Solution $(10 \mathrm{mg} / \mathrm{L})$}

Add $1 \mathrm{~mL}$ of stock solution to $99 \mathrm{~mL}$ of Milli-Q® water.

\section{Check Standard $(2.5 \mathrm{mg} / \mathrm{L})$}

Add $250 \mu \mathrm{L}$ of stock solution to $99.75 \mathrm{~mL}$ Milli-Q® water.

Table 8-5: ATP Analysis Method

\section{Calibration}

1. Add $100 \mu \mathrm{L}$ of enzyme reagent (Luminase) and $100 \mu \mathrm{L}$ of ATP standard (Ultracheck 1) in a $12 \times 55 \mathrm{~mm}$ test tube

2. Measure the relative light units (RLU) using the luminometer (RLUstandard)

\section{Sample Analysis}

1. Weigh $1 \mathrm{~g}$ of sample and transfer to a $5 \mathrm{~mL}$ (pre-packaged) UltraLyse ${ }^{\mathrm{TM}} 7$ tube and $\mathrm{mix}$

2. Wait for 5 minutes

3. Transfer $1 \mathrm{~mL}$ of the UltraLyse ${ }^{\mathrm{TM}} 7$ solution to a $9 \mathrm{~mL}$ (pre-packaged) UltraLute vial

4. After mixing the UltraLute solution, pipette $100 \mu \mathrm{L}$ to a new $12 \times 55 \mathrm{~mm}$ test tube.

5. Add $100 \mu \mathrm{L}$ of Luminase and gently swirl 5 times

6. Place the test tube into the luminometer and measure the RLU (RLU $\left.U_{\text {sample }}\right)$

7. Determine ATP concentration using the following equation:

$$
\operatorname{tATP}\left(\frac{\text { pg ATP }}{\text { g media }}\right)=\frac{R L U_{\text {sample }}}{R L U_{\text {standard }}} \times \frac{50,000(p g \text { ATP })}{\text { mass }_{\text {sample }}(g)}
$$

